\title{
LONG-TERM SAND CAP STABILITY: NEW YORK DREDGED MATERIAL DISPOSAL SITE
}

by

Jeffrey H. Parker, Raymond M. Valente

Science Applications International Corporation

Newport, Rhode Island 02840
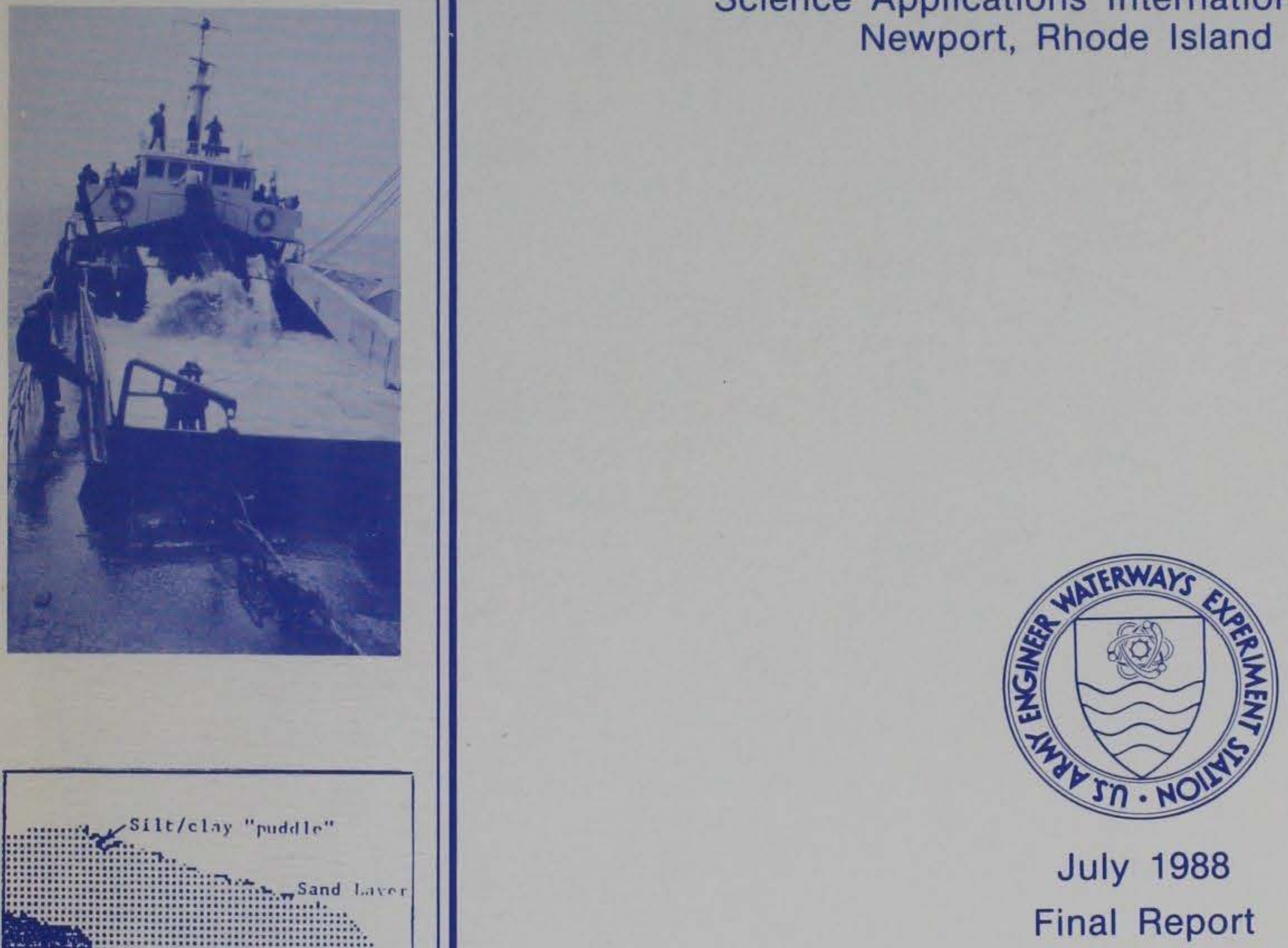

Approved For Public Release; Distribution Unlimited

\section{Library Branch Technical Information Center U.S. Army Engineer Waterways Experiment Station Vicksburg, Mississippi}

Prepared for US Army Engineer District, New York New York, New York 10278-0090

Under Contract No. DACW39-86-C-0076 Monitored by Coastal Engineering Research Center US Army Engineeer Waterways Experiment Station PO Box 631, Vicksburg, Mississippi 39180-0631 
Unclassified

SECURITY CLASSIFICATION OF THIS PAGE

\section{REPORT DOCUMENTATION PAGE}

\begin{tabular}{|c|c|c|}
\hline \multicolumn{2}{|l|}{$\begin{array}{l}\text { 1a. REPORT SECURITY CLASSIFICATION } \\
\text { UnClasSified }\end{array}$} & $1 \mathrm{~b}$. \\
\hline \multicolumn{2}{|l|}{ 2a. SECURITY CLASSIFICATION AUTHORITY } & 3.1 \\
\hline \multicolumn{3}{|c|}{ 2b. DECLASSIFICATION / DOWNGRADING SCHEDULE } \\
\hline \multicolumn{2}{|l|}{$\begin{array}{l}\text { 4. PERFORMING ORGANIZATION REPORT NUM } \\
\text { Contract Report CERC-88-2 }\end{array}$} & 5. $\mathrm{N}$ \\
\hline $\begin{array}{l}\text { 6a. NAME OF PERFORMING ORGANIZATION } \\
\text { Science Applications Inter- } \\
\text { national Corporation }\end{array}$ & $\begin{array}{l}\text { 6b. OFFICE SYMBOL } \\
\text { (If applicable) }\end{array}$ & $7 a$. \\
\hline 6c. ADDRESS (City, State, and ZIP Code) & & $7 \mathrm{~b}$. \\
\hline
\end{tabular}

RESTRICTIVE MARKINGS

3. DISTRIBUTION/AVAILABILITY OF REPORT

Approved for public release; distribution unlimited.

MONITORING ORGANIZATION REPORT NUMBER(S)

Newport, RI 02840

8a. NAME OF FUNDING / SPONSORING

ORGANIZATION

USAED, New York

b. OFFICE SYMBOL

(If applicable)

7a. NAME OF MONITORING ORGANIZATION

USAEWES, Coastal Engineering Research Center

b. ADDRESS (City, State, and ZIP Code)

PO Box 631

Vicksburg, MS 39180-0631

8c. ADDRESS (City, State, and ZIP Code)

New York, NY 10278-0090

11. TITLE (Include Security Classification)

Long-Term Sand Cap Stability: New York Dredged Material Disposal Site

12. PERSONAL AUTHOR(S)

Parker, Jeffrey H.; Valente, Raymond M.

13a. TYPE OF REPORT $13 \mathrm{~b}$. TIME COVERED

Final report

FROM

TO

14. DATE OF REPORT (Year, Month, Day) July 1988

15. PAGE COUNT 85

16. SUPPLEMENTARY NOTATION

Available from National Technical Information Service, 5285 Port Royal Road, Springfield, VA 22161.

\begin{tabular}{|c|c|c|c|}
\hline \multicolumn{3}{|c|}{ COSATI CODES } & \multirow{2}{*}{$\begin{array}{l}\text { 18. SUBJECT TERMS (Continue on reverse if necessary and } \\
\text { Dredged material (WES) }\end{array}$} \\
\hline FIELD & GROUP & SUB-GROUP & \\
\hline & & & Environmental impact analysis (LC) \\
\hline & & & Sand (LC) \\
\hline
\end{tabular}

19. ABSTRACT (Continue on reverse if necessary and identify by block number)

A comprehensive physical oceanographic field study was conducted in November 1986

to determine the bathymetry of the New York Mud Dump site and assess the long-term stability of an experimental sand cap, or mud dump (EMD), located in the southeast quadrant of the site. Results of a precision bathymetric survey were compared with results from surveys conducted in 1980 and 1981. A REMOTS ${ }^{\circledR}$ sediment-profile survey was conducted over the entire site, and a subbottom profiling survey was conducted at the EMD. A significant accumulation of sediment was found at the dredged material disposal point in the northeast quadrant, and decreases in depth to the south and east of this point indicated accumulation of dredged material beyond the eastern boundary of the site. Significant erosion of the sand cap was not detected, and clean sand representing the final cap material was found to persist in a continuous layer in the center of the EMD. A few patches of finer-grained material, possibly dredged material transported from the north, were found to exist over the sand. The effects of bioturbation on the (Continued)

20 DISTRIBUTION/AVAILABILITY OF ABSTRACT

$\bigotimes$ UNCLASSIFIED/UNLIMITED $\square$ SAME AS RPT 22a. NAME OF RESPONSIBLE INDIVIDUAL

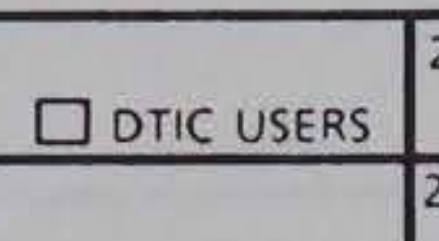

21. ABSTRACT SECURITY CLASSIFICATION Unclassified

22b. TELEPHONE (Include Area Code) 22c. OFFICE SYMBOL


Unclassified

SECURITY CLASSIFICATION OF THIS PAGE

19. ABSTRACT (Continued).

sand cap appeared to be negligible. It was suggested that monitoring should occur during and following disposal operations to ensure adequate management control and later to assess the stability and environmental impacts of disposal mounds. 
This report was prepared by Science Applications International Corporation (SAIC), Newport, Rhode Island, for the Coastal Engineering Research Center (CERC), of the US Army Engineer Waterways Experiment Station (WES) under Contract No. DACW39-86-C-0076, dated 16 July 1986. The work was conducted in accordance with Code CERC-4 of the Broad Agency Announcement.

The report was prepared by Messrs. Jeffrey H. Parker and Raymond M. Valente of SAIC. Overall supervision and quality control were conducted by Drs. Joseph Germano and Robert Morton (SAIC). The contract was managed by Dr. Clifford L. Truitt, Coastal Structures and Evaluation Branch (CD-S), Engineering Development Division (CD), CERC, under direct supervision of Ms. Joan Pope, Chief, CD-S, and Mr. Thomas Richardson, Chief, CD. Chief and Assistant Chief of CERC are Dr. James R. Houston and Mr. Charles C. Calhoun, Jr., respectively.

Mr. Eric Stern, Oceanographer, Operations Division, US Army Engineer District, New York, provided the necessary information on previous work conducted at the Mud Dump Site as well as valuable input during the field operations and review of the final report.

Contracting Officer was COL Dwayne G. Lee, CE, Commander and Director, WES, and Technical Director was Dr. Robert W. Whalin. 
PREFACE

$\underline{\text { Page }}$

PART I: INTRODUCTION . . . . . . . . . . . . . . . . . . . . . . . . . 1

PART II: METHODS . . . . . . . . . . . . . . . . . . . . . . . . . . . . . . 3

Navigation . . . . . . . . . . . . . . . . . . . . . . . . . . . 3

Precision Bathymetric Surveys . . . . . . . . . . . . . . . . . . . . . 4

Sub-Bottom Profiling . . . . . . . . . . . . . . . . . . . . . . . . . 7

REMOTS $^{\circledR}$ Sediment-Profile Imagery . . . . . . . . . . . . . . . . . . . . 8

PART III: RESULTS . . . . . . . . . . . . . . . . . . . . . . . . . . . . . 13

Precision Bathymetric Surveys . . . . . . . . . . . . . . . . . . . 13

Sub-Bottom Profiling . . . . . . . . . . . . . . . . . . . . . . . . 16

REMOTS $^{\circledR}$ Sediment Profiling . . . . . . . . . . . . . . . . . . . . . . 16

PART IV: DISCUSSION . . . . . . . . . . . . . . . . . . . . . . . . . . . . . 21

PART V: CONCLUSIONS . . . . . . . . . . . . . . . . . . . . . . . . . . . . . . . 26

PART VI: RECOMMENDATIONS. . . . . . . . . . . . . . . . . . . . . . . . . . 27

BIBLIOGRAPHY . . . . . . . . . . . . . . . . . . . . . . . . . . . . . . . . 28

TABLES $1-4$

FIGURES 1-39 


\section{LONG-TERM SAND CAP STABILITY}

\section{NEW YORK DREDGED MATERIAL DISPOSAL SITE}

\section{PART I: INTRODUCTION}

1. The New York District (NY District) of the Army Corps of Engineers initiated an experimental capping study at the Mud Dump site in June 1980 to determine the effectiveness of containing contaminated dredged material with a layer of clean sand. Approximately 522,000 cubic meters of contaminated finegrained sediment from New York Harbor were deposited in the southeast quadrant of the Mud Dump site (Figure 1,) referred to as the Experimental Mud Dump (EMD), in the spring of 1980. This material was then covered with approximately 193,000 cubic meters of less contaminated material in August 1980. In November 1980, the entire site was capped with 1.2 million cubic meters of clean fine to coarse sand from Ambrose Channel. The thickness of the completed cap ranged from approximately 0.5 to 1.6 meters, according to sediment cores taken after the capping operation.

2. During the period of 3 November through 25 November 1986 , Science Applications International Corporation (SAIC) under the sponsorship of the Waterways Experiment Station of the Army Corps of Engineers conducted a field study at the Mud Dump site under contract No. DACW39-86-C-0076. The purpose of this study was to continue research into the effectiveness of capping through a comprehensive physical oceanographic study of this area.

3. The specific objectives of this study were:

a. to provide accurate bathymetric information on the overall configuration of the entire Mud Dump site

b. to define the conditions at the boundaries of the entire Mud Dump site

c. to provide information on the configuration and long-term stability of the sand cap

d. to investigate the effects of bioturbation on the sand cap

e. to provide baseline information for a comprehensive long-term monitoring program for the EMD and the Mud Dump site. 
4. These objectives were addressed through implementation of the

following tasks:

Macroscale Survey of the Mud Dump site

a. A precision bathymetric survey was conducted over the entire Mud Dump site in an area of $2050 \mathrm{~m}$ by $3700 \mathrm{~m}$ at a lane spacing of 50 $m$ (Figure 2). This configuration approximates that used by the Survey Branch of NY District during the August 1981 survey (objectives $\underline{\mathrm{a}}$ and $\underline{\mathrm{b}}$ ).

b. To define the boundaries of the Mud Dump site, a grid of REMOTS ${ }^{\circledR}$ images were taken at a $400 \mathrm{~m}$ spacing over the northwest and northeast quadrants and at $200 \mathrm{~m}$ spacing over the southeast and southwest quadrants extending 600 meters beyond the south, east, and southwest boundaries of the Mud Dump site (Figure 3, objective $\underline{b}$ ).

c. The smooth sheet generated by the New York District in their bathymetric survey of the Mud Dump site in August 1981 was digitized in the SAIC data processing laboratory. These data were then used to generate contour plots of the area and compared with those from the November 1986 survey (objectives a and $\underline{b}$ ).

\section{Microscale Survey of the Sand Capping Site}

a. A precision bathymetric survey was conducted over the southeast quadrant at the EMD covering an area $1200 \mathrm{~m}$ by $2000 \mathrm{~m}$ at a lane spacing of $25 \mathrm{~m}$ (Figure 2). This approximates the procedures used during the June 1980 and August 1981 surveys performed by the Survey Branch of NY District (objective c).

b. A sub-bottom profiling survey was conducted at a $50 \mathrm{~m}$ lane spacing over the same area to determine the thickness of the sand cap and areas of possible breaching of the cap (objective $\underline{\text { ) }}$ ).

c. The lateral extent of the sand cap and the dredged material was determined by REMOTS ${ }^{\circledR}$ images taken every $100 \mathrm{~m}$ on eight radial transects emanating out to a distance of $1200 \mathrm{~m}$ from the center of the dredged material mound as determined by previous bathymetric surveys and the "MD" buoy location (Figure 3, objective $\underline{c}$ and $\underline{d}$ ).

d. The smooth sheet generated by the New York District in their bathymetric survey of the Experimental Mud Dump site in June 1980 was digitized in the SAIC data processing laboratory. These data were then used to generate contour plots of the area and compared with those from the November 1986 survey (objective $\underline{c}$ ). 


\section{PART II: METHODS}

\section{$\underline{\text { Navigation }}$}

5. All at-sea operations during this study were conducted on the Research Vessel UCONN under charter from the University of Connecticut. Navigational control of the survey vessel during this investigation was accomplished using the SAIC Integrated Navigation and Data Acquisition System (INDAS). This system is capable of accepting information from one or more positioning systems, processing the data to determine location on an earth model, displaying that location on any one of a number of earth projections, supplying steering information to aid the helmsman in vessel control, and recording position along with other data from one or more sensor systems. The system also provides the capability for set-up, execution and analysis of bathymetric surveys as well as transfer of recorded data to a different computer if required.

6. The heart of the system is the Hewlett Packard Series-200, mode1-20 microcomputer which uses an MCZ-68000 16/32 bit microprocessor. This computer contains one megabyte of on-board memory and is responsible for the control of al1 navigation and data acquisition duties. The INDAS software utilizes advanced Kalman filtering techniques which are essential for removing the noise inherent in any positioning system and to provide a real-time assessment of navigational accuracy.

7. During this study the INDAS system was interfaced to a Del Norte Model 540 Trisponder system. The Del Norte Trisponder is a precision microwave distance measuring instrument capable of determining over-water ranges with a resolution of 0.1 meter. This system is calibrated on a 12 kilometer overwater range immediately prior to field operations and has an absolute accuracy of \pm 1.0 meter over the ranges encountered at this site. The primary sources of positional error in this combined positioning/data acquisition system are dependent on the accuracy of the positioning system and the geometric dilution of precision (GDOP), which is determined by the position of the survey vessel with respect to the positions of the microwave transponders set up on shore. For sampling at the Mud Dump site, these transponders were set up at the Coast Guard maintained lighthouse at Sandy Hook, New Jersey $\left(40^{\circ} 27.696^{\prime} \mathrm{N}\right.$, 
$\left.74^{\circ} 00.145^{\prime} \mathrm{W}\right)$ and over a benchmark established by NY District on the boardwalk in Long Branch, New Jersey $\left(40^{\circ} 18.411^{\prime} \mathrm{N}, 73^{\circ} 58.683^{\prime} \mathrm{W}\right)$. The GDOP of this shore station combination with the absolute accuracy of the positioning system resulted in an operational accuracy of \pm 3.0 meters at the Mud Dump site.

8. During all phases of operations during this study, LORAN-C time differences for the northeast LORAN-C chain (9960) were monitored by the INDAS system. When these time differences are compared with the actual position of the survey vessel as determined by the Del Norte Trisponder, accurate LORAN-C calibration factors are calculated. These factors, when applied to observed and/or calculated LORAN-C time differences yield geodetic positions on the order of \pm 27 meters in accuracy. These will be useful in future operations at this site should precision navigation be unavailable.

9. During the course of operations, the INDAS system provided the operator with useful information such as range and bearing to a selected target, time, signal quality of the positioning system(s) in use and selected data from any optional environmental sensors currently on-line. The survey vessel's position was continually plotted to allow the operator to assess the location relative to other targets in the operations area. A printer recorded position fixes either on-demand or at user-specified intervals, helpful in both operational planning and log keeping. Each fix consisted of the date and time, the vessel's position in both latitude/longitude and local $\mathrm{X} / \mathrm{Y}$ coordinate systems, raw positioning data such as Del Norte ranges and/or LORAN-C time differences, and data from external environmental sensors. In addition to the hard copy, position fixes were stored on disk in ASCII text format which allowed post-operational manipulation with a wide variety of text editors and data base management systems. During the active data acquisition stage of a bathymetric survey, position fixes were taken at one second intervals and stored on disk in a compressed binary format; this allows each data disk to hold enough fixes for more than three hours of continuous operation.

\section{Precision Bathymetric Surveys}

10. Bathymetric surveys performed during this study were accomplished using a Raytheon Model DE-719C survey fathometer. This instrument operates at a frequency of $208 \mathrm{KHz}$ which effectively eliminates bottom penetration and 
provides a true measurement of water depth regardless of bottom composition. The fathometer is calibrated immediately prior to conducting the survey using a bar-check apparatus suspended in the water column at known depths below the transducer. The survey fathometer is interfaced to a Raytheon Model SSD-100 Survey Sounder Digitizer. The digitizer uses timing circuitry separate from that of the fathometer and converts the analog fathometer output into digital depth data. These are transferred to the INDAS system via a binary coded decimal ( $B C D$ ) interface. This instrument is calibrated simultaneously with the survey fathometer and is capable of resolving depth to $1 / 10$ unit. This calibration procedure eliminates any bias errors that may be associated with the fathometer/digitizer system and compensates for the velocity of sound in the water column. The depth data are transferred to the computer in units of either fathoms, meters, or feet; in order to get the maximum advantage of the digitizer's resolution, all depths are measured in feet and the conversion to other required units is accomplished during data reduction.

11. During a bathymetric survey, depth measurements are transferred from the fathometer at a rate of approximately eight per second. These depths are stored in the computer's memory until the start of a data transfer from the positioning system. At that time, depth acquisition is suspended until the positioning data transfer is complete. The ship's geodetic position is then calculated and a depth value is appended to the ship's position fix. This depth value can represent the minimum, maximum, average of all depths, or the last depth obtained since the previous position fix.

12. During data analysis, each survey area is divided up into a number of rows and columns of cells in a matrix. Each of these cells is centered along a survey lane and with dimensions equal to the lane spacing in a perpendicular direction and to one half of the lane spacing in a parallel direction. As the survey data are read into the computer, the depth data from fixes falling within a given cell are weighted with respect to their spatial offset from the center of the cell, an average is calculated, and the resulting value is assigned to that cell. Prior to these calculations, each individual data point is corrected for sound velocity variations, transducer draft, and tidal amplitude. This depth matrix is then used to generate graphic products such as depth contour charts, smooth sheets, three-dimensional plots, or is treated statistically to assess depth differences between successive surveys 
over the same area. The accuracy of the depth measurements assigned to each cell, and therefore presented in smooth sheets and contour plots, is affected by the instrument accuracy of the fathometer ( $0.5 \%$ of indicated depth), the number of depth measurements in that cell, the vertical motion of the research vessel, the difference in depth between the center of the grid cell and the actual position of the vessel, and the accuracy in the prediction of the change in tidal height for the duration of the survey. An error analysis of the depth measurements was performed by estimating the worst-case conditions at the time of the surveys at the Mud Dump site and calculating the standard error. Using the values of $\pm 1.0 \mathrm{ft}$ for the vertical motion of the vessel, $\pm 1.2 \mathrm{ft}$ for the difference in depth within the grid cell, $\pm 0.8 \mathrm{ft}$ for the error in the tidal height measurement ( 208 of tidal range; a very conservative estimate), and a minimum of 4 to 5 seconds of bathymetry data per cell at a rate of 8 depth measurements per second, the root mean square (RMS) of the accumulation of these errors was calculated with allowances for the machine error of the fathometer and divided by the square root of the number of actual depth measurements to determine the standard error on the depth in the each grid cel1; the standard error equalled approximately $\pm 15 \mathrm{~cm}$. This error can decrease to approximately $\pm 8 \mathrm{~cm}$ for areas of the survey where the bottom topography was relatively flat and during survey operations when the seas are calm.

13. The bathymetric smooth sheet charts generated by New York District during the surveys of the EMD in June 1980 and of the Mud Dump site in August 1981 were digitized in the SAIC data processing laboratory using the SAIC digitizing system developed for the Defense Mapping Agency. This proven system consists of an Houston Instruments Series-7000 digitizing table interfaced to an Apple II+ microcomputer. During this process, documents to be digitized are placed on the digitizing table and covered with a thin sheet of transparent mylar. This provides both protection of the original document and a convenient medium on which the operator can cross off points already digitized to speed data entry and to eliminate duplicate points. The document is then registered relative to the table with five points, one in each of the four corners and a fifth, defined by a parallel and a meridian passing through the center of the chart. In addition, limits of digitization are set through registration of points in the southwest and northeast quadrants of the chart. Following 
completion of the registration procedure, the computer calculates the horizontal and vertical scales of the chart. If these do not agree within a specified amount, an error signal is generated preventing digitization of the chart. Once the document has been registered on the table, the depth points are digitized. This is accomplished using a cursor to locate the point and a keypad to input the depth at that location. Each measurement is stored in a data file on disk. After the charts were digitized, a verification plot was generated at the same size and scale as the original document. This verification plot was then compared with the original smooth sheet on a pointby-point basis and any errors found were corrected. This process was repeated with each of the 17 charts supplied by NY District.

14. Following completion of the digitization sequence, the data files generated were transferred to the Hewlett Packard Series-200 computer system and converted to data files compatible with those generated by the INDAS system. These data were then analyzed using the procedure described above.

\section{Sub-Bottom Profiling}

15. Sub-bottom profiling was accomplished using an ORE, Inc. Model 1032 Sub-Bottom Profiling System interfaced to an EPC 3200 Recorder and a computerized data acquisition system from Caulfield Engineering, Alberta, Canada. The ORE System included a transceiver capable of outputting signals of $10 \mathrm{kw}$ at frequencies of from 1 to $12 \mathrm{kHz}$ that would allow optimal penetration of the sediment. The over-the-side vehicle contained a 3.0 to $7.0 \mathrm{kHz}$ transducer and a $12 \mathrm{kHz}$ transducer.

16. The sub-bottom survey was conducted at a $50 \mathrm{~m}$ lane spacing over the same area as the bathymetric survey at the EMD. The return signals were immediately plotted on the EPC recorder and stored on magnetic tape for subsequent analysis. Caulfield Engineering has developed a computer system that analyzes the return signals from the ORE System using classical multilayer reflection mathematics. A CE 7000 microcomputer was used for the analyses that includes Fourier transforms, energy and impedance calculations, and corrections for absorption and loss. By normalizing the data from each sediment layer to the seawater rather than the layer above it, the depth of the interface of different sediment types can be distinguished. Several detailed 
acoustic cores were produced during the analysis to determine the depth of the sand/silt interface.

17. The output from the Caulfield Engineering computer analysis system included amplitude records and acoustic impedance records that have had colors assigned to different ranges of values for graphical illustration (Figure 4). Acoustic impedances have been reliably assigned to different sediment types and, therefore, can be used to detect interfaces between two dissimilar sediment types (Hamilton; 1970, 1971). For a more detailed discussion of the analysis procedures, see Caulfield and Yim (1983) and Caulfield (1984).

18. For the purposes of this study, the acoustic impedance records were interpreted in two ways. Based on the color of the trace at the surface of the sediment, a percent-sand value was assigned and the values along each survey lane were digitized and contoured to the same scale as the bathymetric analysis plots. The same records were then used to determine the thickness of the sand layer where it existed by observing where colors changed from sand to finergrained material; these values were also digitized and contoured. To produce enough power to effectively penetrate the sand cap, a finite pulse length of $0.4 \mathrm{~m}$ was chosen. In effect, this means that the return signals were averaged over that depth of sediment. To improve resolution of the estimates of sediment layer thickness, more powerful and expensive seismic systems would have to be employed. The larger sound source would also improve the signal-tonoise ratio over highly absorptive bottoms and, therefore, improve penetration.

\section{REMOTS ${ }^{\circledR}$ Sediment-Profile Imagery}

19. The REMOTS ${ }^{\circledR}$ Sediment Profile Camera was used to map the distribution of dredged material layers on the order of 1 to $20 \mathrm{~cm}$ thick (small-scale). This capability compliments the precision bathymetric data which can resolve differences in depth greater than or equal to $15 \mathrm{~cm}$ (large-scale). At the EMD site, REMOTS ${ }^{\circledR}$ was also used to detect the presence of the sand cap. In addition, benthic disturbance gradients were mapped and the status of infaunal recolonization at the site was monitored.

20. REMOTS $^{\circledR}$ images were taken with a Benthos Model 3731 Sediment-Profile Camera (Benthos, Inc. North Falmouth, MA; Figure 5). The REMOTS ${ }^{\circledR}$ camera was designed to obtain in-situ profile images of the top $15-20 \mathrm{~cm}$ of sediment. 
Functioning like an inverted periscope, the camera consists of a wedge-shaped prism with a top-mounted horizontal camera and a front face plate with a back mirror mounted at a 45 degree angle to reflect the profile of the sediment-water interface up to the camera. The prism assembly is moved up and down by producing tension or slack on the winch wire. Tension on the wire keeps the prism in the up position. When the camera frame is lowered to the seafloor, slack on the wire allows the prism to vertically penetrate the seafloor. A piston ensures that the prism enters the bottom slowly and does not disturb the sediment-water interface. On impact with the bottom, a trigger activates a 13 -second time delay on the shutter release to allow maximum prism penetration before a photo is taken. Because the sediment photographed is directly against the face plate, turbidity of the ambient seawater does not affect image quality. When the camera is raised, a wiper blade cleans off the faceplate; the film is advanced by a motor drive, the strobe is recharged, and the camera can be lowered for another image.

21. REMOTS ${ }^{\circledR}$ prism penetration is estimated from a penetration indicator which measures the distance the prism falls relative to the camera base. If penetration is inadequate, two weight packs, each capable of holding $1251 \mathrm{bs}$ of lead (in $25 \mathrm{lb}$ increments), can be loaded to give the assembly increased penetration (e.g., for work in sandy or high shear strength, compacted sediments). If penetration appears to be too great, adjustable stops, which control the distance the prism can descend, can be lowered and "mud" doors can be attached to each side of the frame to increase the bearing surface of the entire unit. In the present study, frequent adjustments to the weight packs were required; sampling transects often crossed transitional boundaries in sediment grain-size (sand to fine-grained dredged material to sand/mud mixtures). Stations where penetration was suboptimal were verified at the end of each survey day after the film was developed and examined; typically, field operations the following day included a return to those stations identified the previous evening to take additional photographs with the proper corrections made to the adjustable stops or the weight packs. Unfortunately, every station where suboptimal penetration occurred could not be corrected; a long period of adverse weather conditions prevented the return to every station where overpenetration occurred. Underpenetration that occurred due to the hard- 
packed sand even when the camera weight packs were carrying the maximum load of lead weights could not be corrected.

22. REMOTS ${ }^{\circledR}$ measurements of all physical parameters and some biological parameters are measured directly from black and white film negatives using a video digitizer and computer image analysis system. Negatives are used for analysis instead of positive prints in order to avoid changes in image density that can accompany the printing of a positive image. The image analysis system can discriminate up to 256 different gray scales, so subtle features can be measured accurately. Proprietary SAIC software allows the measurement and storage of data on 21 different variables for each REMOTS ${ }^{\circledR}$ image obtained (Table 1). Automatic disk storage of all parameters measured allows data of interest to be compiled, sorted, compared statistically, or displayed graphically.

23. Specific measurement techniques for the REMOTS ${ }^{\circledR}$ parameters indicated in Table 1 are presented below:

\section{Sediment Type Determination}

24. The sediment grain-size major mode and range are visually estimated from the photographs by overlaying a grain-size comparator composed of seven Udden-Wentworth size classes: $\geq 4$ phi (silt or finer), 4-3 phi (very fine sand), 3-2 phi (fine sand), 2-1 phi (medium sand), 1-0 phi (coarse sand), 0-(-)1 phi (very coarse sand), < -1 phi (granules or larger). The accuracy of this method has been documented by comparing REMOTS ${ }^{\circledR}$ estimates with grain-size statistics determined from laboratory sieve analyses (Table 2). In the present study, much of the dredged material had a grain size similar to the ambient "mud" bottom in the northern half of the disposal site. However, dredged material can still be distinguished during the analysis of the REMOTS ${ }^{\circledR}$ images, because it typically has a lower optical reflectance than ambient mud (i.e., it will appear darker in the photos).

\section{Prism Penetration Depth}

25. The REMOTS ${ }^{\circledR}$ prism penetration depth is determined by measuring both the largest and smallest linear distance between the sediment-water interface and the bottom of the film frame. Prism penetration is potentially a noteworthy parameter; if the number of weights used in the camera is held constant throughout a survey, the camera functions as a static-load penetrometer. Comparative penetration values from sites of similar grain-size 
can give an indication of the relative sediment water content. In the present study, the large variation in sediment type required changes in the weight pack configuration preventing valid comparison of the penetration depths.

\section{Surface Boundary Roughness}

26. Surface boundary roughness is determined by measuring the vertical distance (parallel to the film border) between the highest and lowest points of the sediment-water interface. In addition, the origin of this small-scale topographic relief is indicated when it is evident (physical or biogenic).

\section{Mud Clasts}

27. When fine-grained, cohesive sediments are disturbed either by physical bottom scour or faunal activity (e.g., decapod foraging), intact clumps of sediment are often scattered about the seafloor and detected in REMOTS $^{\circledR}$ images. These mud clasts are counted, the diameter of a typical clast measured, and their oxidation state assessed. The abundance, distribution, oxidation state, and shape of mud clasts are used to make inferences about the recent pattern of seafloor disturbance in an area.

Apparent Redox Potential Discontinuity (RPD) Depth

28. When there is oxygen in the overlying water column in coastal areas having fine-grained sediment, the near-surface material will have a higher reflectance value relative to hypoxic or anoxic sediment underlying it. This is because the oxidized surface sediment contains particles coated with ferric hydroxide (an olive color when associated with particles), while the sulphidic sediments below this oxygenated layer are grey to black. The boundary between these two sediment types is called the apparent redox potential discontinuity (RPD). This oxidized, high-reflectance area is digitized, measured to scale, and divided by the prism window width to obtain a mean depth for the apparent RPD. The RPD depth is a sensitive indicator of the biological mixing depth, infaunal successional status, and within-station patchiness. In the absence of bioturbating infauna, the RPD will achieve a maximum depth of $2 \mathrm{~mm}$ in fine-grained sediments solely by diffusion (Rhoads, 1974).

Sedimentary Methane

29. At extreme levels of organic-loading, pore-water sulphate is depleted and methane bubbles are produced in the sediment column. These gas-filled voids are readily discernable because of their irregular, generally circular aspect and glassy texture (due to the reflection of the strobe 
illumination off the gas). If present, the number and total areal coverage of all methane pockets is measured.

\section{Infaunal Successional Stage}

30. The mapping of infaunal successional stages is based on the theory that primary succession results in "the predictable appearance of macrobenthic invertebrates belonging to specific functional types following a benthic disturbance. Because functional types are the biological units of interest..., our definition does not demand a sequential appearance of particular invertebrate species or genera" (Rhoads and Boyer, 1982). The term disturbance can refer to a natural process such as seafloor erosion, changes in seafloor chemistry, foraging disturbances which cause major reorganization of the resident benthos, or anthropogenic impacts such as dredged material disposal, sewage sludge dumping, thermal effluents from power plants, industrial discharge, etc.

31. Pioneering benthic assemblages (Stage I) usually consist of dense aggregations of near-surface, tube-dwelling polychaetes. This functional type is usually associated with a shallow depth of bioturbation which results in a shallow redox boundary. In the absence of further disturbance, these early successional assemblages are eventually replaced by infaunal deposit feeders (Stage II). Typical Stage II species are shallow-dwelling bivalves or tubicolous amphipods. Stage III taxa represent high-order successional stages typically found in low-disturbance regimes. Many of these invertebrates feed at greater depth in a head-down orientation. The localized feeding activity results in distinctive excavations called feeding voids. These deep-dwelling infaunal taxa preferentially ingest the finer sediment particles and reject coarse-grained material. The bioturbational activities of these deposit feeders are responsible for aerating the sediment and causing the redox horizon to be located several centimeters below the sediment-water interface. In the retrograde transition of Stage III to Stage I, it is sometimes possible to recognize the presence of relict (i.e., collapsed and inactive) feeding voids.

32. These end-member stages (Stages I and III) are easily recognized in REMOTS ${ }^{\circledR}$ images by the presence of dense assemblages of near-surface polychaetes and/or the presence of subsurface feeding voids; both types of assemblages may be present in the same image (classified as a Stage I on Stage III). 


\section{REMOTS ${ }^{\circledR}$ Organism-Sediment Index}

33. A multi-parameter REMOTS ${ }^{\circledR}$ Organism-Sediment Index (OSI) has been constructed to characterize habitat quality in terms of disturbance frequency. Habitat quality is defined relative to two end-member standards. The lowest value is given to those bottom substrates which have low or no dissolved oxygen in the overlying bottom water, no apparent macrofaunal life, and methane gas present in the sediment. The REMOTS ${ }^{\circledR}$ Organism-Sediment Index for such a condition is minus 10. An aerobic bottom with a deeply depressed RPD, evidence of a mature macrofaunal assemblage, and no apparent methane gas bubbles at depth will have a REMOTS ${ }^{\circledR}$ Organism-Sediment Index value of plus 11 . The REMOTS $^{\circledR}$ Organism-Sediment Index is arrived at by summing the subset indices shown in Table 3. The Organism-Sediment Index is an excellent parameter for mapping disturbance gradients in an area and documenting ecosystem recovery after disturbance (see Germano and Rhoads, 1984). Because secondary succession can take place in the absence of a disturbance event, the presence of Stage I on Stage III or Stage II on Stage III assemblages will not affect the final index value.

\section{PART III: RESULTS}

\section{Precision Bathymetric Surveys}

\section{Mud Dump Site}

34. Digitized depth data from the August 1981 NY District survey were analyzed to produce a contoured depth chart (Figure 6) for comparison with the bathymetric survey conducted in November 1986 (Figure 7). In order to make valid comparisons of bathymetric surveys that were conducted five years apart with different navigation and depth measuring systems, it was necessary to assume that the depth in a small area (approximately $1000 \mathrm{X} 1000$ feet) in the southwest corner of the Mud Dump site has not changed significantly since August 1981. An average value for the difference between the 1981 and 1986 surveys in this area was then applied to all 1986 bathymetric data during analysis. Even though it is possible that erosion or deposition could have occurred over the five year period between these two surveys, the fact that the shape of the depth contours in this southwest corner were identical before and 
after this correction was applied suggested this assumption was quite reasonable.

35. The most significant change in bottom topography is the development of a large disposal mound in the northeast quadrant (Figure 7). The peak of the mound reaches up to a depth of 44 feet $(13.4 \mathrm{~m})$ from an original bottom depth of approximately 74 feet $(22.6 \mathrm{~m})$. By overlying the two contour charts, the extent of the impact from dredged material disposal operations at this location can be seen as far as 1500 meters to the southeast and beyond the boundaries of the disposal site to the east. Decreases in depth can also be seen to the northwest boundary of the site; however, the bottom slopes up in this direction from previous disposal operations over the past decades.

36. A volume calculation was made between the bathymetric surveys conducted in August 1981 and November 1986. Analysis of the bathymetric data produced a matrix of cells, each having an area of $50 \mathrm{~m}$ by $25 \mathrm{~m}$. Each cell is assigned a mean depth value based on any data points that fell within that cell during the surveys. The digitized data from the NY District 1981 survey were treated as raw bathymetric data that was already corrected for tide and draft. The two matrices were compared on a cell by cell basis and the difference in depth of each cell times the area of the cell was summed over the entire matrix (i.e., the Mud Dump site). The standard error of the volume ( $\mathrm{S}_{\mathrm{v}}$ ) for the entire survey was defined as:

$$
\mathrm{S}_{\mathrm{v}}=\left(\mathrm{S}_{\mathrm{c}} / \sqrt{\mathrm{N}}\right) \mathrm{XA}
$$

where $S_{c} / \sqrt{ } N=$ the standard error of the depth of any individual cell in the matrix,

$\mathrm{S}_{\mathrm{c}}=$ the error on each depth measurement $(15 \mathrm{~cm})$,

$\mathrm{N}=$ the number of cells in the survey, and

$A=$ the area of the survey.

The volume of dredged material deposited between August 1981 and November 1986 that is within the disposal site boundaries was calculated to be approximately $7.6 \times 10^{6} \mathrm{~m}^{3}\left( \pm 14,400 \mathrm{~m}^{3}\right)$. This is considered to be a very conservative estimate because the dredged material obviously accumulated beyond the boundaries of the area surveyed (i.e., the disposal site). An estimate supplied by NY District of the amount of material actually dumped, based on scow logs, was approximately $18.6 \times 10^{6} \mathrm{~m}^{3}$ for the years 1982-1986. A previous investigation into the effect of disposal on the volume estimates of dredged 
material by the NY District (Tavolaro, 1984) determined that the volume of material on the bottom, measured acoustically, was approximately 40.78 less than the estimate of volume in the scows. Of this amount, 15.48 was attributed to the loss of interstitial water and compaction. The remaining loss was probably due to the thin layers of dredged material that typically are not detected by the fathometer (Germano and Rhoads, 1984). Applying this factor $(40.7 \%)$ to the present scow volume estimate yields $11.0 \mathrm{X} 10^{6} \mathrm{~m}^{3}$ expected to have accumulated on the bottom. A conservative estimate of the volume of dredged material outside the disposal site would be the corrected scow load estimate minus the calculated volume from the comparison of the 1981 and 1986 bathymetric surveys; this estimate equals approximately $3.4 \mathrm{X} 10^{6} \mathrm{~m}^{3}$.

\section{EMD Site}

37. Digitized depth data from the NY District June 1980 (pre-capping) and August 1981 (post-capping) surveys and the data collected in November 1986 were analyzed to produce contoured depth charts (Figures 9, 10, and 11) of the southeast quadrant of the Mud Dump site, otherwise known as the EMD. Depth matrices were constructed and compared to produce contoured depth difference charts for the 1980/1981 (Figure 12) and 1981/1986 (Figure 13) surveys. The depth difference chart of the 1980/1981 surveys reveals the presence of the sand cap to thicknesses of up to 6 feet $(1.8 \mathrm{~m})$. Volume calculations were also made to estimate the amount of material deposited at the EMD during the capping operation. These calculations estimated that approximately $814,000 \mathrm{~m}^{3}( \pm 3700$ $\mathrm{m}^{3}$ ) of material were deposited between June 1980 and August 1981 . Scow logs indicate that approximately $1.2 \times 10^{6} \mathrm{~m}^{3}$ of material were used to cap the EMD site. Correcting this volume for the 40.78 loss yields $0.71 \times 10^{6} \mathrm{~m}^{3}$.

38. The depth difference chart of the $1981 / 1986$ surveys reveals that little or no change was detected at the sand cap site but dredged material has accumulated around it and especially to the north and east. This accumulation may be the result of disposal operations at other locations in the disposal site between August 1981 and November 1986. Volume calculations indicate that approximately $136,000 \mathrm{~m}^{3}\left( \pm 3700 \mathrm{~m}^{3}\right)$ of material has been deposited in the southeast quadrant since 1981 . 


\section{Sub-Bottom Profiling}

39. A percent-sand contour chart for the surface sediments (Figure 14) was constructed from the results of the analysis of acoustic impedance records provided by the Caulfield Engineering system. The sand layer occurring from the center of the southeast quadrant to the south (shaded area in Figure 14) indicates the presence of the sand cap and the presence of sand that normally composes the natural bottom. Patches of finer-grained material occur within the area of the sand cap but have sand under them, indicating deposition has occurred rather than erosion of the sand cap itself. Earlier work by Freeland et al. (1976) indicated the presence of sand in the surface sediment at the southeast quadrant (Figure 15). In 1978, Dayal et al. (1981) obtained a sediment core (Core \#1, Figure 16) from just south of the southeast quadrant that revealed a $0.5 \mathrm{~m}$ thick layer of sand over mud indicating the presence of sand prior to the capping operations in 1980.

40. A sand layer thickness contour chart (Figure 17) was also constructed from the analysis of the color acoustic impedance records. Based on the color assigned to the sand sediment type (green), the depth of the top and bottom of this layer were digitized separately and then subtracted to determine the thickness. As seen in the percent-sand contour chart, the sand layer is the result of both the capping operation and the ambient sand of the natural bottom. The thickest layer of sand (approximately 4-6 ft in Figure 17) does occur at the center of the EMD where the cap should be the dominant factor. The most obvious feature is the break from sand to fine-grained material to the north (where thicknesses diminish from approximately 3 to 0 feet).

\section{REMOTS ${ }^{\circledR}$ Sediment Profiling}

41. A single REMOTS $^{\circledR}$ image was obtained and analyzed for each station shown in Figure 3 . Out of a total of 330 stations, 287 stations were occupied. The remaining 43 could not be completed die to adverse weather conditions. Variability in sediment type and shear strength among different areas of the Mud Dump site affected the penetration of the REMOTS ${ }^{\circledR}$ prism. During the field 
operations, the amount of weight loaded on the prism and the position of stops were adjusted frequently to optimize image quality at each station.

42. At twelve stations, prism penetration was prevented by rocks or large cobbles at the sediment surface. In addition, many of the stations in the southern portion of the Mud Dump site, particularly those centered around the sand cap in the southeast quadrant, consisted of fine-grained sands which were very resistant to the penetration of the REMOTS ${ }^{\circledR}$ prism. As a result, the images from approximately 70 stations exhibited suboptimal penetration. Table 4 describes how this underpenetration potentially affects image interpretation.

43. Most of the Mud Dump site consisted of generally low shear strength, fine-grained sediments which allowed optimal penetration of the REMOTS $^{\circledR}$ prism. Overpenetration of the prism occurred at twenty stations due to the thixotropic nature of the surface sediments. The effect of overpenetration on image interpretation is also described in Table 4.

\section{Physical/Sedimentary Characteristics}

44. Figure 18 shows the distribution of sediment grain-size major mode at the Mud Dump site. The stations which fall outside the hatched areas in this figure predominantly have a major mode of silt/clay ( $\geq 4$ phi) or very fine sand - silt/clay (>4-3 phi). Many images showed a distinct cross-sectional stratigraphy with abrupt transitions between sedimentary layers of different grain size (Figure 19). At such stations, very fine sand - silt/clay layers (>4-3 phi) were found to overlay slightly finer-grained layers of silt/clay ( $\geq 4$ phi). These latter depositional intervals appear to be organic-rich, low reflectance mud (most likely dredged material) which occurs primarily in the northeast quadrant as well as in the northern halves of the southwest and southeast quadrants. In addition, an isolated patch of this sediment exists southwest of the center of the EMD.

45. The majority of stations within the hatched areas in Figure 18 exhibit a major mode of very fine to fine sand (4-2 phi). In those cases where layering is distinguishable, very fine sand (4-3 phi) overlays silt/clay ( $>4$ phi) (Figure 20). Sandy areas occur primarily in the southern portion of the Mud Dump site as well as in the northwest quadrant.

46. The benthic "process" map shown in Figure 21 illustrates the occurrence of low-reflectance mud having apparent high sediment oxygen demand (SOD) in the immediate vicinity of the dredged material disposal mound in the 
northeast quadrant (Figure 22). Methane gas bubbles, indicative of extreme levels of organic loading, are visible in the REMOTS ${ }^{\circledR}$ images from a few stations in this area (Figure 23). Mud and/or dredged material also occurs in areas to the east and to the west of the center of the EMD, as well as in a small patch to the southwest of this point.

47. Clean, fine-grained, high-reflectance sand comprises the sand cap at the center of the microscale REMOTS $^{\circledR}$ survey in the southeast quadrant (Figure 24). This cap occupies an elliptical area having a north-south diameter of approximately $500 \mathrm{~m}$ and an east-west diameter of approximately 700 $m$ (Figure 21b). The area south of the sand cap is comprised of fine-grained sand which can be distinguished from the "cap sand" by its intermediate reflectance (Figure 25). Numerous sand ripples occur in this area south of the sand cap and the sand generally appears to contain a higher percentage of fines compared to the cap sand. At some stations, this sand also contains reduced mud clasts which presumably have been either transported by prevailing currents from elevated areas of dredged material to the north (Figure 26) or have fallen from scows after depositing a load and turning back to port. On the flanks of the sand cap, particularly to the west, there exist areas where mud or dredged material is covered by a relatively thin layer of fine-grained sand having intermediate reflectance (Figure 27). This sand is possibly a mixture of cap sand and ambient sediment from areas surrounding the site.

48. The exact thickness of the sand layer on the central part of the EMD could not be determined solely by REMOTS ${ }^{\circledR}$ because of the resistance of the sand to penetration of the REMOTS $^{\circledR}$ prism. However, several stations exhibit interesting sediment structure. The REMOTS ${ }^{\circledR}$ image from the station at the center of the EMD (Figure 28) shows a high-reflectance sand layer of approximately $4.1 \mathrm{~cm}$ overlaying a low-reflectance dredged material layer, which in turn overlays a second sand layer. At many of the stations on the flanks of the sand cap, a thin layer of sand having intermediate reflectance overlays a thicker dredged material layer (Figure 27). At station 200NE, which is within the apparent boundaries of the sand cap, reduced, low-reflectance mud characterizes the sediment surface (Figure 29).

49. Several other REMOTS $^{\circledR}$ parameters help to define the physical characteristics of the Mud Dump site. The frequency distribution of boundary roughness values is skewed right with a major mode of $0.8 \mathrm{~cm}$ (Figure 30 ). 
Stations on the sand cap as well as those to the southeast of the cap generally account for the highest boundary roughness values, due to the presence in these area of sand ripples (Figures 31 and 21b). At the remainder of stations, there appears to be no systematic spatial pattern in boundary roughness.

50. A map of RPD depths at the Mud Dump site is given in Figure 32, and the frequency distribution for these values is shown in Figure 33 . The frequency distribution is extremely right-skewed, reflecting the large number of low values associated with areas of organic loading as a consequence of past and ongoing dredged material disposal. Results of past studies have indicated that RPD depths less than $3 \mathrm{~cm}$ generally occur in those areas having low apparent dissolved oxygen levels and low reflectance (apparently high SOD) sediment (Figure 22). Such areas occur north of the sand cap and represent the depositional zone around the large disposal mound in the northeast quadrant.

51. RPD depths greater than $3 \mathrm{~cm}$ primarily occur on the sand cap mound and in the areas of ambient sand to the south (Figure 32b). At many of these stations, the RPD depth is a minimum estimate because of underpenetration of the camera prism. In general, determining the depth of the apparent RPD in fine-grained sands such as these is difficult because of the overall high reflectance of the sediment.

\section{Biological Characteristics}

52. The mapped distribution of infaunal successional stages is shown in Figure 34. The northern half of the survey area consists primarily of Stage I or Stage I on III assemblages. The Stage I communities are concentrated in the immediate vicinity of the large disposal mound in the northeast quadrant. This association consists of small tube-dwelling polychaetes and oligochaetes which appear in dense aggregations on the sediment surface (Figure 35). Spionid and capitellid polychaetes most likely dominate this assemblage. The occurrence and persistence of these pioneering successional stages in this area is related to a combination of physical disturbance and organic loading as a result of the ongoing disposal operations.

53. The presence of Stage III assemblages on the flanks of the disposal mound may be due to lateral migration of adult deposit-feeding taxa from surrounding areas unaffected by disposal activities. An alternate explanation is that these infaunal deposit feeders have become established in this area over longer time scales through the normal successional recovery process 
described in earlier sections of this report (see Rhoads and Germano, 1982). It may be possible for these Stage III organisms to persist on the mound in areas subject to periodic disturbance by simply burrowing back up to the surface following burial by disposed dredged material (Nichols et al., 1978).

54. The occurrence of Stage III infauna in REMOTS ${ }^{\circledR}$ images is typically indicated by the presence of void spaces (feeding pockets) produced as a result of head-down feeding (Figure 36). The burrowing anemone Ceriantheopsis americanus was also evident at several stations, particularly those characterized by sediment with high apparent SOD (Figure 37).

55. In the southern portion of the Mud Dump site, including the sand cap and the sandy areas to the south and east, Stage I assemblages are numerous. At a number of sandy stations, it is possible that stage III infauna occurring at depth were not detected because of the shallow penetration of the camera prism. These stations are indicated by the "Ind" symbol in Figure 34b. Generally, the majority of stations on the sand cap are characterized by Stage I assemblages, which suggests that the cap has been effective in preventing the colonization and subsequent bioturbation of underlying muds. Stage III organisms are found on the fringes of the sand cap, particularly to the west and southwest. Stage I assemblages on the ambient sandy bottom south and east of the sand cap occur in depositional troughs between the numerous sand bedforms in this region (Figure 31 ).

56. The frequency distribution of Organism-Sediment Index (OSI) values (Figure 38 ) is polymodal, with values ranging from -3 to +11 . The high OSI values are clustered around a major mode of 7 . These occur with roughly the same frequency as the low OSI values, which have a major mode of 2 . This distribution reflects the wide range of disturbance gradients which exists at the Mud Dump site.

57. The mapped distribution of OSI values is shown in Figure 39 . Regions with the highest OSI values (range: 5 to 11) occur east and west of the disposal mound in the northern half of the Mud Dump site. Directly on the disposal mound and sloping away from the mound to the southeast, extremely low OSI values are encountered. This presumably is related to the frequent physical disturbance of the bottom as a result of the disposal activity in the region. Low OSI values are generally associated with areas of low reflectance sediment wherever it occurs at the site. 
58. Stations at the flanks of the sand cap, particularly to the west, are characterized by relatively high OSI values. At many of these stations, especially those clustered around the center of the sand cap, the OSI values are high because mean apparent RPD values are relatively high. RPD depths generally appear to be deeper than the prism penetration in this area. On the fringes of the sand cap and at isolated sand cap stations, the high OSI values reflect the occurrence of Stage III infauna, indicating an environment which is less routinely affected by physical disturbance as stations to the north. OSI values could not be calculated for some stations south of the sand cap because of indeterminate successional stages.

\section{PART IV: DISCUSSION}

59. A major objective of this study was to provide accurate bathymetric information on the overall configuration of the entire Mud Dump site and describe the conditions at its boundaries. Comparison of the bathymetric surveys conducted in 1980, 1981, and 1986 revealed the development of a large disposal mound in the northeast quadrant of the Mud Dump site. The impact of disposal operations at this one location can be seen in all directions but most significantly to the east of the disposal location, where accumulations of sediment of up to 8 feet $(2.4 \mathrm{~m})$ can be seen, and to the south, where $2-3$ feet (0.6-0.9 m) of sediment has collected (Figures 6 and 7). Evidence of transport to the south is also seen in the data collected with the REMOTS ${ }^{\circledR}$ camera. The OSI values to the south of the disposal mound are significantly less than those to the east and west (Figure 39), indicating continual disturbance in this direction. Whether this widespread distribution of dredged material is due to the lack of tight controls on disposal operations (e.g., drifting during actual disposal of dredged material) or to the physical oceanographic characteristics of the site is unknown at the present time. However, the Mud Dump site is vulnerable to the effects of storm events that can develop waves large enough to contribute to sediment resuspension and transport, especially at the shallower peak of the disposal mound in the northeast quadrant. R.A. Young (Freeland et al., 1983) conducted a study to determine the sediment transport conditions at the Mud Dump site in 1980-1981. Bottom-mounted current meters, wave gauges, and transmissometers were used to document the conditions required 
to resuspend and transport sediment. The overall conclusion of the study was that little transport was expected to occur at the sand cap site in the southeast quadrant at a depth of 80 feet. However, the data did show that waves capable of resuspending sediment in 80 feet of water could occur several times a month. Additionally, transport rates increase rapidly as the depth of water decreases. It is reasonable to expect increased resuspension and transport of dredged material at the shallower depths of the disposal mound ( 44 feet) in the northeast quadrant. The fact that large accumulations of sediment are seen at the eastern boundary of the Mud Dump site suggests that an unknown amount of material has traveled beyond that boundary, possibly due to a combination of transport during disposal operations and/or resuspension and transport after disposal.

60. Comparison of the estimate of the volume of dredged material deposited at the Mud Dump site based on scow logs and the estimate of the volume of material seen on the bottom acoustically within the boundaries of the Mud Dump site reveals a significant discrepancy. Volume calculations determined that approximately $7.6 \times 10^{6}$ cubic meters of material has accumulated since August 1981. Scow $\log$ estimates indicate that over $18.6 \mathrm{X}$ $10^{6}$ cubic meters of dredged material were dumped from 1982 to 1986 . As mentioned above, a loss of approximately 40.78 of the scow volume (Tavolaro, 1984) is expected to occur after the material leaves the scow, with approximately 15.48 attributed to the loss of interstitial water during disposal and compaction after disposal. Much of the remaining 25.38 loss is most likely due to the thin layers of dredged material on the flanks of a deposit that typically are not detected acoustically (Germano, 1983; Germano and Rhoads, 1984). By using this correction factor of 40.78 , we would expect to have detected approximately $11.0 \times 10^{6} \mathrm{~m}^{3}$ of dredged material within the boundaries of the Mud Dump site. This indicates that about $31 \%$ of this material (or $3.4 \times 10^{6} \mathrm{~m}^{3}$ ) is unaccounted for and presumably outside the site. The REMOTS ${ }^{\circledR}$ station locations at the Mud Dump site were defined prior to field operations and based on the assumption that all dredged material was contained within the disposal site boundaries; extending stations to 600 meters beyond the site boundary should have been adequate to detect any layer of dredged material less than $20 \mathrm{~cm}$ in thickness if this assumption were true. The results of the REMOTS ${ }^{\circledR}$ survey confirms the information from the bathymetric 
survey about the areal extent of dredged material and indicates that dredged material not only extends more than $600 \mathrm{~m}$ beyond the eastern boundary of the disposal site, but occurs at all stations in layers thicker than the penetration depth of the camera $(20 \mathrm{~cm})$. Because there is no information on exactly how thick the dredged material layer is at these REMOTS ${ }^{\circledR}$ stations outside the site and because all stations sampled outside the site at the northeast quadrant showed the presence of dredged material, it is impossible to accurately calculate either the volume or areal extent of material outside the disposal site boundaries with the existing data.

61. In order to achieve the objective of accurately determining the configuration and long-term stability of the sand cap, a more detailed bathymetric survey and a subbottom survey were conducted at the EMD in 1986, and additional REMOTS ${ }^{\circledR}$ stations were sampled at closely-spaced intervals. The bathymetric survey did not indicate any significant erosion of the sand cap. However, comparison of the 1986 and 1981 surveys revealed small amounts of sediment accumulation on the order of 1-2 feet (0.3-0.6 m, Figure 13) around the capped mound. This may be due to dredged material being deposited at other locations in the disposal site and being transported into the deeper areas around the capped mound.

62. The discrepancy between volume calculations on the 1980 and 1981 surveys (pre- and post- capping) and corrected scow log estimates at the EMD $\left(814,000\right.$ vs. $\left.712,000 \mathrm{~m}^{3}\right)$ is not significant, indicating that little if any loss of capping material occurred either during the capping operations or during the period to the present survey.

63. As determined from the REMOTS ${ }^{\circledR}$ images, an area of fine-grained, high reflectance sand occurred almost in a circle at the center of the EMD with a diameter of approximately 1800 feet (550 m, Figure 21b). This compares well with the results of the bathymetric data from the June 1980 and August 1981 surveys. Comparison of these two surveys indicated an accumulation of sediment (sand capping material) in a circular area of approximately 2600 feet (790 m, Figure 12). The reason for the discrepancy between the two numbers ( 1800 versus 2600) is that toward the edges of the cap, the distinction between cap material and ambient fine-grained sediment has become more subtle with time. In general, the ambient sands surrounding the sand cap have the same grain-size major-mode (4-3 phi or 3-2 phi) as sand comprising the cap but tend to be of 
intermediate reflectance (see Figure 25). This intermediate reflectance presumably is imparted to the sand by its higher proportion of heavy minerals and/or mica. In addition, at many stations at the edge of the sand cap, it appears that the clean cap sand has become diluted with the addition of fines from surrounding areas, resulting in surface sediments having relatively lower reflectance (e.g., Figure 27). An increase in percent fines in the surface sediment on the edges of the sand cap was noted by Freeland et al. (1983) based on grab samples obtained in November 1980 and June 1981 . Whatever the cause (transport, detrital deposition, dredged material disposal, etc.), the phenomenon tends to obscure the boundaries of the cap as determined from the cross-sectional images of the upper 15 to $20 \mathrm{~cm}$.

64. The results of the subbottom profiles also documented the extent of the sand at the southeast quadrant but could not distinguish between the ambient sand and the sand cap material because of similar acoustic qualities. However, the percent-sand contour chart (Figure 14) compares very well with the benthic "process" map (Figure 21) that shows the extent of sand determined by the REMOTS ${ }^{\circledR}$ images. As expected, the results also agree with the grain size map (Figure 18) determined by the REMOTS ${ }^{\circledR}$ photos. This is perhaps one of the first times a seismic bottom survey has had such a wide distribution of discrete sampling points to confirm and calibrate the acoustic information. In this study, a pulse length of $40 \mathrm{~cm}$ was required by the seismic system to penetrate the sand layer; the resolution of the seismic system, therefore, was considerably less than that of the REMOTS ${ }^{\circledR}$ images. Analysis of the REMOTS ${ }^{\circledR}$ images was able to detect thin layers $(<15 \mathrm{~cm})$ of sand or fine-grained material while the return signals from the seismic system integrated over $40 \mathrm{~cm}$ of sediment. This would account for surface patches of fine-grained material over the sand cap that were seen by the REMOTS ${ }^{\circledR}$ camera but undetected by the subbottom profiles.

65. The occurrence of small fine-grained sediment deposits on the sand cap has been documented by previous investigators. Freeland et al. (1983) found some sites on the cap with 50 to $80 \%$ muds and attributed this to deposition on the cap of silt and clay-sized sediment from peripheral areas. $O^{\prime}$ Connor and $O^{\prime}$ Connor (1983) also cite data from cores showing some locations on the cap with mud at the surface and relatively clean sand between 0.25 and 
0.50 meters below. REMOTS ${ }^{\circledR}$ images have detected these "puddles" of mud on top of the sand cap while the subbottom profiles detected the sand underneath.

66. A major source of the fine-grained material seen in patches on the sand cap is probably the dredged material deposited at the disposal location in the northeast quadrant. The decreases in depth occurring as far as $1500 \mathrm{~m}$ to the south-southeast of this location between 1981 and 1986 indicate that 1 foot $(0.3 \mathrm{~m})$ of sediment has accumulated throughout much of the area and that as much as 3 feet $(0.9 \mathrm{~m})$ has accumulated in the eastern section of the southeast quadrant. A study of sediment transport in the area was conducted in 1980 and 1981 by R.A. Young (Freeland et al., 1983). Results of that study indicated that the direction of net transport of resuspended sediment would be in the south-southeast direction and that intermediate-size waves could occur several times per month and supply enough energy to resuspend fine-grained sediment.

67. The REMOTS ${ }^{\circledR}$ image obtained at station CTR (Figure 28) may help to explain some of the processes mentioned above. The bottom sand layer may be the "true" sand cap upon which the dredged material (the low-reflectance band of fine-grained sediment in the middle) was deposited as a result of transport from areas to the north. This middle layer of dredged material subsequently has been covered by a relatively thin layer of sand, presumably transported from surrounding areas on the sand cap. It is also possible that occasionally scows attempting to dispose of sand in the NW quadrant did not navigate accurately and deposited the sand in the SE quadrant instead.

68. Another objective of the REMOTS ${ }^{\circledR}$ survey was to investigate the effect of bioturbation on the sand cap. This effect appears to be negligible, as indicated by the concentration of Stage I organisms in this area (Figure $34 \mathrm{~b})$ and the lack of evidence of colonization by deposit-feeding or deep burrowing infauna. Given the fact that the sand layer appears to be on the order of several feet thick (Figure 17), it is not likely that bioturbational mixing would readily compromise cap integrity, especially because the majority of bioturbational activity even by head-down, deposit-feeding infauna (Stage III assemblages) occurs within the top $15-30 \mathrm{~cm}$ of sediment. Both Stage III and Stage I on III successional seres are present on the perimeter of the sand cap in all directions except to the southeast. As bioturbational mixing of the thin sand layer with underlying muds occurs at these flank locations, the areal extent of the sand cap can be expected to continue to shrink. 
69. The potential effects of bioturbation at the rest of the disposal site is dependent upon the distribution of stage III benthic communities. In the deeper areas, normal current velocities are not sufficient to resuspend the sediment, and transport during significant wave conditions would be minimal (Freeland et el., 1983). However, once disposal operations are halted at the shallower areas of the NE disposal point, the lack of continual disturbance will allow colonization by Stage III infauna and increase the potential for bioturbation. The bioturbational activities of these deep-dwelling, head-down deposit feeders increase the sediment water-content, decrease the sediment shear strength, and render the surface more susceptible to erosion (Rhoads and Boyer, 1982). Therefore, over time and in the lack of continued disturbance, one could expect an increase in the amount of sediment resuspended in and transported from the northeast quadrant during intermediate to heavy wave conditions.

\section{PART V: CONCLUSIONS}

70. Examination of the contoured bathymetric charts for the surveys conducted at the Mud Dump site and the EMD reveal the significant accumulation of sediment to the south and east of the present disposal point in the northeast quadrant. The decrease in depth at the eastern boundary of the Mud Dump site and the layers of dredged material greater than $20 \mathrm{~cm}$ thick seen in REMOTS $^{\circledR}$ images 600 meters beyond this boundary indicate the accumulation of dredged material well beyond this limit. This could be due to inaccurate positioning during disposal operations, spreading of the material after leaving the scow, or resuspension and transport after disposal is complete. Waves of sufficient height to resuspend bottom sediment at the shallowest point of disposal mound frequently occur at the site (Freeland et al., 1983). Once suspended, material is transported by the dominant current flow in the southsoutheast direction.

71. Throughout the disposal site, the mapped REMOTS ${ }^{\circledR}$ parameters (RPD depth, successional stage, OSI) reflect disturbance gradients related to the ongoing dredged material disposal activities in the northeast quadrant. Directly on the dredged material mound, the extremely low OSI values are indicative of a highly-disturbed bottom, resulting from inputs of organic-rich 
dredged material. On the flanks of the disposal mound, the presence of Stage III infauna suggests a benthic community moving toward a more stable successional sere and subjected to less frequent disturbance. Nevertheless, the generally shallow RPD depths and persistence of Stage I taxa in these areas are indicative of the frequency of disturbance related to ongoing disposal activities.

72. The bathymetric surveys did not detect significant erosion of the sand cap. The persistence at the surface of clean sand representing the final cap material at the EMD indicates that the integrity of the cap to date has not been seriously compromised. The results of the subbottom survey revealed a continuous layer of sand over the small mound at the EMD with only a few patches of finer-grained material over the sand, most likely the result of disposal operations at other areas in the disposal site.

73. The potential for bioturbation to significantly affect the integrity of the sand cap is quite small. Even though the sand cap is thicker $(0.5-1.5$ $\mathrm{m})$ than the maximum depth of mixing by Stage III infauna $(0.2-0.3 \mathrm{~m})$, the benthic community on the cap is dominated by Stage I assemblages that only burrow to about $5 \mathrm{~cm}$. The relatively high organism-sediment index (OSI) values existing in areas to the northeast and southwest of the sand cap indicate that a fairly healthy benthic community is established in the peripheral areas. (The OSI's reflect the condition of the benthic habitat by taking into account the successional stage of the benthic community, the redox potential discontinuity (RPD) depth, and the presence or absence of methane and/or low dissolved oxygen concentrations.) The presence of this community suggests that the relatively thin layers of sand that exist on the flanks of the sand cap eventually may be mixed with underlying mud as a result of bioturbation.

\section{PART VI: RECOMMENDATIONS}

74. Based on the results of the surveys conducted during November 1986, several recommendations can be made to more effectively manage the disposal of dredged material at the Mud Dump site. With the realization that a large percentage of dredged material has accumulated outside the designated boundaries of the Mud Dump site, it would seem necessary to conduct bathymetry surveys at least annually to document the distribution of dredged material. 
This would also prevent the formation of disposal mounds that are high enough to be more susceptible to erosion during storm events with intermediate to heavy wave conditions. The work by R.A. Young (Freeland et al., 1983) indicated that waves commonly occurred that could resuspend material at a depth of 80 feet, although transport at that depth would be minimal. However, the transport rates increase rapidly as the depth is reduced and could cause significant erosion at a depth of 50 feet. It would also be quite useful to determine if the distribution of dredged material outside the site boundaries is due to poor navigational control of disposal operations or to erosion and transport from the existing mound. The use of inspectors aboard each scow load to record coordinates of each disposal event would be invaluable in reconstructing events leading to the final dispersion pattern of dredged material on the bottom.

75. REMOTS ${ }^{\circledR}$ surveys of the area outside the site boundary which is affected by the accumulation of dredged material could determine if recolonization is occurring at a normal rate. The results of these surveys could confirm that accumulation outside of the site was not adversely affecting the benthic habitat. Additional REMOTS ${ }^{\circledR}$ surveys should be conducted at the northeast quadrant to determine the physical processes at work on the peak of the mound. The fine sand cap recently placed at the northeast disposal point could experience significant resuspension and transport during storm events and possibly during maximum current flows. In order to assess the magnitude and extent of the bioturbational mixing occurring at the flanks of the sand cap, further monitoring of the biota should take place during warmer months when infaunal bioturbation rates are at their maximum.

\section{BIBLIOGRAPHY}

Caulfield, D.D. 1984. Shallow seismic derived acoustic core logs, Offshore Technology Conference, Houston, TX, 7-9 May.

Caulfield, D.D. and Y.C. Yim. 1983. Prediction of shallow sub-bottom sediment acoustic impedance while estimating absorption and other losses, J. Can. Soc. Exp1. Geophys., Vo1. 19(1): 44-50

Dayal, R., Heaton, M.G., Fuhrmann, M., and I.W. Duedall. 1981. A geochemical and sedimentological study of the dredged material deposit in the New York Bight, NOAA Technical Memorandum OMPA-3, Dept. of Commerce, 174p. 
Freeland, G.L, R.A. Young, G. Drapeau, T.L. Clarke and B.T. Berggio. 1983. Sediment cap stability study, New York dredged material dumpsite, Final Report under support agreement \#NYD80-124(C), NYDCOE.

Freeland, G.L., D.J.P. Swift, W.L. Stubblefield and A.E. Cok. 1976. Surficial sediments of the NOAA-MESA study areas in the New York Bight, In: M.G. Gross (ed.) Middle Atlantic Continental Shelf and the New York Bight, Am. Soc. Limnol. Oceanogr. Spec. Symp., Vol. 2:90-101.

Hamilton, E.L. 1970. Reflection coefficients and bottom loses at normal incidence computed from Pacific sediment properties, Geophysics, Vol. 35: 9951004 .

Hamilton, E.L. 1971. Elastic properties of marine sediments, J. Geophys. Res., Vo1. 76: 579-604.

Germano, J.D. 1983. High resolution sediment profiling with REMOTS camera system, Sea Technology, Vo1. 24: 35-41.

Germano, J.D. and D.C. Rhoads. 1984. REMOTS ${ }^{\circledR}$ Sediment Profiling at the Field Verification Program (FVP) disposal site, In: R.L. Montgomery and J.W. Leach (eds.), Dredging and Dredge Material Disposal, Volume 1, ASCE, New York, pp. $536-544$.

O'Connor, J.M. and S.G. O'Connor. 1983. Evaluation of the 1980 capping operations at the Experimental Mud Dump Site, New York Bight Apex, U.S. Army Waterways Experiment Station, Technical Report D-83-3, Vicksburg, MS.

Nichols, J.A., G. T. Rowe, C.H. Clifford and R.A. Young. 1978. In situ experiments on the burial of marine invertebrates, J. Sed. Petrol., Vol. 48: 419-425.

Rhoads, D.C. and L.F. Boyer. 1982. The effects of marine benthos on physical properties of sediments, In: P.L. McCall and J.J.S. Tevesz (eds.), AnimalSediment Relations, Plenum Press, New York, pp.3-52.

Rhoads, D.C. and J.D. Germano. 1982. Characterization of organism-sediment relations using sediment profile imaging: an efficient method of Remote Ecological Monitoring of the Seafloor (REMOTS ${ }^{\text {m }}$ system), Marine Ecology Progress Series, Vol. 8: 115-128.

Rhoads, D.C. 1974. Organism-sediment relations on the muddy seafloor, Oceanogr. Mar. Biol. A. Rev., Vol. 12: 263-300.

Tavolaro, J.F. 1984. Sediment budget study of clamshell dredging and ocean disposal activities in the New York Bight. Environ. Geol. Water Sci., Vol. 6(3): $133-140$. 
Table 1

Typical REMOTS ${ }^{\circledR}$ Data Sheet Showing the 21 Parameters

Which can be Measured During Image Analysis

FEMOTS DATA SHEET

SCiEnCE ARPlications

PROJECT : NEW YORK MUD DUMPSITE

FIELD DATE: $11 / 12 / 86$

Me asuremerits By: RMU

STATION: $600 \mathrm{SE}$

FRAME \#: 4

Time of Fhoto: 14:53

Data. Record \#: 39

$* * * * * * * * * * * * *$ PHYSICAL - CHEMICAL PARAMETERS

1. Grain Size:

Major Mode: $4-3$ क Range: $24-2 \phi$

2. Total Prism Penetration Depth:

Minimum: $4.17 \mathrm{~cm}$. Maximum: $5.81 \mathrm{~cm}$. Average: $4.99 \mathrm{~cm}$.

3. Surface Boundary Roughness: $1.55 \mathrm{~cm}$. ----- Physical

4. Mud $C l a s t s$

\# Of Clasts: 1

Average Diameter: $.49 \mathrm{~cm}$. Status: Both oxidized and reduced

5. Mean Redox Depth: $4.92 \mathrm{~cm}$.

6. Redox Rebound (former distance from sed. surface): Nat Present

7. Methane Gas Pockets: Not Present Number: 0 Area: $0 \mathrm{sq}$. $\mathrm{cm}$.

Min. Range: $0 \mathrm{~cm}$. Max. Range: $0 \mathrm{~cm}$. Average Depth: $0 \mathrm{~cm}$.

8. Low Dissolved Oxygen in Guerlying Water: No

9. Dredged Material thickness (cm.): Not Present

10. Additional Measurement: $0 \mathrm{~cm}$. Label: NA

11. Comment: RPD greater than perietration (SD) BDFFM

\section{BIOLOGICAL PARAMETERS}

12. Epifauna: Norie Visible

13. Tube Density (\#/linear $\mathrm{cm}$.): 0

14. Tube TYpe: NA

15. Fecal Pellet layer:

Min. Thickness: $0 \mathrm{~cm}$. Max. Thickness: $0 \mathrm{~cm}$. Average: $0 \mathrm{~cm}$.

16. Microbial Aggregations Present?: 0

17. Feeding Voids -- Average Depth: $0 \mathrm{~cm}$. Number: 0 Minimum Depth: $0 \mathrm{~cm}$. Maximum Depth: $0 \mathrm{~cm}$.

18. Faunal Dominants:

19. Apparent Species Richness:

20. Successional Stage: STAGE 1

21. Organism-Sediment Index: 7 
Table 2

Comparison of REMOTS ${ }^{\circledR}$ Grain-Size Major Mode Estimates With Conventional Sediment Analyses

Rappahannock Disposal Sites-Chesapeake Bay

February, 1984

Numbers represent percent weight (\&) in phi (ø) intervals.

Station 01

\begin{tabular}{rrr}
$\varnothing$ & \multicolumn{1}{c}{8} & REMOTS $^{\circledR}$ \\
\hline$-1-1$ & 0.00 & \\
$1-2$ & 0.00 & $\geq 4 \varnothing$ \\
$2-3$ & 0.00 & \\
$3-4$ & 0.00 & \\
$\geq 4$ & 100.00 &
\end{tabular}

Station 04

\begin{tabular}{rrr}
$\varnothing$ & \multicolumn{1}{c}{8} & REMOTS $^{\circledR}$ \\
\hline$-1-1$ & 0.00 & \\
$1-2$ & 0.00 & $\geq 40$ \\
$2-3$ & 0.00 & \\
$3-4$ & 0.00 & \\
$\geq 4$ & 100.00 &
\end{tabular}

Station 07

\begin{tabular}{rrr}
\multicolumn{1}{c}{8} & \multicolumn{1}{c}{8} & REMOTS $^{\circledR}$ \\
\hline$-1-1$ & 0.00 & \\
$1-2$ & 4.04 & $\geq 40$ \\
$2-3$ & 19.70 & \\
$3-4$ & 4.96 & \\
$\geq 4$ & 71.30 &
\end{tabular}

Station 10

\begin{tabular}{rrr}
$\varnothing$ & \multicolumn{1}{c}{8} & REMOTS $^{\circledR}$ \\
\hline$-1-1$ & 0.00 & \\
$1-2$ & 0.00 & $\geq 4 \varnothing$ \\
$2-3$ & 0.00 & \\
$3-4$ & 8.31 & \\
$\geq 4$ & 91.69 &
\end{tabular}

Station 13

\begin{tabular}{rrr}
$\varnothing$ & \multicolumn{1}{c}{8} & \\
\hline$-1-1$ & 0.00 & \\
$1-2$ & 0.00 & $\geq 40$ \\
$2-3$ & 0.00 & \\
$3-4$ & 0.00 & \\
$\geq 4$ & 100.00 &
\end{tabular}

Station 16

\begin{tabular}{rrr}
\multicolumn{1}{c}{8} & REMOTS $^{\circledR}$ \\
\hline$-1-1$ & 0.00 & \\
$1-2$ & 0.00 & $\geq 40$ \\
$2-3$ & 0.00 & \\
$3-4$ & 0.00 & \\
$\geq 4$ & 100.00 &
\end{tabular}

Station 02

\begin{tabular}{crr}
$\varnothing$ & \multicolumn{1}{c}{8} & REMOTS $^{\circledR}$ \\
\hline$-1-1$ & 0.00 & \\
$1-2$ & 0.00 \\
$2-3$ & 0.00 \\
$3-4$ & 0.00 \\
$\geq 4$ & 100.00
\end{tabular}

Station 05

\begin{tabular}{ccc}
$\varnothing$ & \multicolumn{1}{c}{8} & REMOTS $^{\circledR}$ \\
\hline$-1-1$ & 0.00 & \\
$1-2$ & 0.00 \\
$2-3$ & 0.00 \\
$3-4$ & 0.00 \\
$\geq 4$ & 100.00
\end{tabular}

Station 08

\begin{tabular}{crr}
\multicolumn{1}{c}{8} & \multicolumn{1}{c}{8} & REMOTS $^{\circledR}$ \\
\hline$-1-1$ & 0.00 \\
$1-2$ & 0.00 \\
$2-3$ & 0.00 \\
$3-4$ & 0.00 \\
$\geq 4$ & 100.00
\end{tabular}

Station 11

\begin{tabular}{rrr}
$\varnothing$ & \multicolumn{1}{c}{8} & REMOTS $^{\circledR}$ \\
\hline$-1-1$ & 0.00 & \\
$1-2$ & 45.68 & $2-3 \varnothing$ \\
$2-3$ & 52.67 & \\
$3-4$ & 1.65 & \\
$\geq 4$ & &
\end{tabular}

Station 14

\begin{tabular}{rrr}
\multicolumn{1}{c}{$\varnothing$} & \multicolumn{1}{c}{8} & REMOTS $^{\circledR}$ \\
\hline$-1-1$ & 0.00 & \\
$1-2$ & 0.00 & $\geq 4 \varnothing$ \\
$2-3$ & 0.00 \\
$3-4$ & 0.00 \\
$\geq 4$ & 100.00
\end{tabular}

Station 17

\begin{tabular}{rrr}
$\varnothing$ & \multicolumn{1}{c}{8} & REMOTS $^{\circledR}$ \\
\hline$-1-1$ & 0.00 & \\
$1-2$ & 0.00 \\
$2-3$ & 0.00 \\
$3-4$ & 0.00 \\
$\geq 4$ & 100.00
\end{tabular}

Station 03

\begin{tabular}{crc}
$\varnothing$ & \multicolumn{1}{c}{8} & REMOTS \\
\hline$-1-1$ & 0.00 & \\
$1-2$ & 0.00 \\
$2-3$ & 0.00 & $\geq 40$ \\
$3-4$ & 0.00 & \\
$\geq 4$ & 100.00 &
\end{tabular}

Station 06

\begin{tabular}{rrr}
$u$ & \multicolumn{1}{c}{8} & REMOTS \\
\hline$-1-1$ & 13.22 & \\
$1-2$ & 83.05 & $1-2 ø$ \\
$2-3$ & 3.71 & \\
$3-4$ & 0.00 & \\
$\geq 4$ & 0.00 &
\end{tabular}

Station 09

\begin{tabular}{rrr}
$\varnothing$ & \multicolumn{1}{c}{8} & REMOTS $^{\circledR}$ \\
\hline$-1-1$ & 0.00 & \\
$1-2$ & 0.00 \\
$2-3$ & 0.00 \\
$3-4$ & 0.00 \\
$\geq 4$ & 100.00
\end{tabular}

Station 12

\begin{tabular}{rrr}
$\varnothing$ & \multicolumn{1}{c}{8} & REMOTS $^{\circledR}$ \\
\hline$-1-1$ & 0.00 & \\
$1-2$ & 74.70 & $1-2 \varnothing$ \\
$2-3$ & 14.70 & \\
$3-4$ & 0.00 & \\
$\geq 4$ & 11.60 &
\end{tabular}

Station 15

\begin{tabular}{rrr}
\multicolumn{1}{c}{8} & \multicolumn{1}{c}{ REMOTS $^{\circledR}$} \\
\hline$-1-1$ & 0.00 & \\
$1-2$ & 0.00 \\
$2-3$ & 0.00 \\
$3-4$ & 0.00 \\
$\geq 4$ & 100.00
\end{tabular}

Station 18

\begin{tabular}{rrc}
$\varnothing$ & \multicolumn{1}{c}{8} & REMOTS $^{\circledR}$ \\
\hline$-1-1$ & 5.76 & $* * *$ \\
$1-2$ & 40.81 & $1-2 \varnothing$ \\
$2-3$ & 42.00 & \\
$3-4$ & 1.03 & \\
$\geq 4$ & 10.40 &
\end{tabular}

*** Stations where REMOTS $^{\circledR}$ and conventional analyses disagree. 
Table 2 continued.

\begin{tabular}{|c|c|c|c|c|c|c|c|c|c|}
\hline Stat & 19 & & Stati & 20 & & & Stati & ก 21 & \\
\hline$\varnothing$ & 8 & REMOTS ${ }^{\circledR}$ & $\varnothing$ & 8 & REMC & $\mathrm{TS}^{(1)}$ & $\theta$ & 8 & REMOTS ${ }^{\circledR}$ \\
\hline$-1-1$ & 0.00 & $* * *$ & $-1-1$ & 0.00 & & 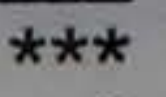 & $-1-1$ & 0.00 & \\
\hline $1-2$ & 69.16 & $2-3 \emptyset$ & $1-2$ & 83.42 & 2 & -30 & $1-2$ & 68.17 & $1-2 \varnothing$ \\
\hline $2-3$ & 20.61 & & $2-3$ & 9.30 & & & $2-3$ & 23.74 & \\
\hline $3-4$ & 0.00 & & $3-4$ & 0.00 & & & $3-4$ & 0.00 & \\
\hline$\geq 4$ & 10.23 & & $\geq 4$ & 7.28 & & & $\geq 4$ & 8.09 & \\
\hline
\end{tabular}

Station 22

\begin{tabular}{rrr}
\multicolumn{1}{c}{8} & \multicolumn{1}{c}{ REMOTS $^{\circledR}$} \\
\hline$-1-1$ & 0.00 & \\
$1-2$ & 0.00 \\
$2-3$ & 0.00 \\
$3-4$ & 0.00 & $\geq 4 \varnothing$ \\
$\geq 4$ & 100.00
\end{tabular}

Station 25

\begin{tabular}{rrr}
\multicolumn{1}{c}{} & \multicolumn{1}{c}{8} & REMOTS \\
\hline$-1-1$ & 0.00 & $* * *$ \\
$1-2$ & 47.55 & $2-30$ \\
$2-3$ & 19.40 & \\
$3-4$ & 4.23 & \\
$\geq 4$ & 28.82 &
\end{tabular}

Station 28

\begin{tabular}{rrr}
\multicolumn{1}{c}{8} & \multicolumn{1}{c}{8} & REMOTS \\
\hline$-1-1$ & 0.00 & \\
$1-2$ & 47.83 & $1-2 \emptyset$ \\
$2-3$ & 41.31 & \\
$3-4$ & 0.33 & \\
$\geq 4$ & 10.53 &
\end{tabular}

Station 31

\begin{tabular}{rrr}
\multicolumn{1}{c}{$\frac{1}{\sigma}$} & REMOTS $^{\circledR}$ \\
\hline$-1-1$ & 0.00 & \\
$1-2$ & 0.00 & $\geq 40$ \\
$2-3$ & 0.00 & \\
$3-4$ & 0.00 & \\
$\geq 4$ & 100.00 &
\end{tabular}

Station 34

\begin{tabular}{rrr}
$\varnothing$ & \multicolumn{1}{c}{8} & REMOTS \\
\hline$-1-1$ & 0.00 & \\
$1-2$ & 0.23 & $\geq 40$ \\
$2-3$ & 0.43 & \\
$3-4$ & 28.04 & \\
$\geq 4$ & 71.30 &
\end{tabular}

Station 37

\begin{tabular}{ccc}
$\varnothing$ & \multicolumn{1}{c}{8} & REMOTS $^{\circledR}$ \\
\hline$-1-1$ & 0.00 & \\
$1-2$ & 0.00 & $\geq 4 \varnothing$ \\
$2-3$ & 0.00 & \\
$3-4$ & 4.73 & \\
$>4$ & 95.27 &
\end{tabular}

$\geq 4 \quad 95.27$

$* * *$ Stations where REMOTS ${ }^{\circledR}$
Station 23

\begin{tabular}{|c|c|c|}
\hline$\emptyset$ & 8 & REMOTS ${ }^{\circledR}$ \\
\hline$-1-1$ & 0.00 & \\
\hline $1-2$ & 0.00 & $\geq 40$ \\
\hline $2-3$ & 0.00 & \\
\hline $3-4$ & 0.00 & \\
\hline$\geq 4$ & 100.00 & \\
\hline
\end{tabular}

Station 26

\begin{tabular}{crc}
\multicolumn{1}{c}{8} & \multicolumn{1}{c}{8} & REMOTS $^{\circledR}$ \\
\hline$-1-1$ & 0.58 & \\
$1-2$ & 77.02 & $1-2 \varnothing$ \\
$2-3$ & 16.80 & \\
$3-4$ & 0.00 & \\
$\geq 4$ & 5.60 &
\end{tabular}

Station 29

\begin{tabular}{rrr}
\multicolumn{1}{c}{8} & \multicolumn{1}{c}{8} & REMOTS $^{\circledR}$ \\
\hline$-1-1$ & 0.00 \\
$1-2$ & 0.00 \\
$2-3$ & 0.00 \\
$3-4$ & 0.00 \\
$\geq 4$ & 100.00
\end{tabular}

Station 32

\begin{tabular}{rrr}
\multicolumn{1}{c}{8} & \multicolumn{1}{c}{8} & REMOTS $^{\circledR}$ \\
\hline$-1-1$ & 0.00 & \\
$1-2$ & 8.77 \\
$2-3$ & 35.29 \\
$3-4$ & 5.10 \\
$\geq 4$ & 50.84 &
\end{tabular}

Station 35

\begin{tabular}{rrr}
\multicolumn{1}{c}{8} & \multicolumn{1}{c}{ REMOTS $^{\circledR}$} \\
\hline$-1-1$ & 0.00 & \\
$1-2$ & 0.00 \\
$2-3$ & 0.00 \\
$3-4$ & 0.00 \\
$\geq 4$ & 100.00
\end{tabular}

Station 38

\begin{tabular}{crr}
$\varnothing$ & \multicolumn{1}{c}{8} & REMOTS $^{\circledR}$ \\
\hline$-1-1$ & 0.00 & \\
$1-2$ & 0.00 \\
$2-3$ & 0.00 \\
$3-4$ & 18.21 \\
$>4$ & 81.79 &
\end{tabular}

Station 24

\begin{tabular}{rrr}
$\varnothing$ & \multicolumn{1}{c}{8} & REMOTS \\
\hline$-1-1$ & 0.00 & \\
$1-2$ & 0.00 & $\geq 4 \varnothing$ \\
$2-3$ & 0.00 \\
$3-4$ & 0.00 \\
$\geq 4$ & 100.00
\end{tabular}

Station 27

\begin{tabular}{crl}
$\varnothing$ & \multicolumn{1}{c}{8} & REMOTS \\
\hline$-1-1$ & 0.00 & \\
$1-2$ & 6.05 \\
$2-3$ & 25.47 \\
$3-4$ & 5.42 & \\
$\geq 4$ & 63.06 &
\end{tabular}

Station 30

\begin{tabular}{rrr}
\multicolumn{1}{c}{} & \multicolumn{1}{c}{8} & REMOTS $^{\circledR}$ \\
\hline$-1-1$ & 0.00 & \\
$1-2$ & 0.00 \\
$2-3$ & 0.00 \\
$3-4$ & 0.00 \\
$\geq 4$ & 100.00
\end{tabular}

Station 33

\begin{tabular}{crr}
$\varnothing$ & \multicolumn{1}{c}{8} & REMOTS $^{\circledR}$ \\
\hline$-1-1$ & 0.00 & \\
$1-2$ & 0.00 \\
$2-3$ & 0.00 \\
$3-4$ & 4.68 \\
$\geq 4$ & 95.32
\end{tabular}

Station 36

\begin{tabular}{rrr}
$\varnothing$ & \multicolumn{1}{c}{8} & REMOTS $^{\circledR}$ \\
\hline$-1-1$ & 0.00 & \\
$1-2$ & 0.00 \\
$2-3$ & 0.00 & $\geq 40$ \\
$3-4$ & 0.00 & \\
$\geq 4$ & 100.00 &
\end{tabular}

Station 39

\begin{tabular}{rrr}
$\varnothing$ & \multicolumn{1}{c}{8} & REMOTS \\
\hline$-1-1$ & 0.00 & \\
$1-2$ & 0.00 & $\geq 4 \varnothing$ \\
$2-3$ & 0.00 & \\
$3-4$ & 11.35 & \\
$\geq 4$ & 88.65 &
\end{tabular}




\section{Table 3 \\ Calculation of the REMOTS ${ }^{\circledR}$ \\ Organism-Sediment Index (OSI) Value}

CHOOSE ONE VALUE:

$\begin{array}{lll}\text { Mean RPD Depth } & \text { Index Value } \\ >0-0.00 \mathrm{~cm} & 0 \\ 0.76-1.50 \mathrm{~cm} & 1 \\ 1.51-2.25 \mathrm{~cm} & 2 \\ 2.26-3.00 \mathrm{~cm} & 3 \\ 3.01-3.75 \mathrm{~cm} & 4 \\ & >3.75 \mathrm{~cm} & 5\end{array}$

CHOOSE ONE VALUE:

Successional Stage

Azoic

Stage I

Stage I $\rightarrow$ II

Stage II

Stage II $\rightarrow$ III

Stage III

Stage I on III

Stage II on III
Index Value

$-4$

1

2

3

4

5

5

5

CHOOSE ONE OR BOTH IF APPROPRIATE:

Chemical Parameters

Methane Present

No/Low Dissolved Oxygen
Index Value

$-2$

$-4$

REMOTS $^{\circledR}$ ORGANISM-SEDIMENT INDEX $=$ Total of above subset indices

RANGE: -10 to +11 


\section{Table 4 \\ Interpretative Information Loss from REMOTS images Due to \\ Over- and Under-Penetration of the REMOTS Prism}

\section{Problem with Image}

Insufficient penetration

Overpenetration

\section{Implication for Analysis}

- If RPD depth > penetration, then RPD depth is minimum estimate

- Presence of Stage III infauna often indeterminate, resulting in indeterminate Organism-Sediment Index

- RPD depth is minimum estimate because interface is above window

- No boundary roughness measurement

- No surface features visible, such as: mud clasts

worm tubes

fecal layer

epifauna 


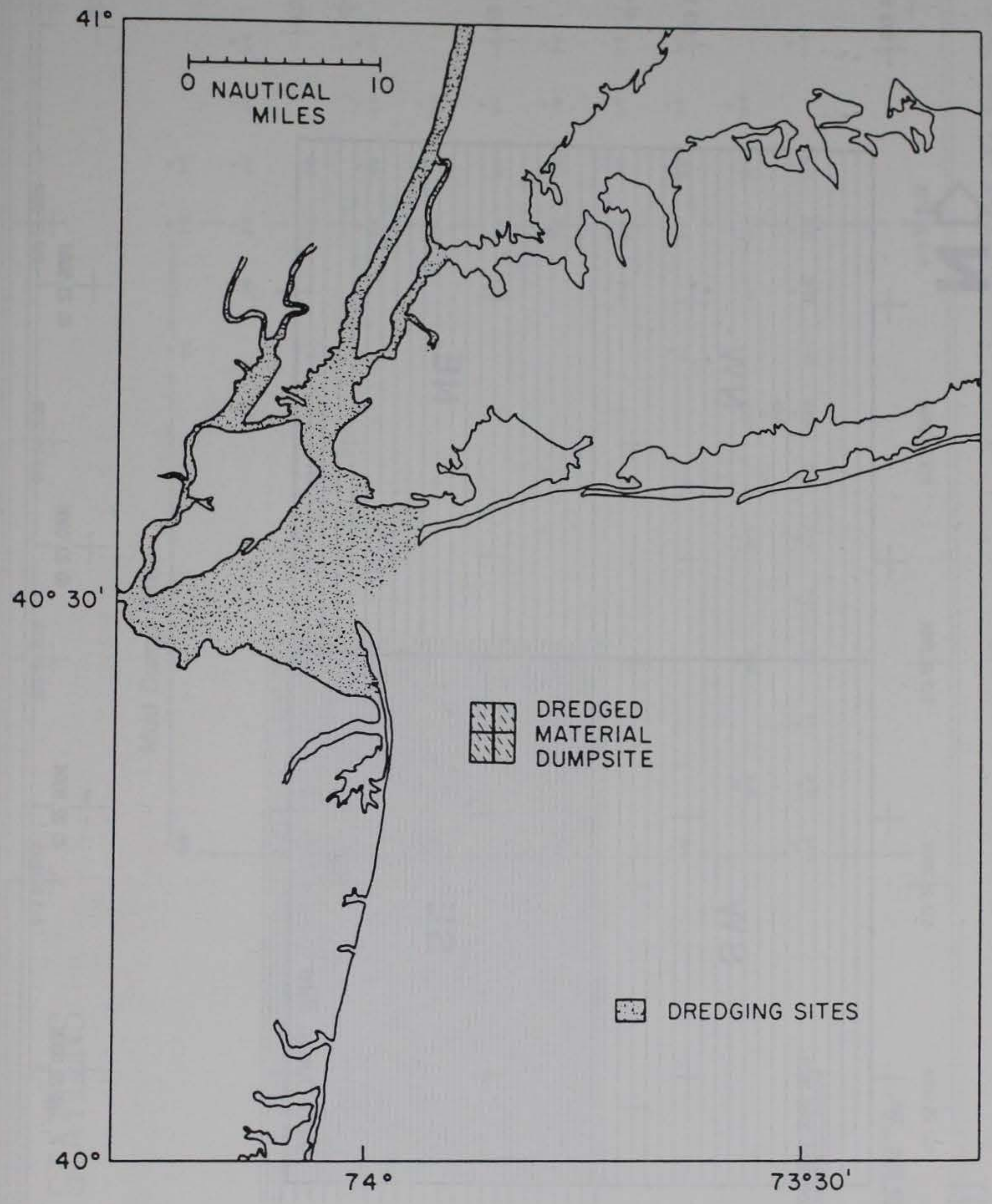

Figure 1. Location map of the Mud Dump site. 


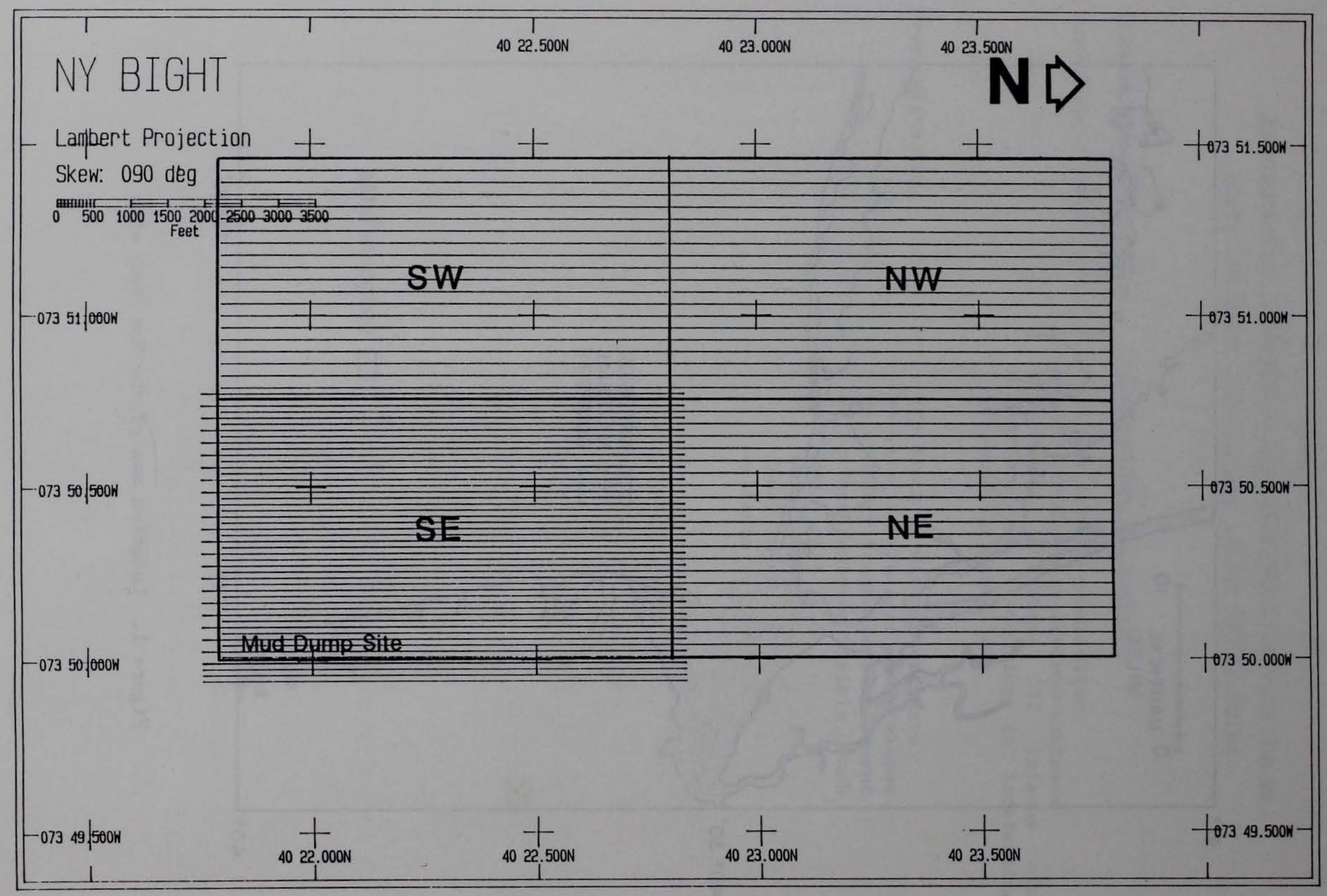

Figure 2. Survey lanes used for the precision bathymetric survey. 


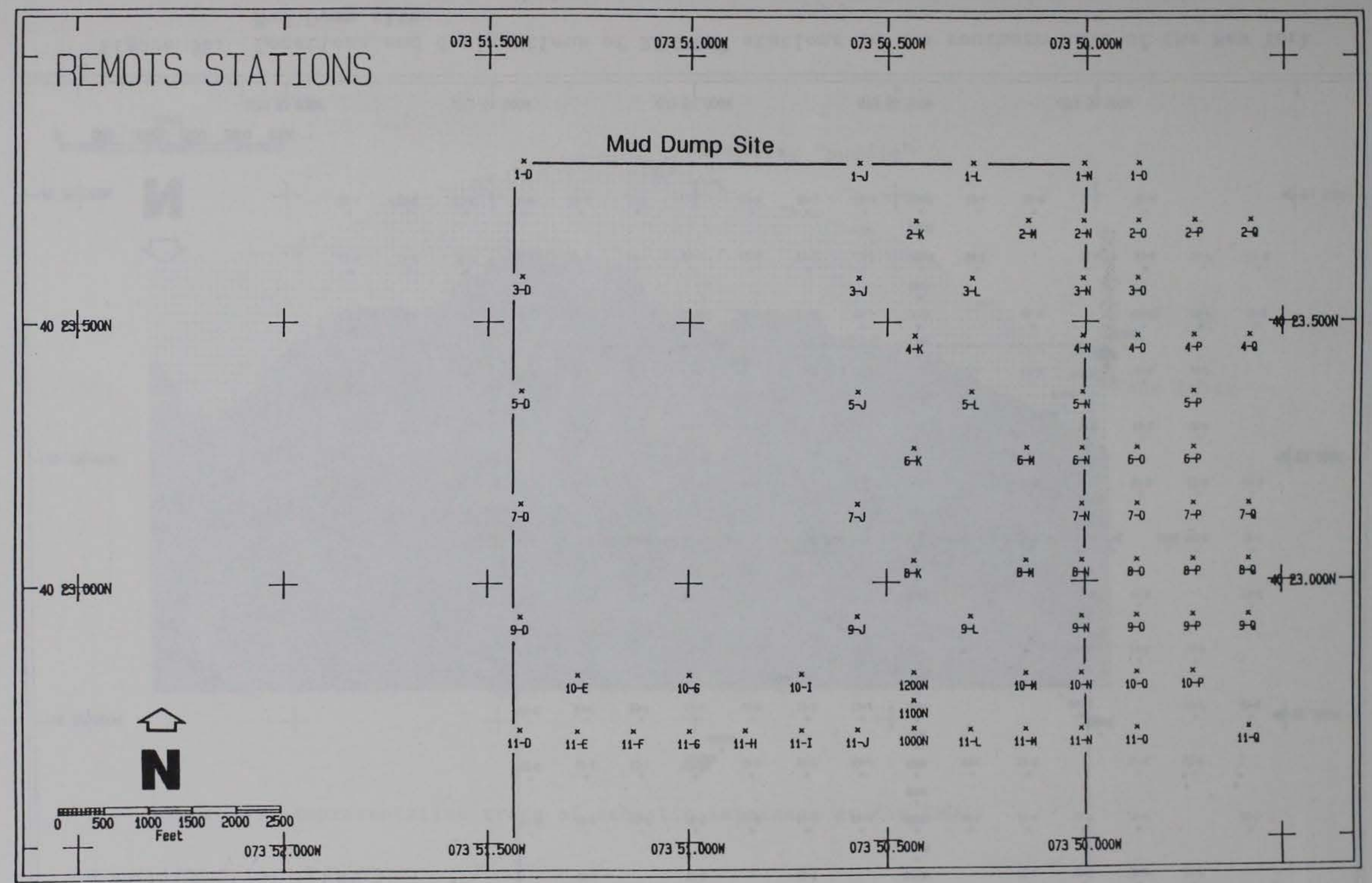

Figure 3a. Locations and designations of REMOTS ${ }^{\circledR}$ stations in the northern half of the New York Mud Dump site. 


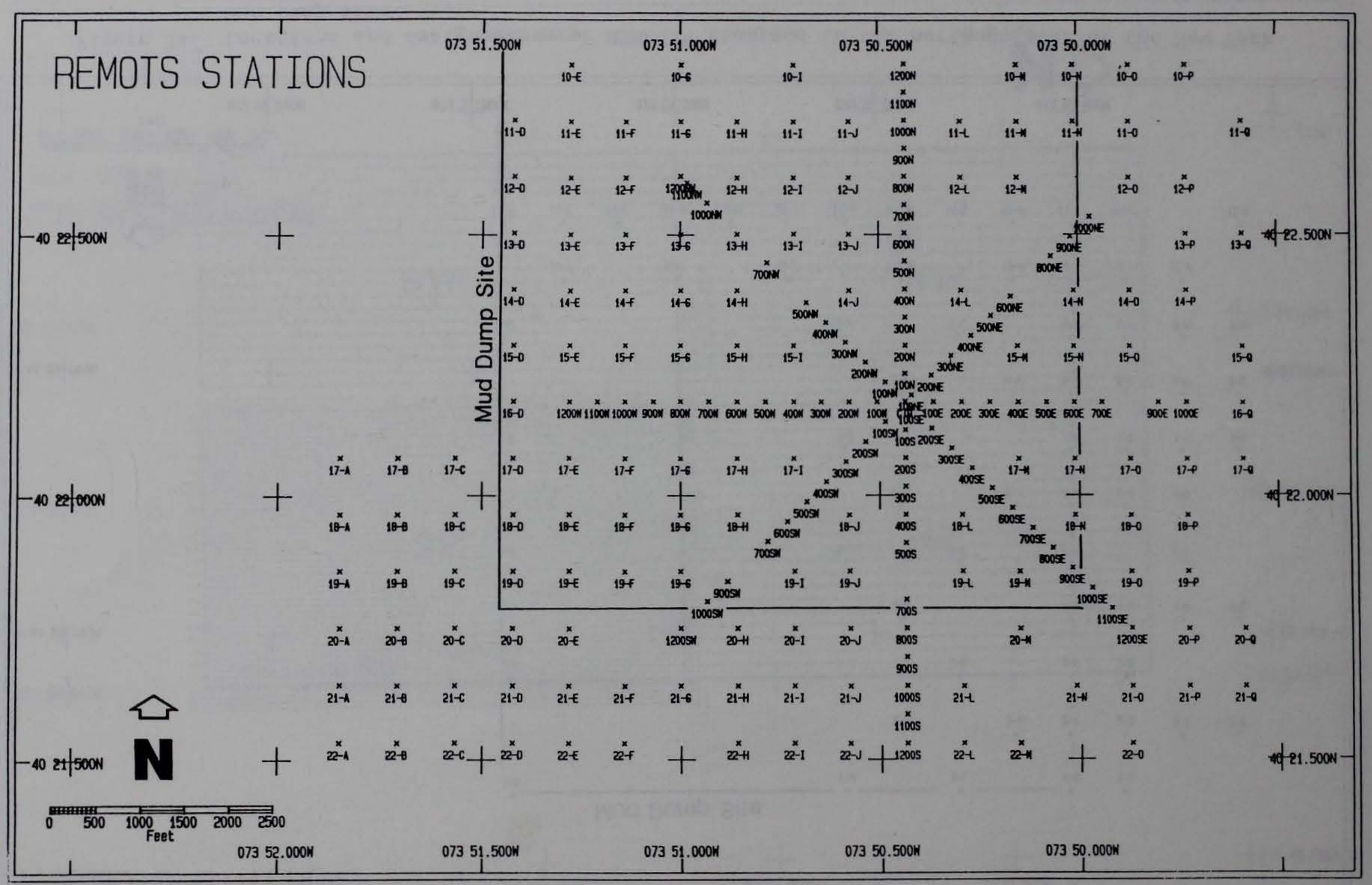

Figure 3b. Locations and designations of REMOTS ${ }^{\circledR}$ stations in the southern half of the New York Mud Dump site. 


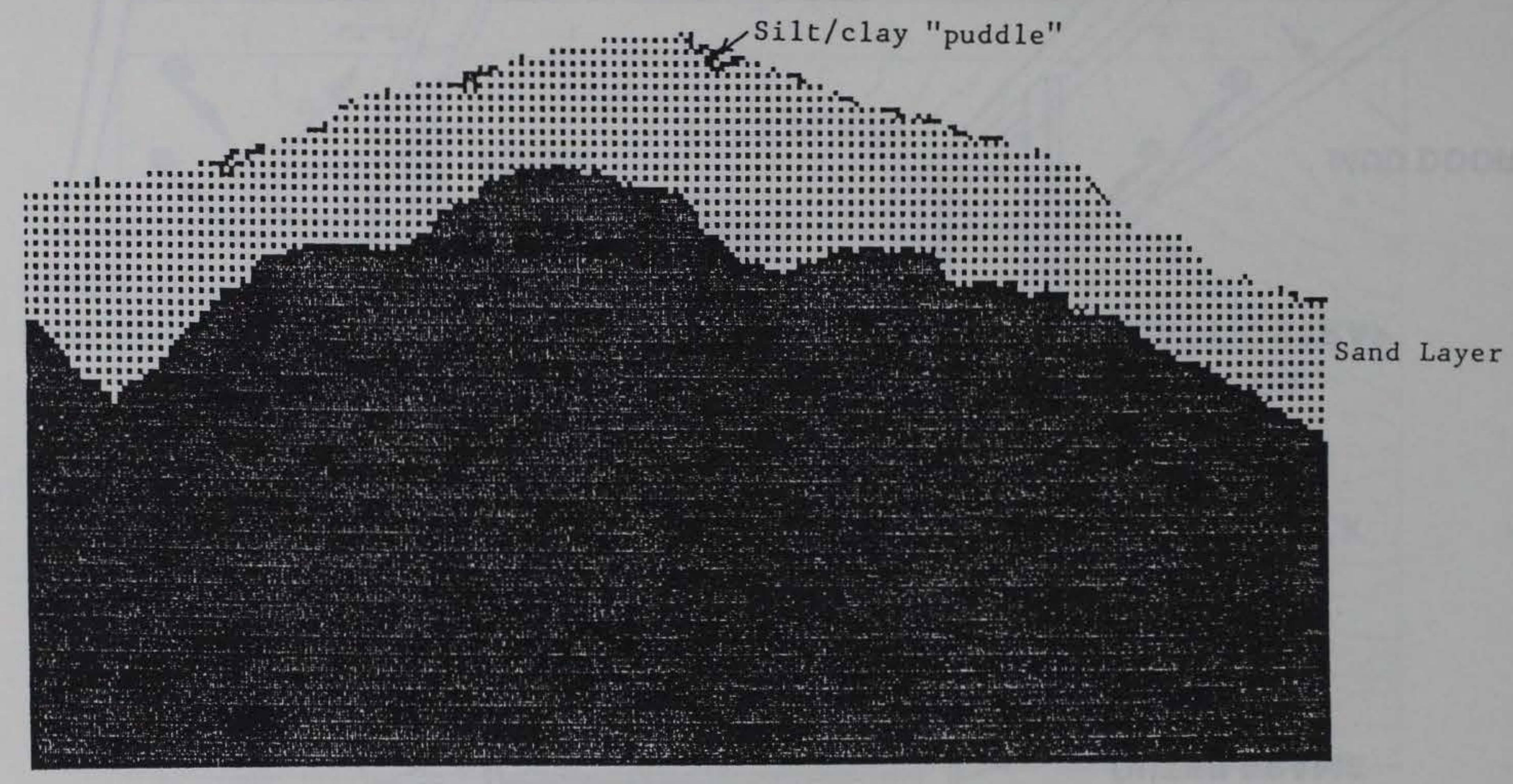

Figure 4. Representative trace of acoustic impedance at the EMD. 


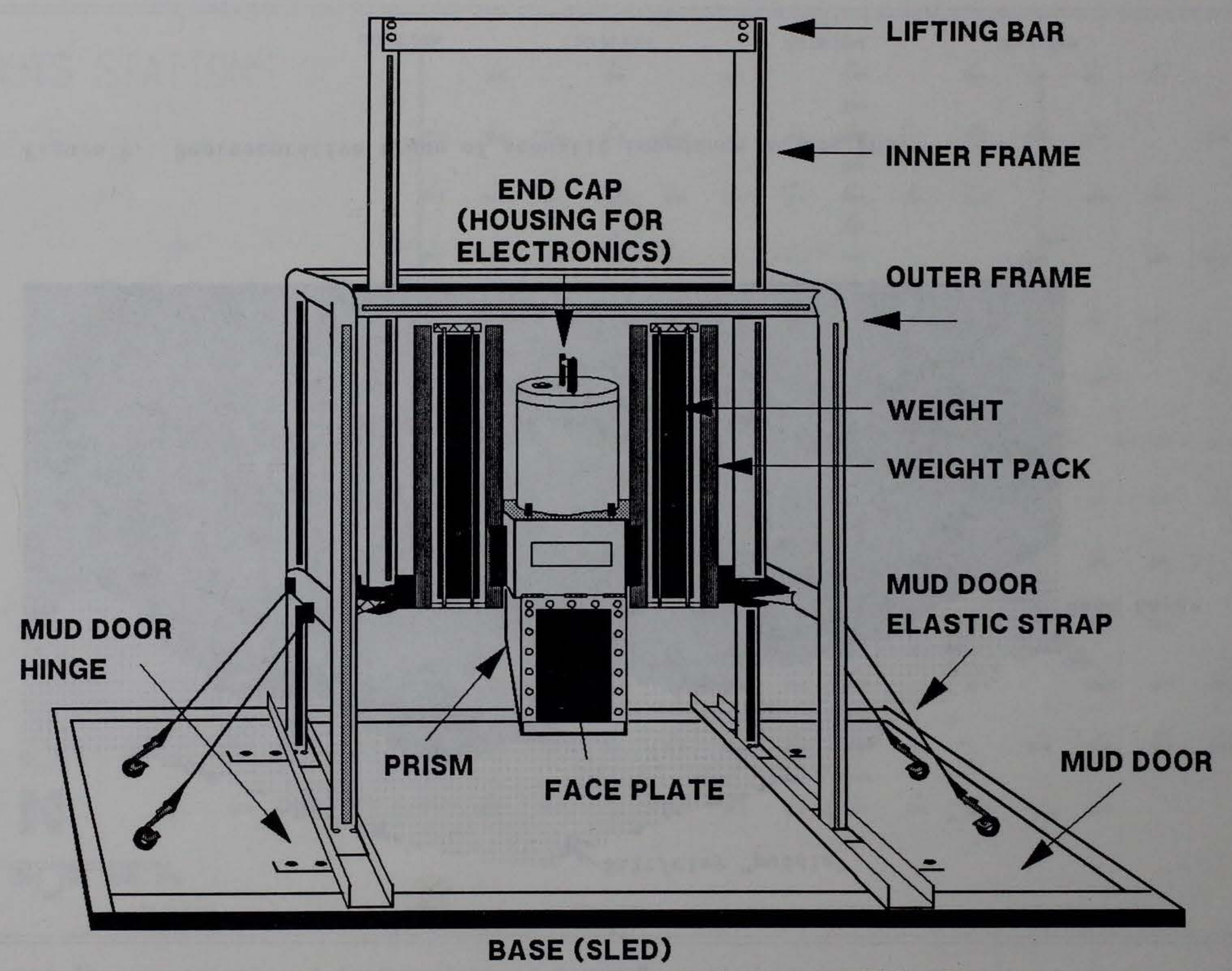

Figure 5. Benthos Model 3731 Sediment-Profile Camera. 


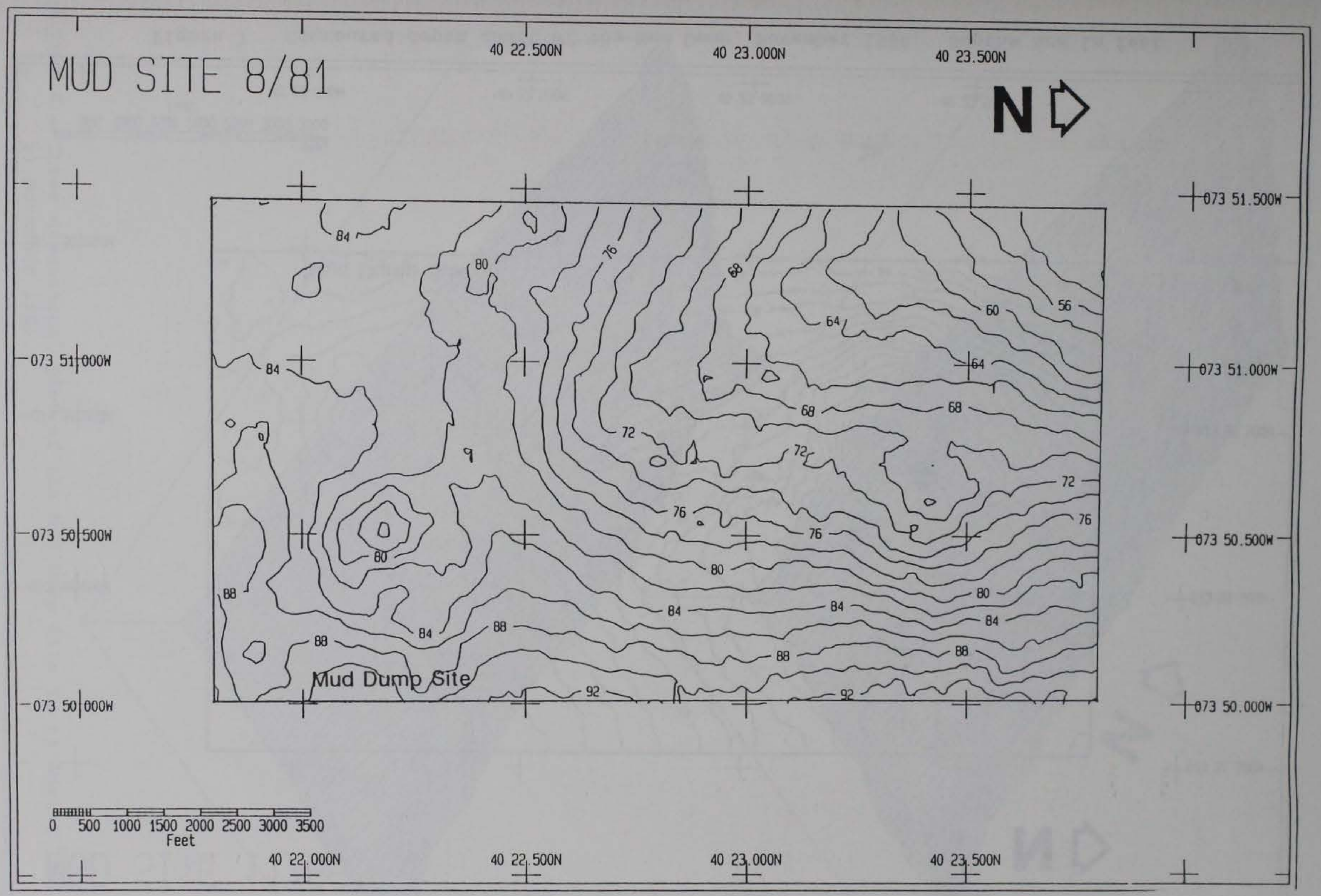

Figure 6. Contoured depth chart of the Mud Dump, August 1981. Depths are in feet. 


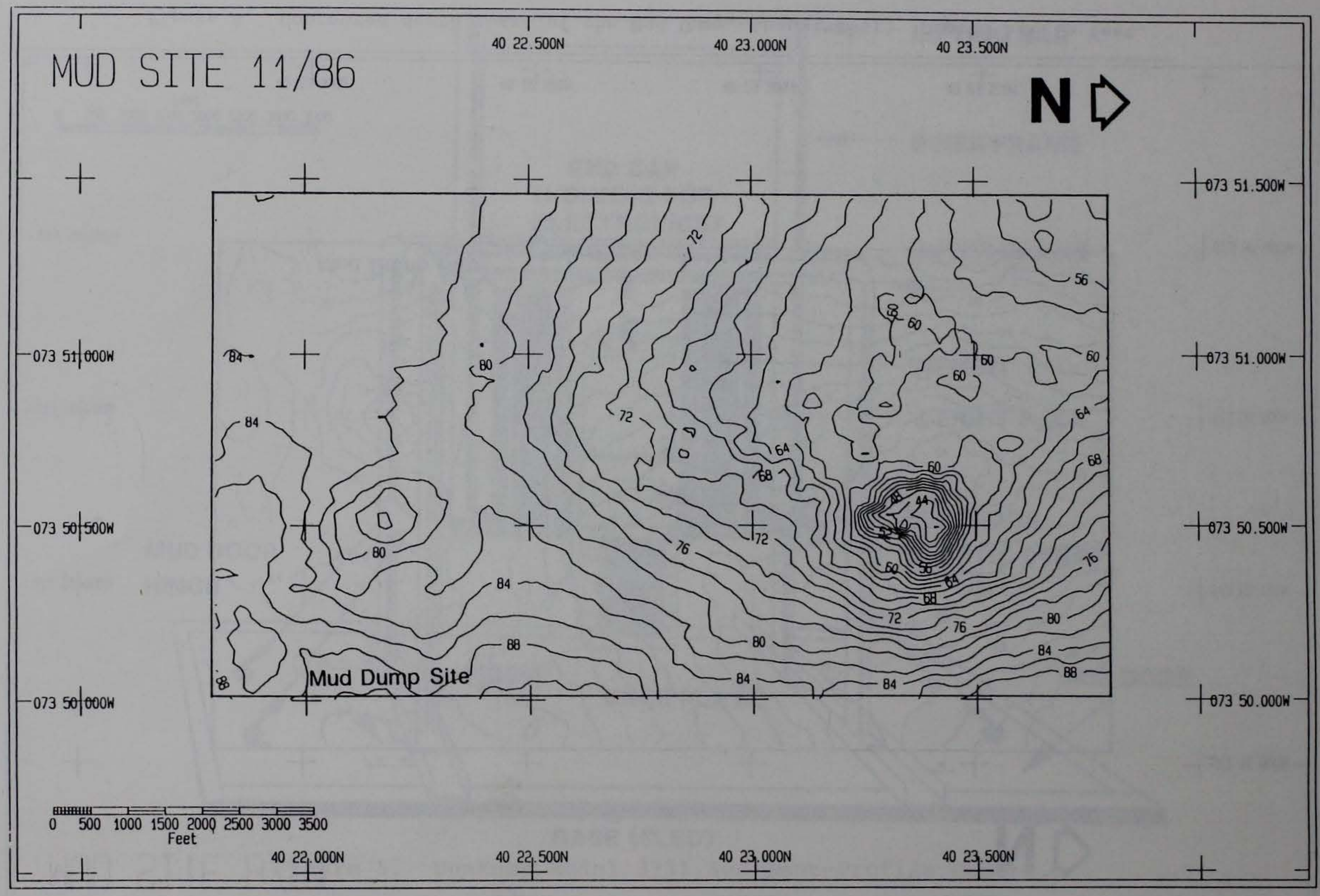

Figure 7. Contoured depth chart of the Mud Dump, November 1986. Depths are in feet. 


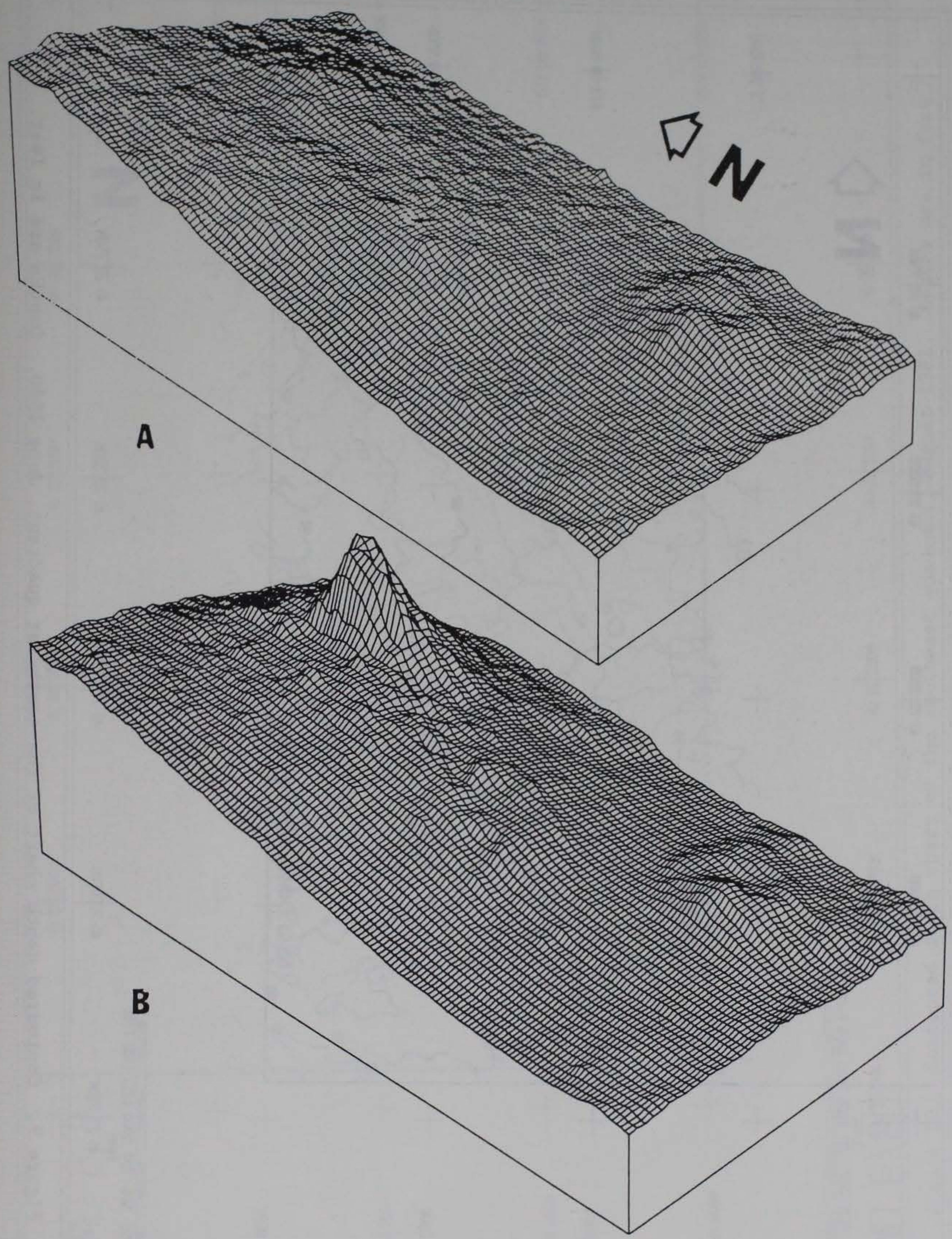

Figure 8. Three dimensional plot of the Mud Dump site in a) August 1981 and b) November 1986 . 


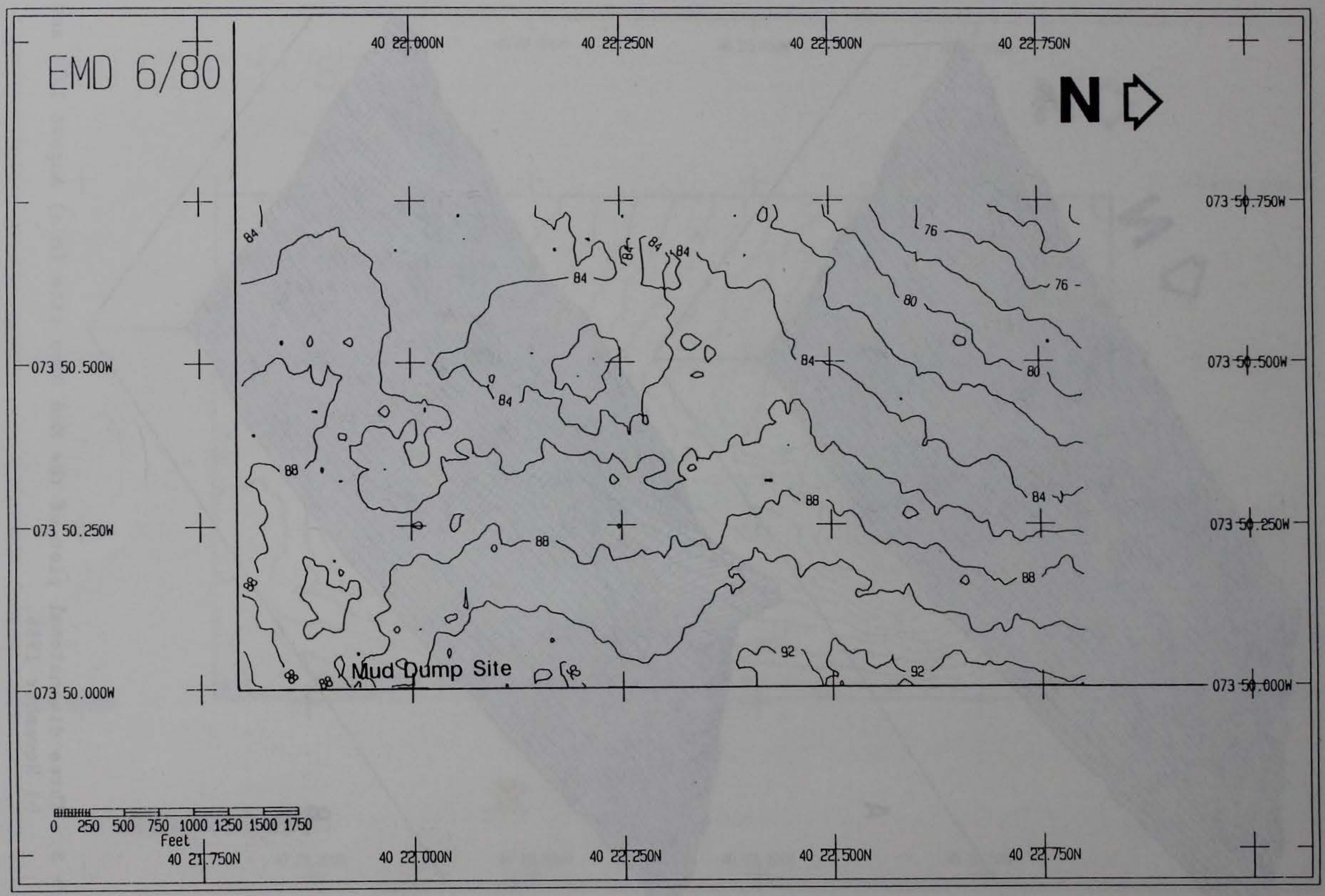

Figure 9. Contoured depth chart of the southeast quadrant, June 1980. Depths are in feet. 


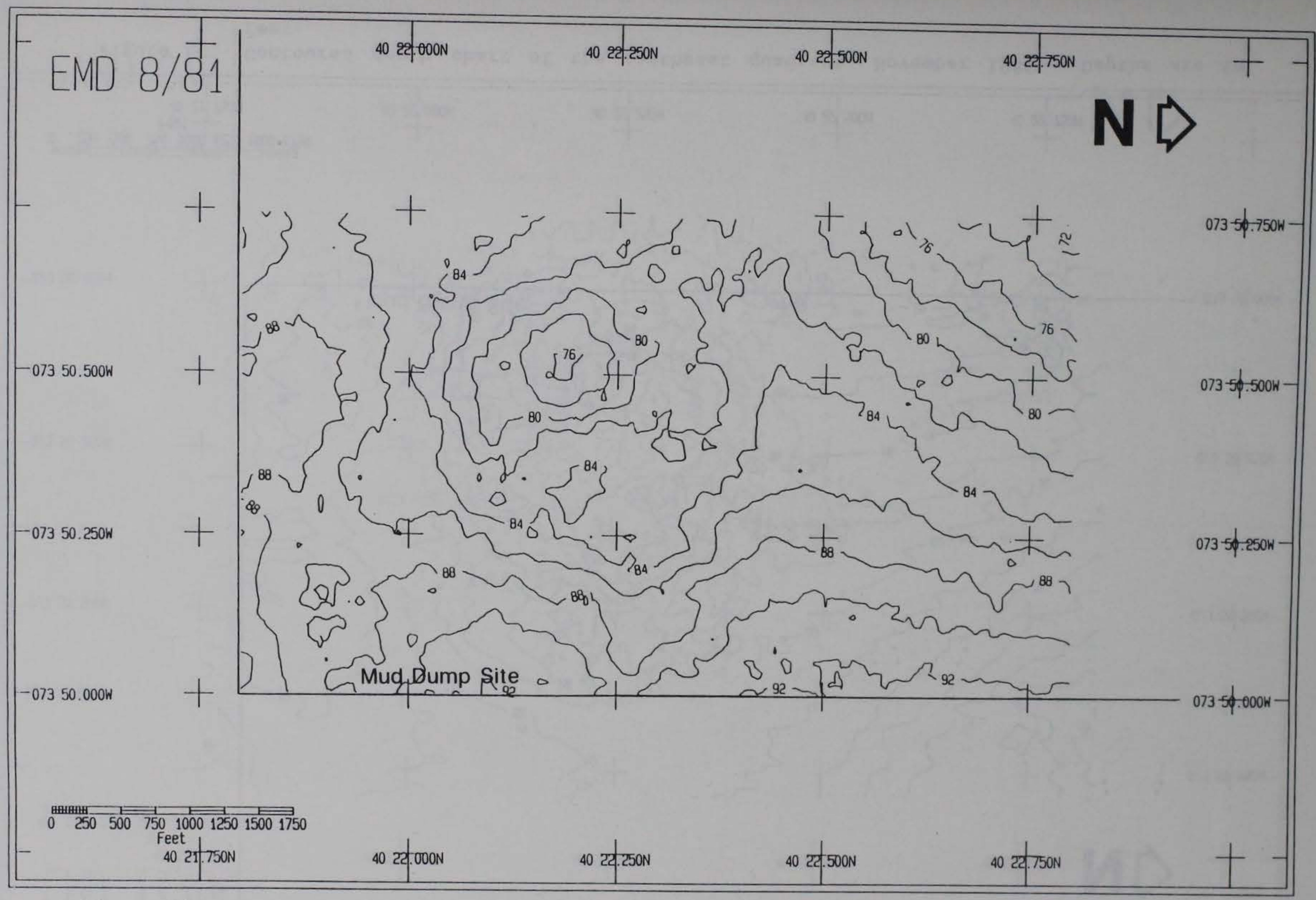

Figure 10. Contoured depth chart of the southeast quadrant, August 1981 . Depths are in feet. 


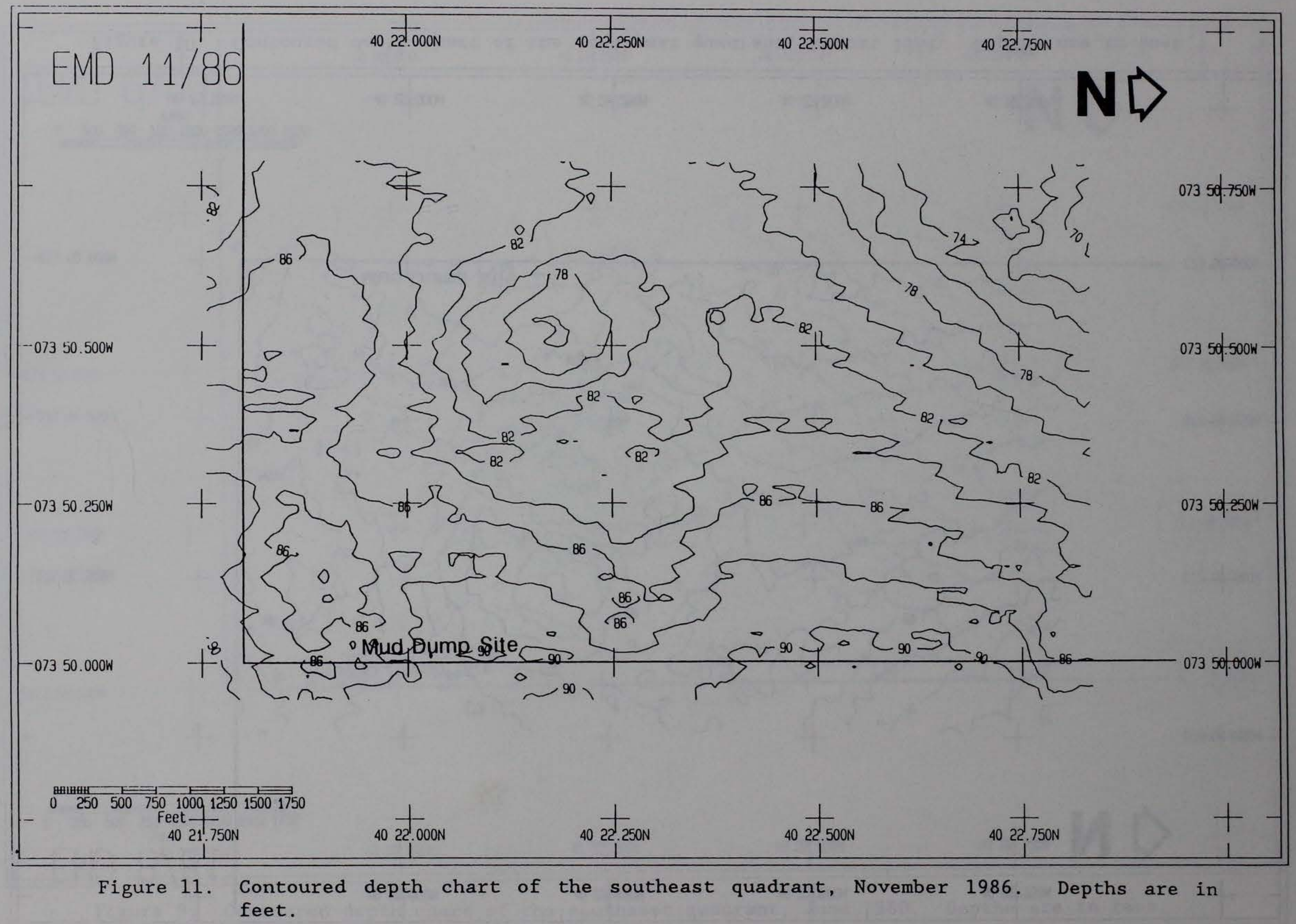




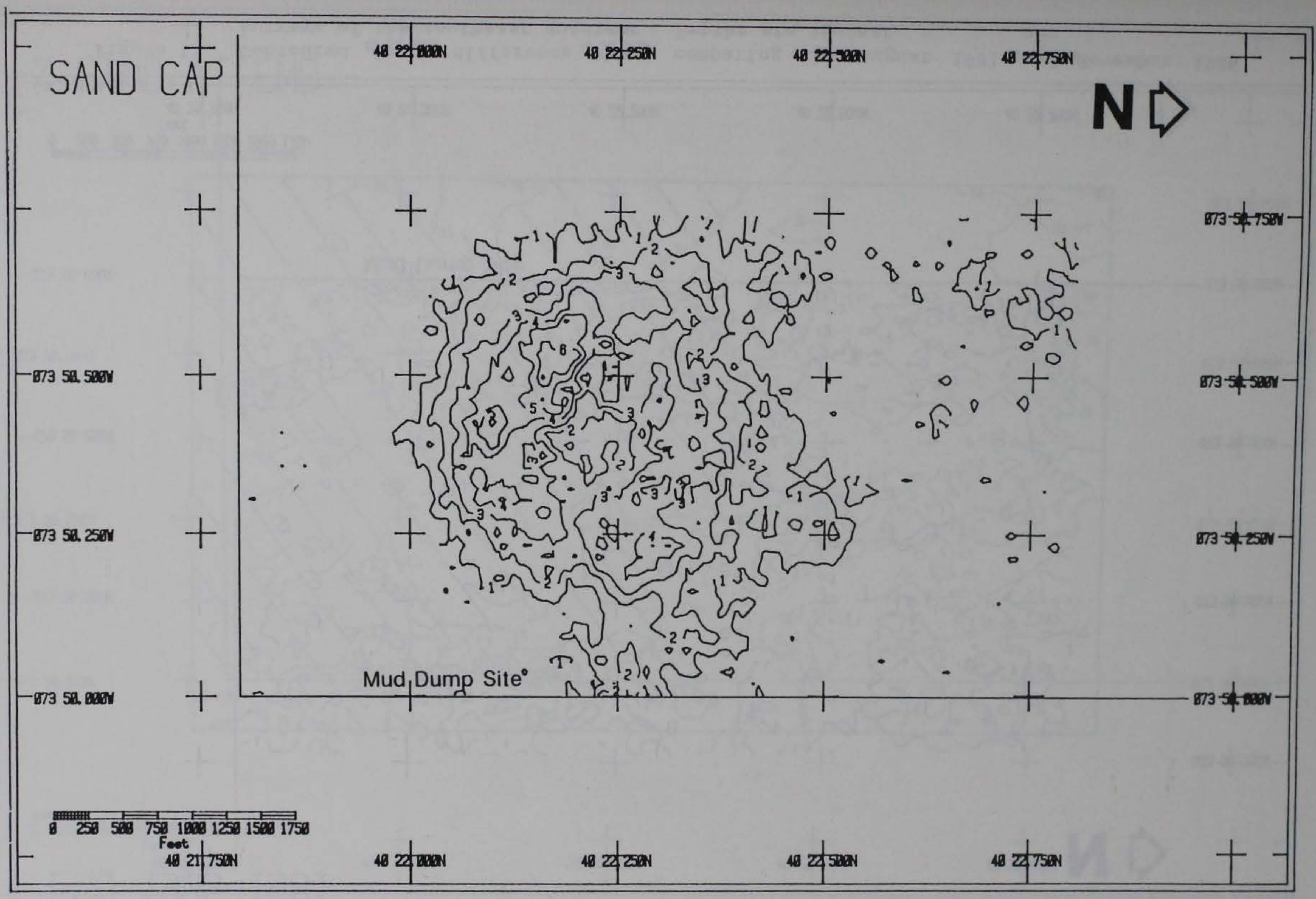

Figure 12. Contoured depth difference chart comparing the June 1980 and August 1981 surveys of the southeast quadrant. Depths are in feet. 


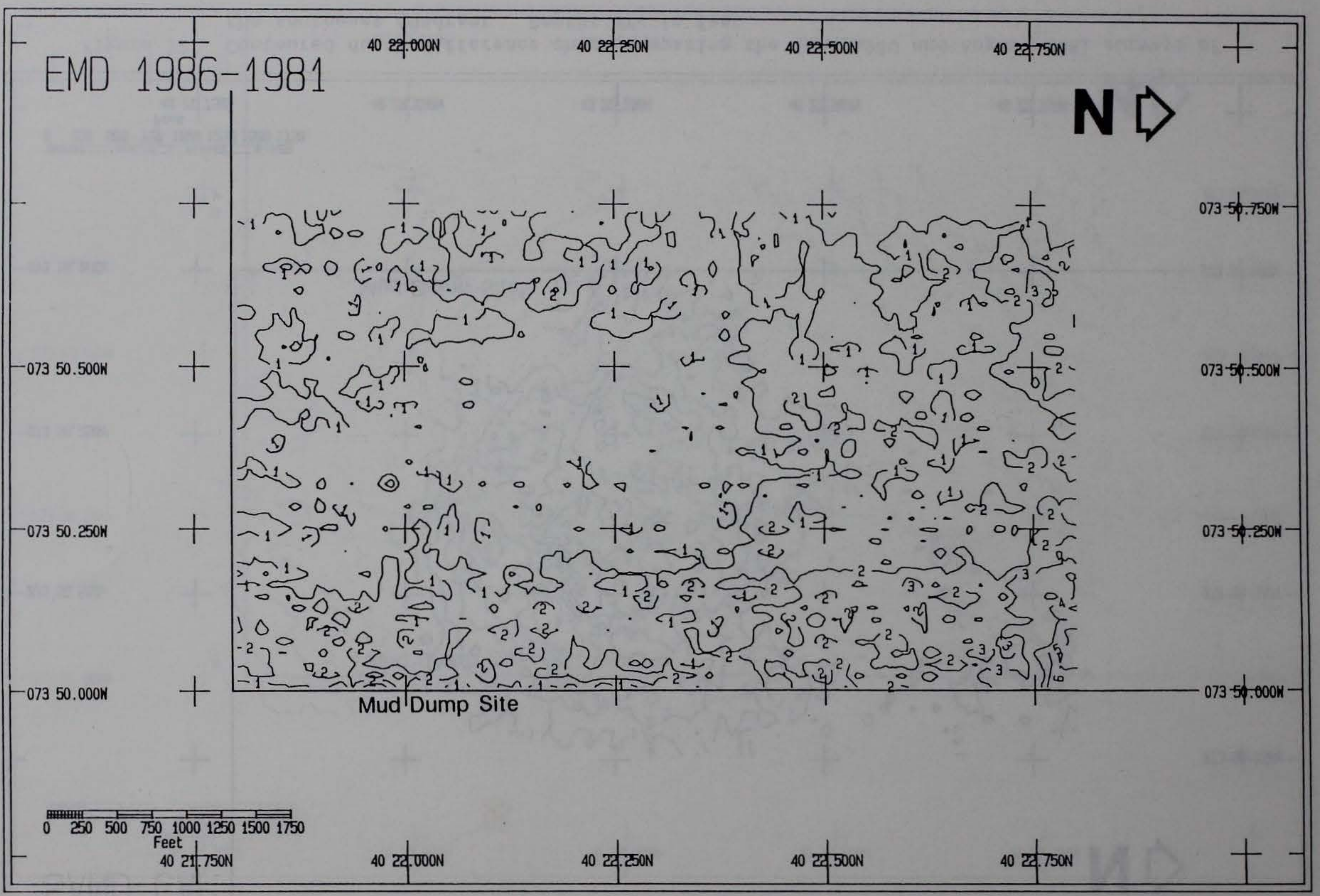

Figure 13. Contoured depth difference chart comparing the August 1981 and November 1986 surveys of the southeast quadrant. Depths are in feet. 


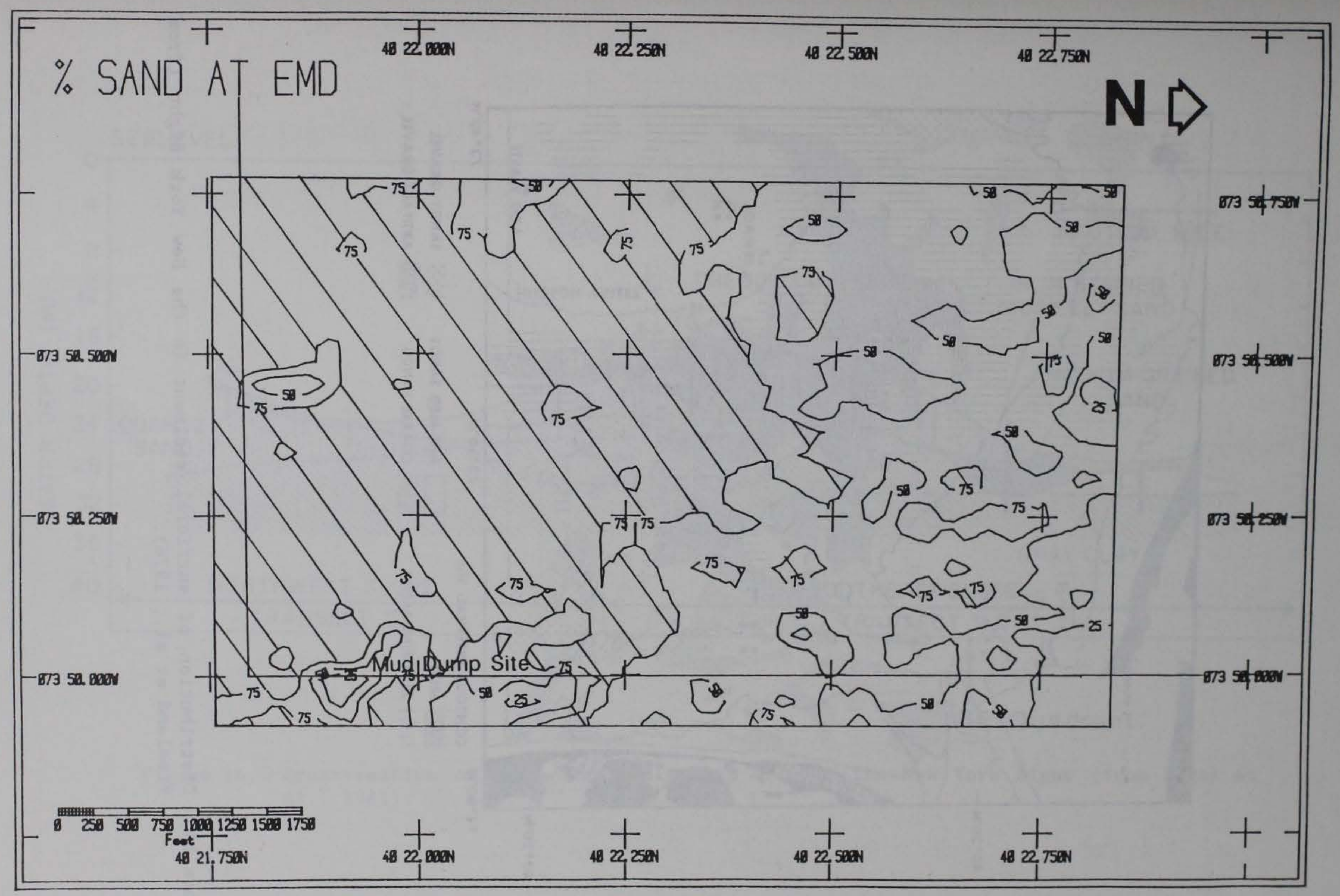

Figure 14. Percent-sand contour chart of the southeast quadrant. 


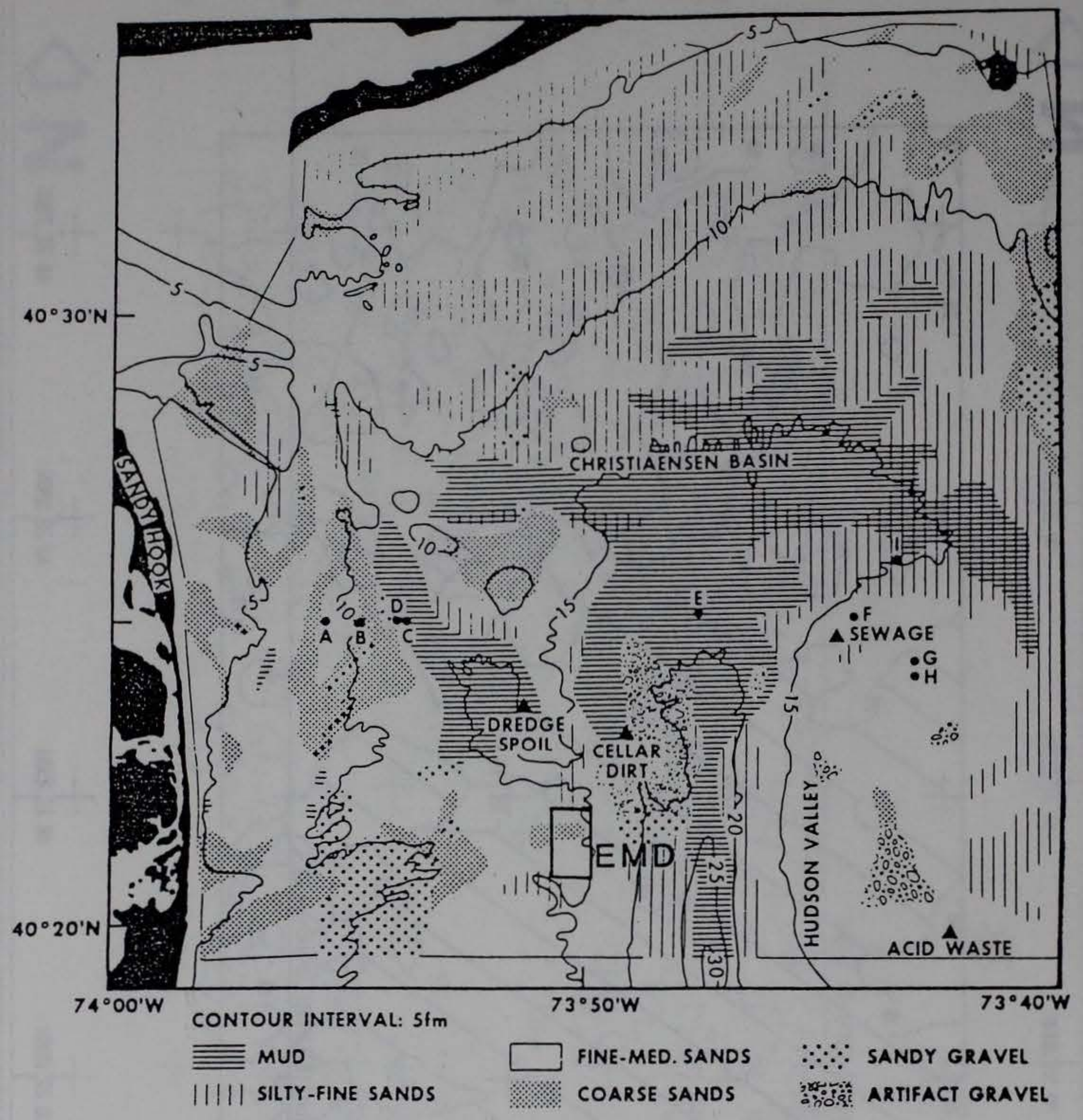

Figure 15. Distribution of surficial sediment in the New York Bight (from Freeland et al., 1976). 


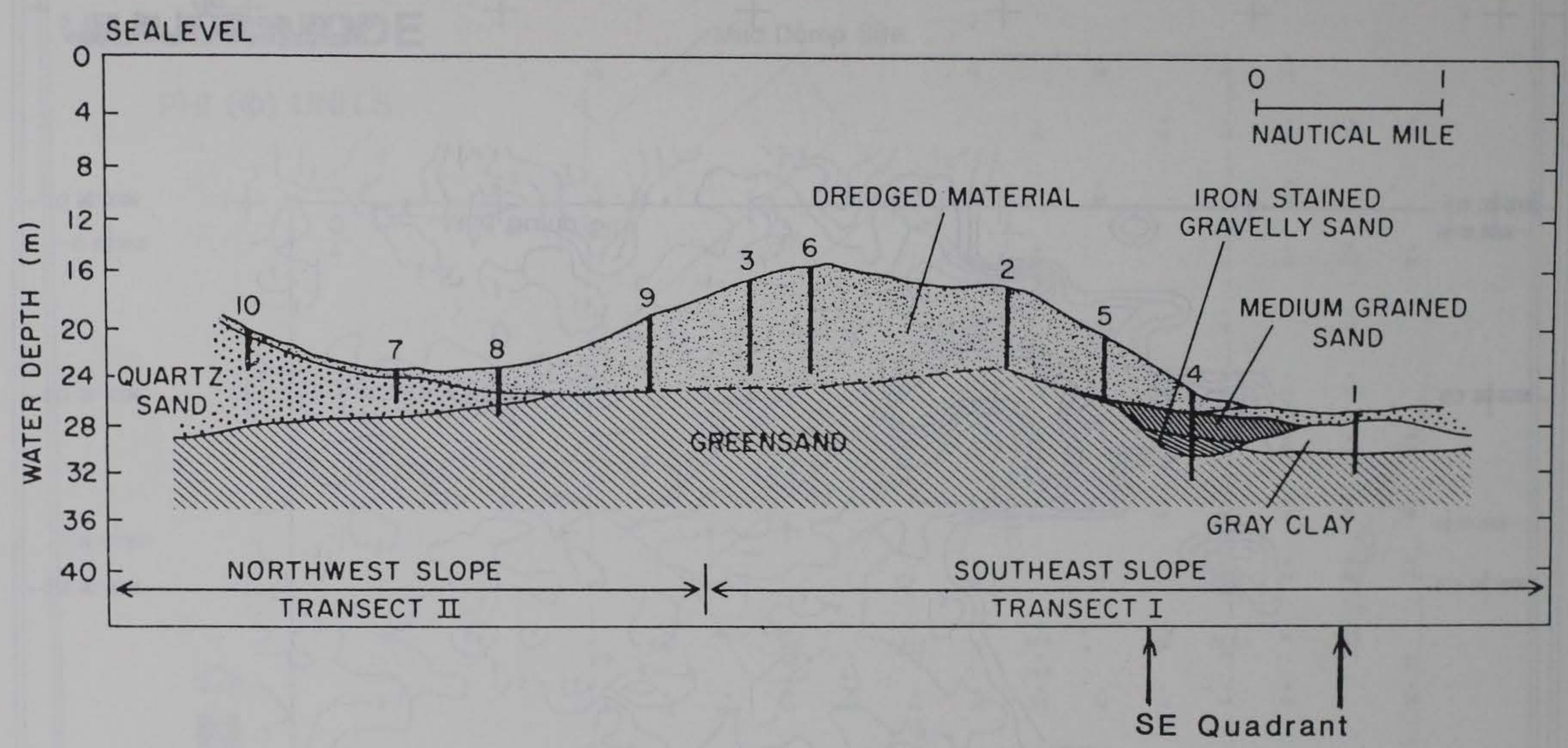

Figure 16. Cross-section of the general disposal area in the New York Bight (from Dayal et al., 1981). 


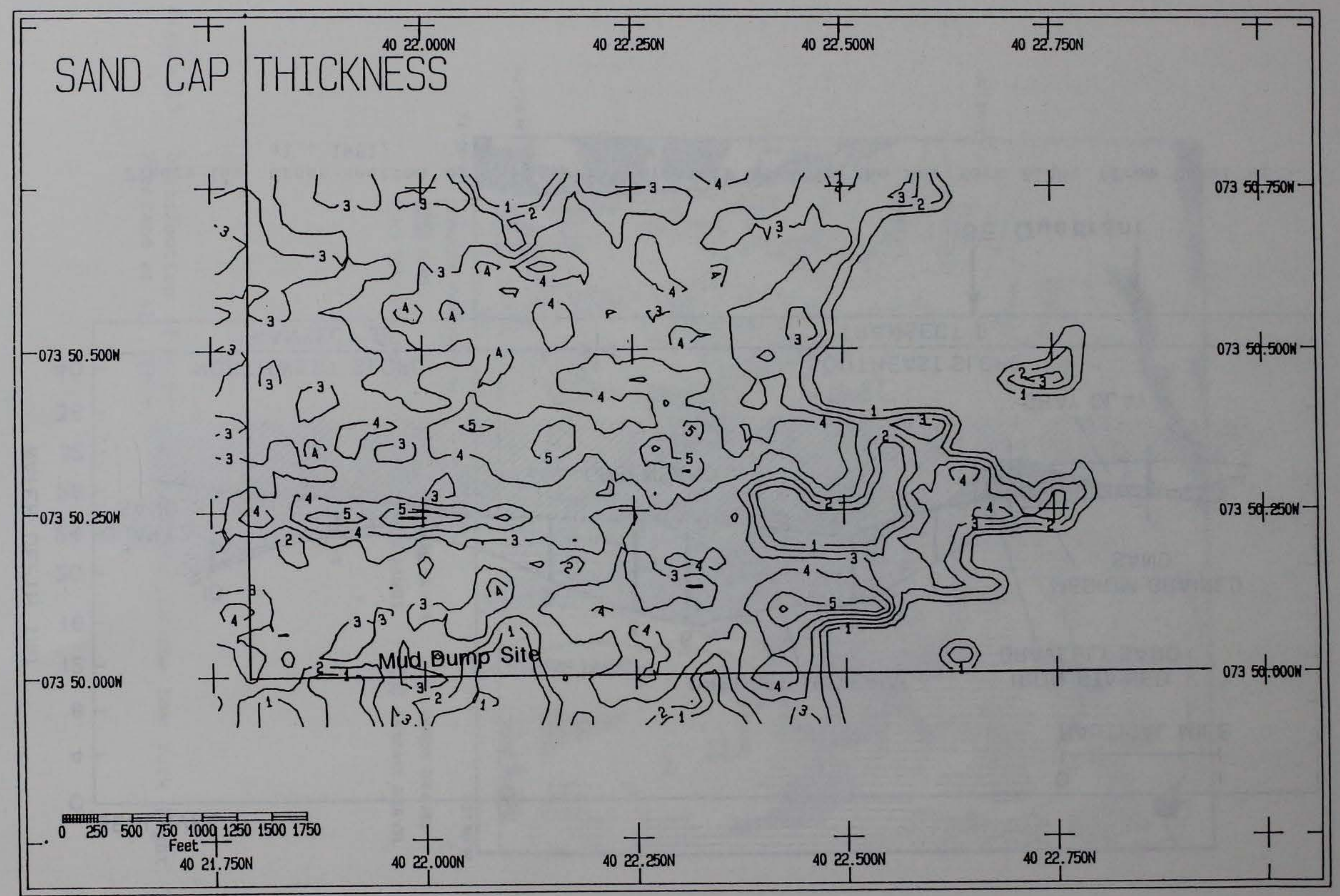

Figure 17. Sand layer thickness contour chart of the southeast quadrant. Values are in feet. 


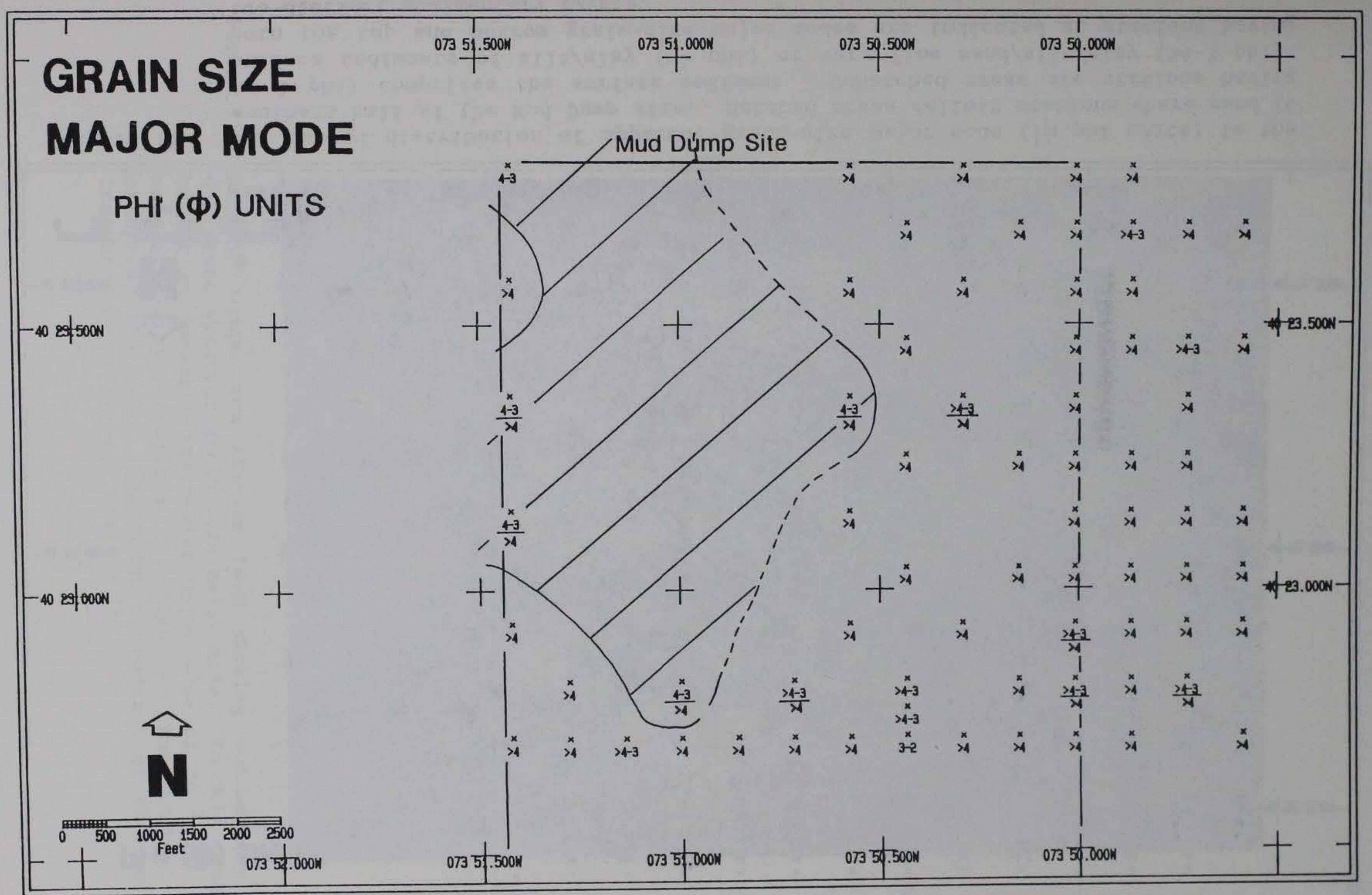

Figure 18a. The mapped distribution of apparent grain-size major mode (in phi units) in the northern half of the Mud Dump site. Hatched areas delimit stations where sand (4 to $1 \mathrm{phi}$ ) comprises the surface sediment. Unhatched areas are stations having surface sediments of silt/clay $(>4 \mathrm{phi})$ or very fine sand/silt/clay $(>4-3 \mathrm{phi})$. Both the top and bottom grain-size major modes are indicated at stations having two distinct sedimentary layers. 


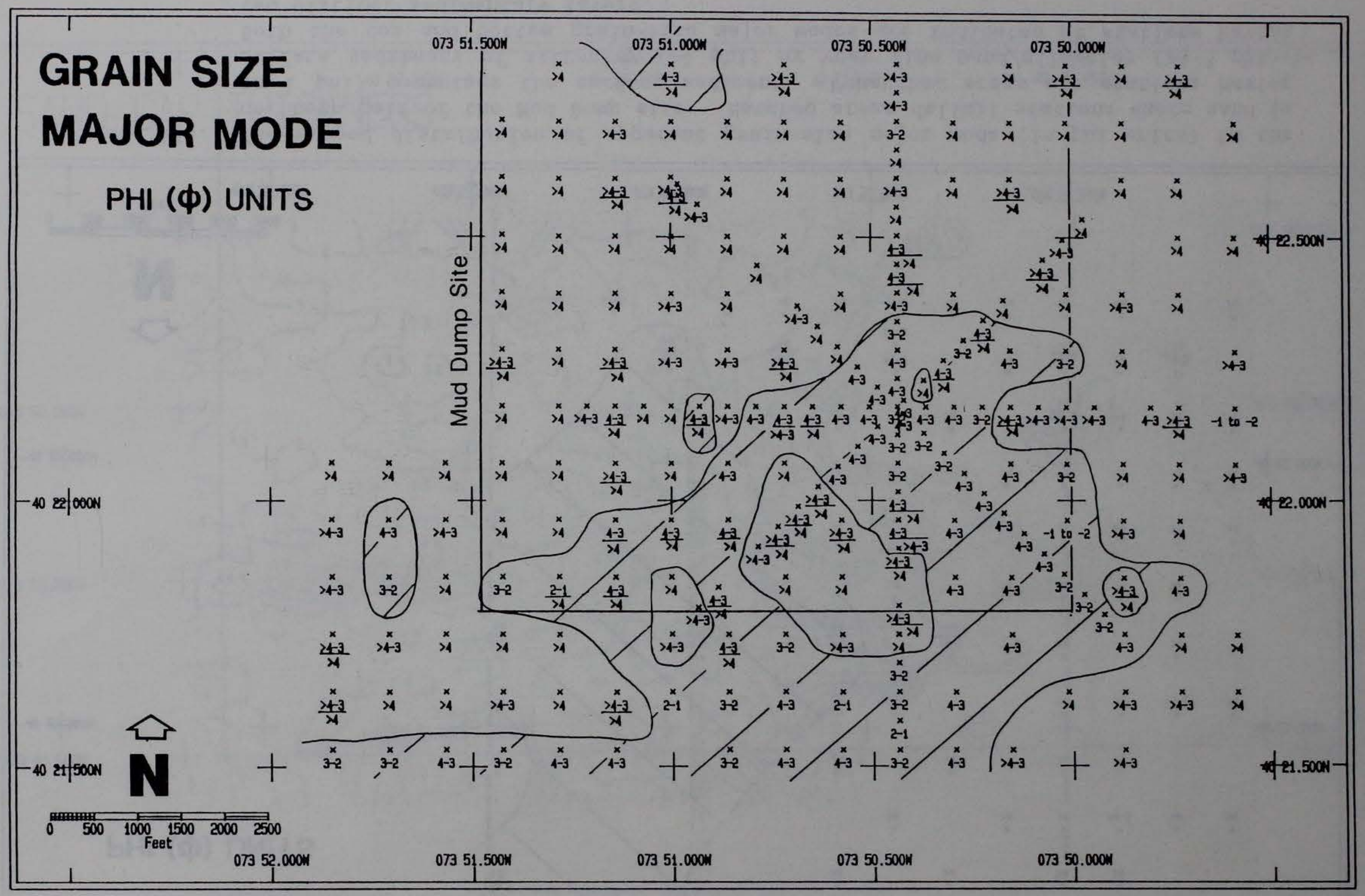

Figure 18b. The mapped distribution of apparent grain-size major mode (in phi units) in the southern half of the Mud Dump site. Hatched areas delimit stations where sand (4 to $1 \mathrm{phi}$ ) comprises the surface sediment. Unhatched areas are stations having surface sediments of silt/clay $(>4 \mathrm{phi})$ or very fine sand/silt/clay $(>4-3 \mathrm{phi})$. Both the top and bottom grain-size major modes are indicated at stations having two distinct sedimentary layers. 
Figure 19. REMOTS ${ }^{\circledR}$ image from station $18-\mathrm{H}$ showing sedimentary layers of different apparent grain-size major mode. In this case, sediment having an apparent grain-size major mode of $>4-3$ phi (very fine sand/silt/clay) overlays a slightly finer-grained layer of silt/clay ( $>4$ phi). The point of contact of the two layers is indicated by an arrow. Scale $=1 X$. 


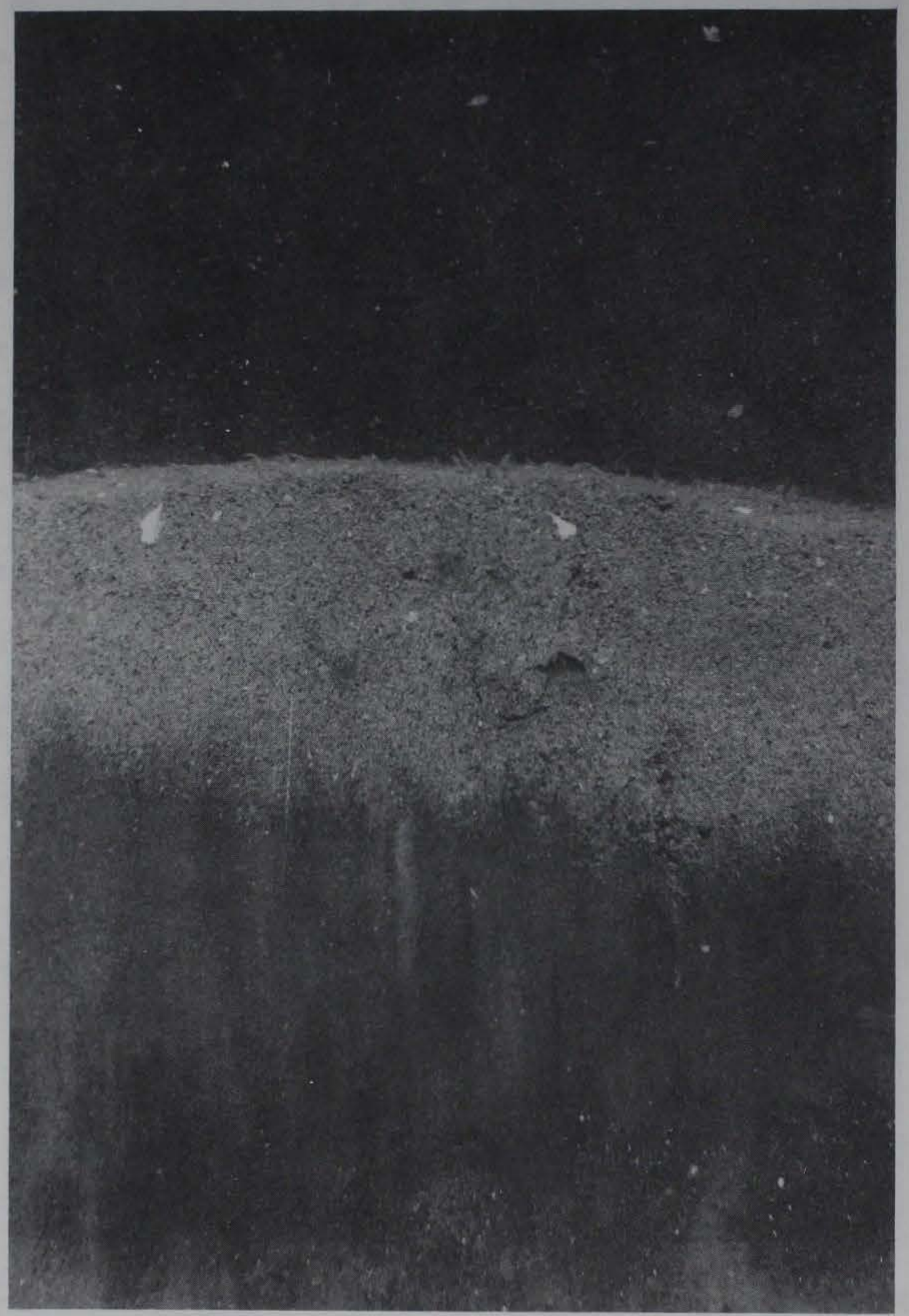

Figure 20. REMOTS $^{\circledR}$ image from station $19-\mathrm{F}$ showing a layer of very fine sand (4-3 phi) overlaying silt/clay ( $>4 \mathrm{phi})$. Scale $=1 \mathrm{X}$. 


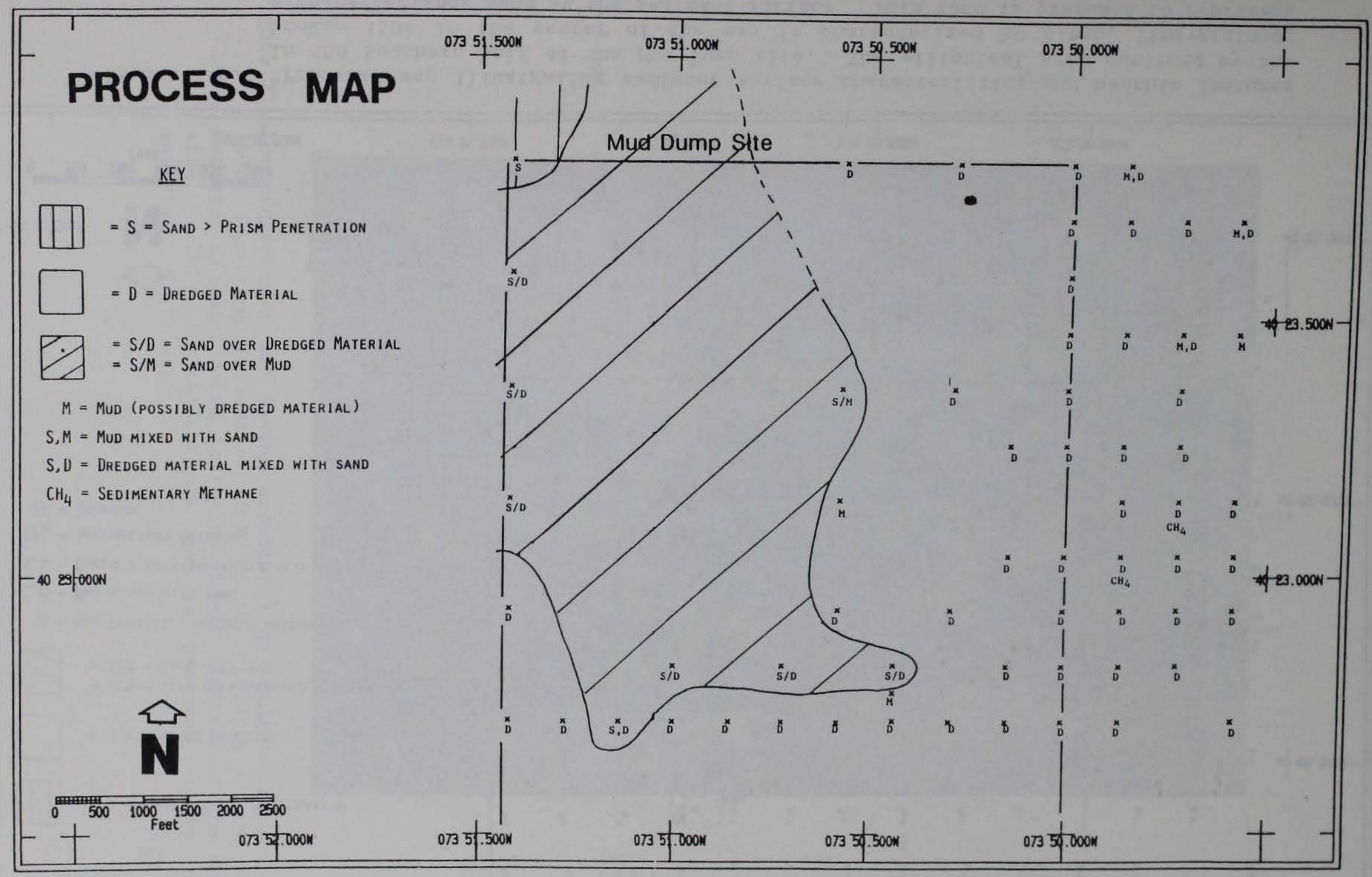

Figure 21a. "Process" map illustrating sediment surface characteristics and benthic features in the northern half of the Mud Dump site. 


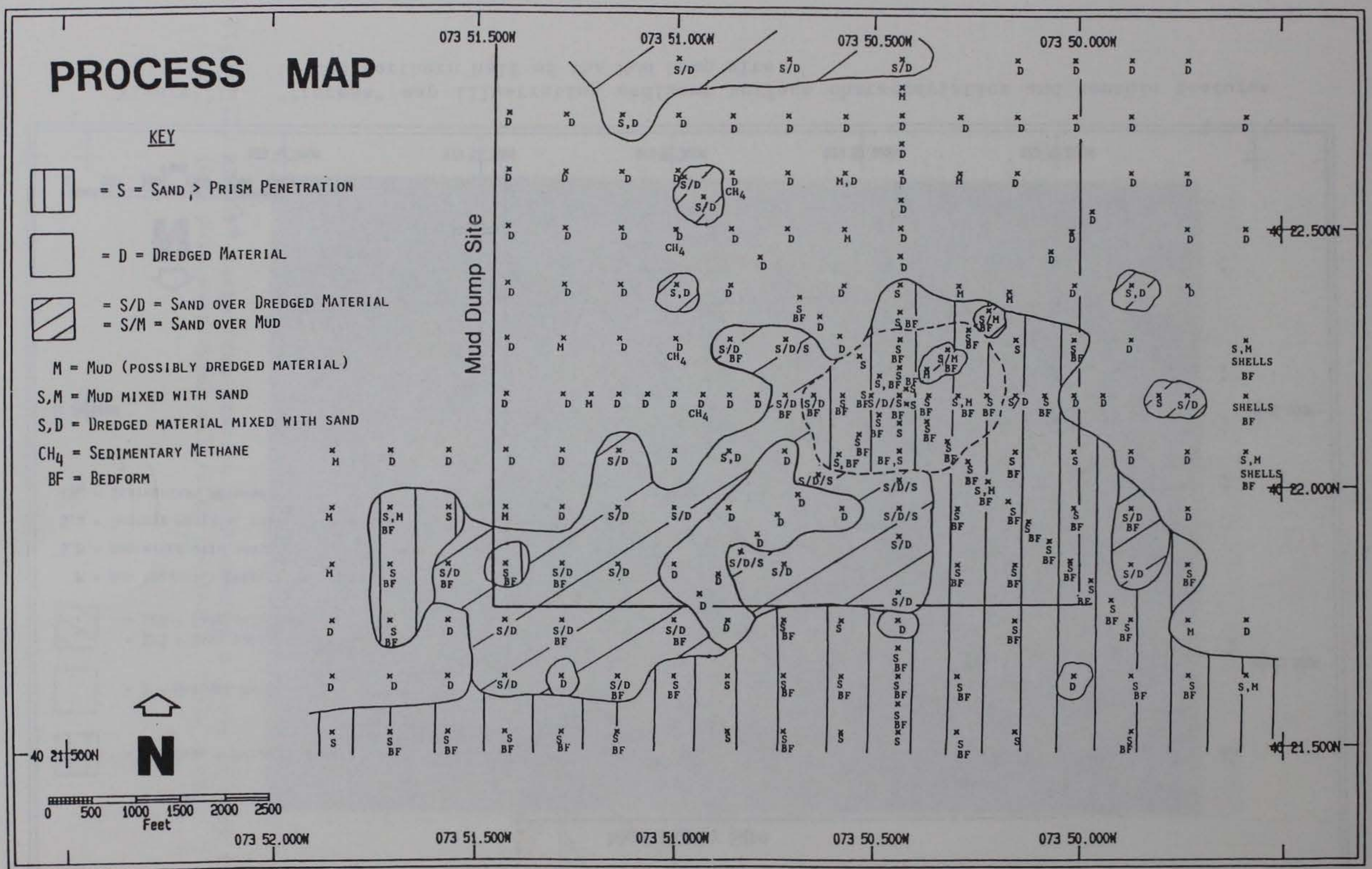

Figure 21b. "Process" map illustrating sediment surface characteristics and benthic features in the southern half of the Mud Dump site. The elliptical area outlined by the broken line in the center of the map is characterized by clean, fine-grained, high-reflectance sand at the sediment surface. This sand is presumed to represent the original sand cap material. 


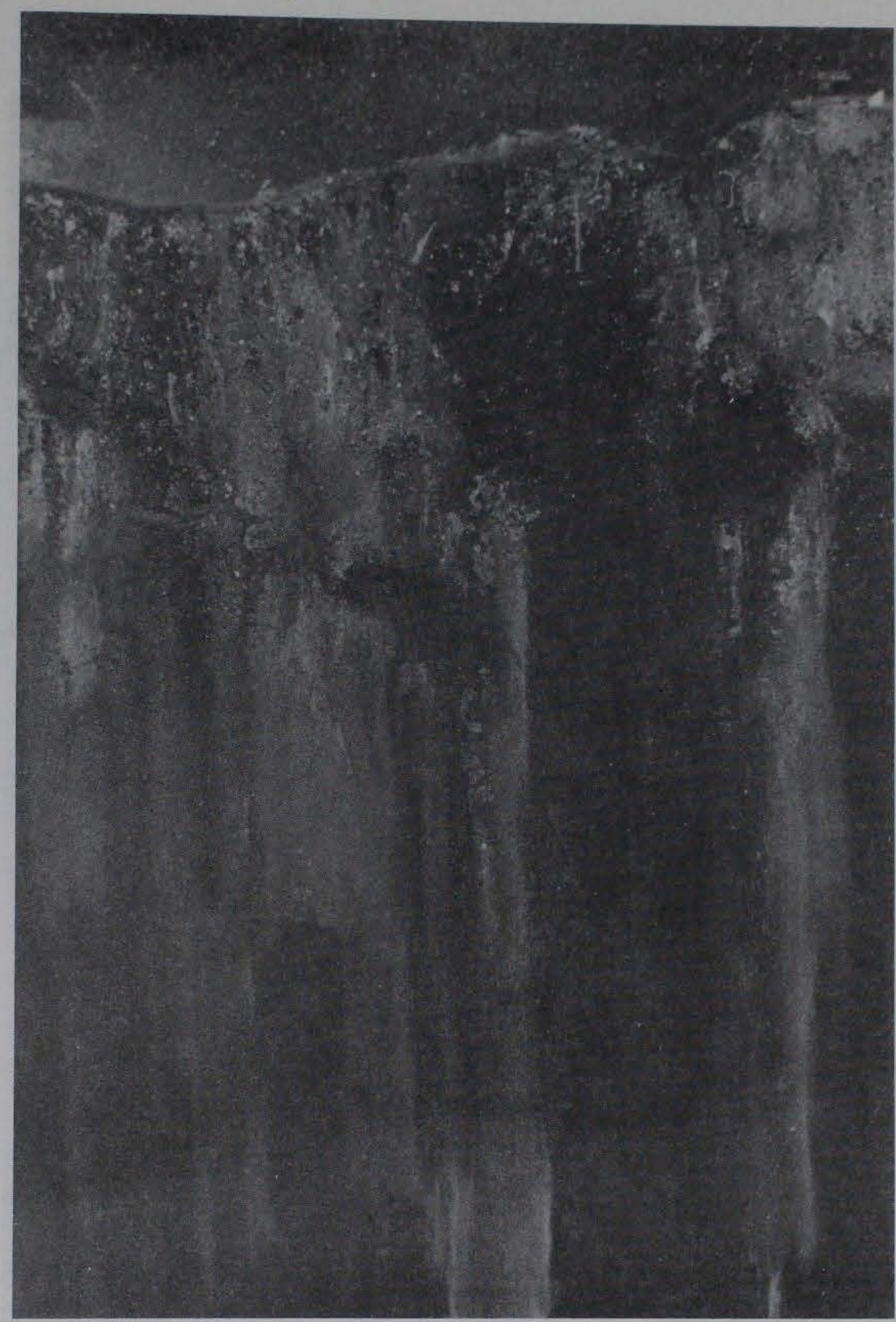

Figure 22. Low-reflectance mud having apparent high sediment oxygen demand (SOD) occurring at station $10-\mathrm{M}$ in the vicinity of the dredged material disposal mound in the northeast quadrant of the Mud Dump site. This low-reflectance mud is presumed to be dredged material. Scale $=1 \mathrm{X}$. 


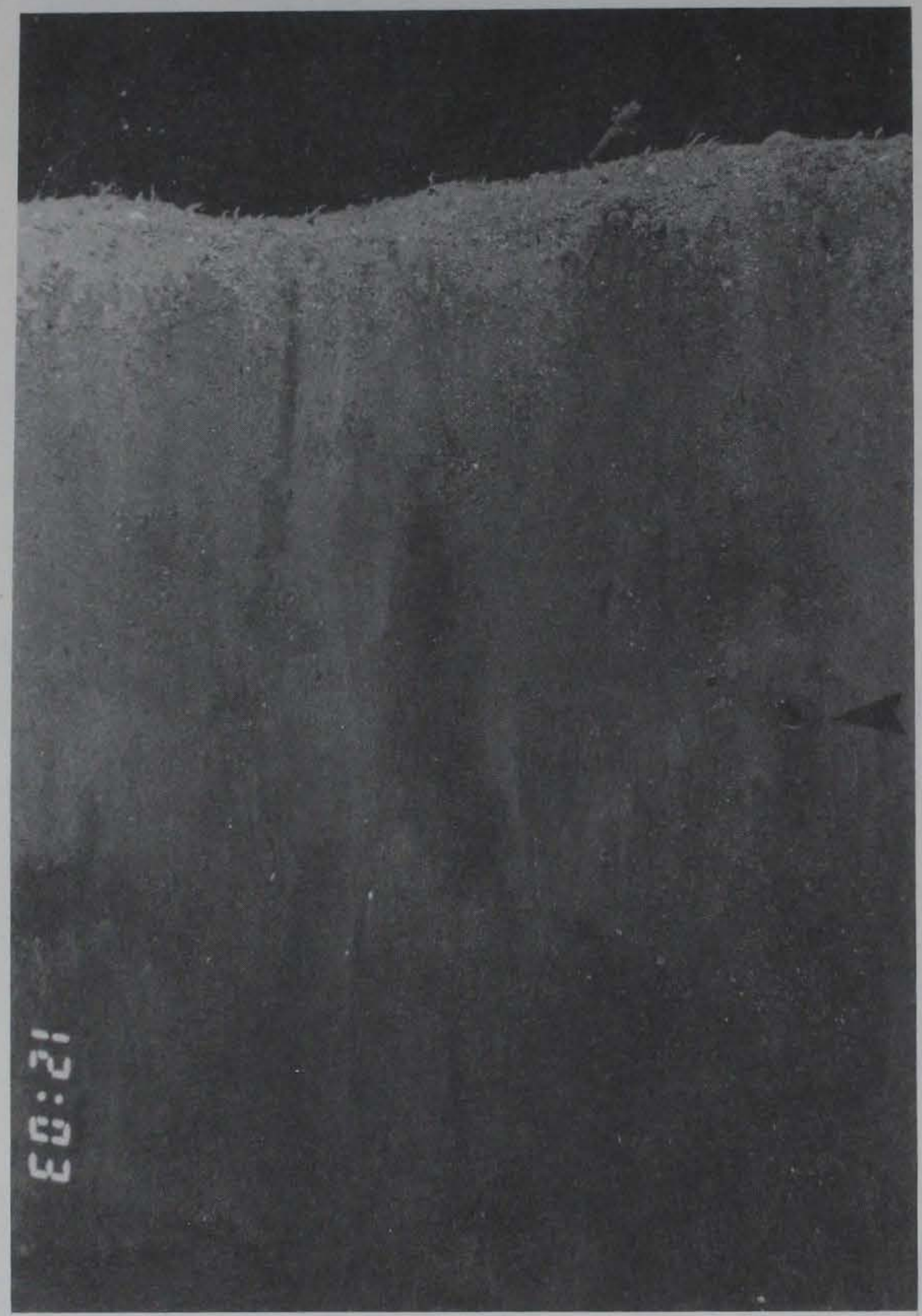

Figure 23. Methane gas bubbles (arrow) are visible in the sediment in this REMOTS $^{\circledR}$ image from station $8-0 . \quad$ Scale $=1 \mathrm{X}$. 


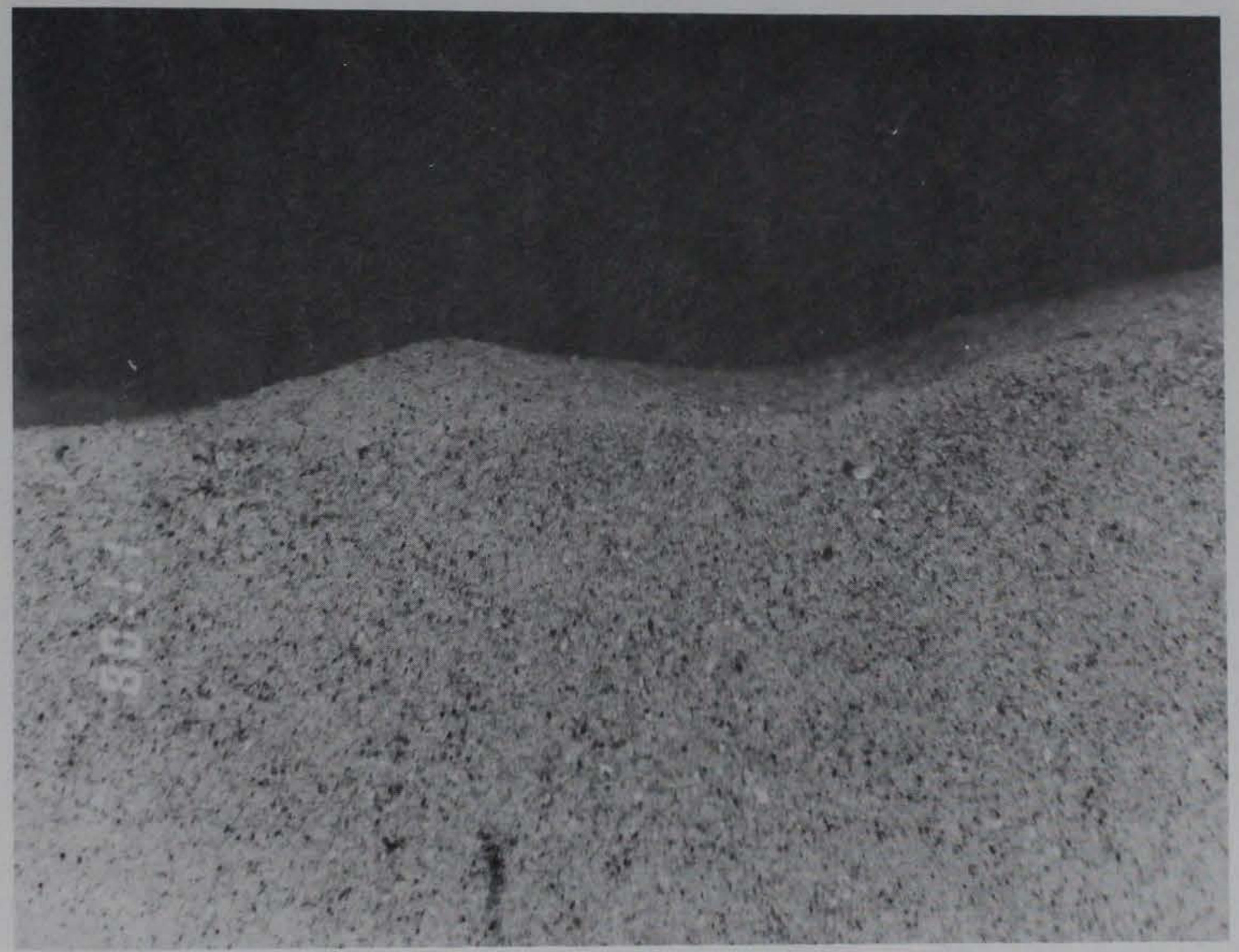

Figure 24. Clean, fine-grained, high-reflectance sand at the sediment surface at station $200-\mathrm{S}$. This sand is presumed to represent the original capping material. Scale $=1 \mathrm{X}$. 

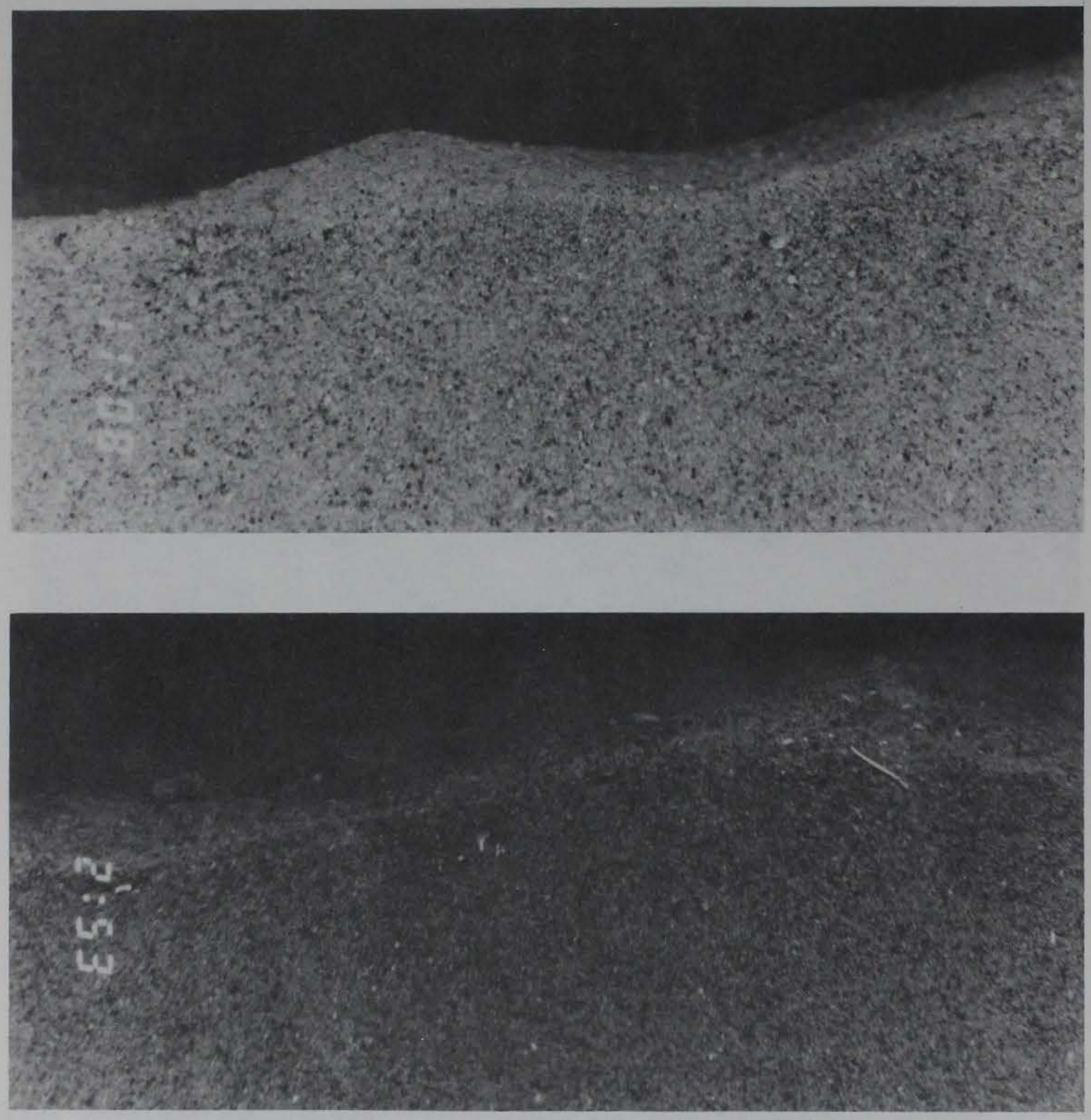

Figure 25. Two REMOTS ${ }^{\circledR}$ images illustrating the distinction between clean, high-reflectance "cap sand" (top) and sand from areas south of the cap having intermediate reflectance (bottom). The top image is from station 200-S; the bottom image from station 600-SE shows sand which appears to contain a higher percentage of fines compared to the "cap sand." Intermediate reflectance may also be imparted to this sand by a higher proportion of heavy minerals and/or mica. Scale of both images $=1 \mathrm{X}$. 


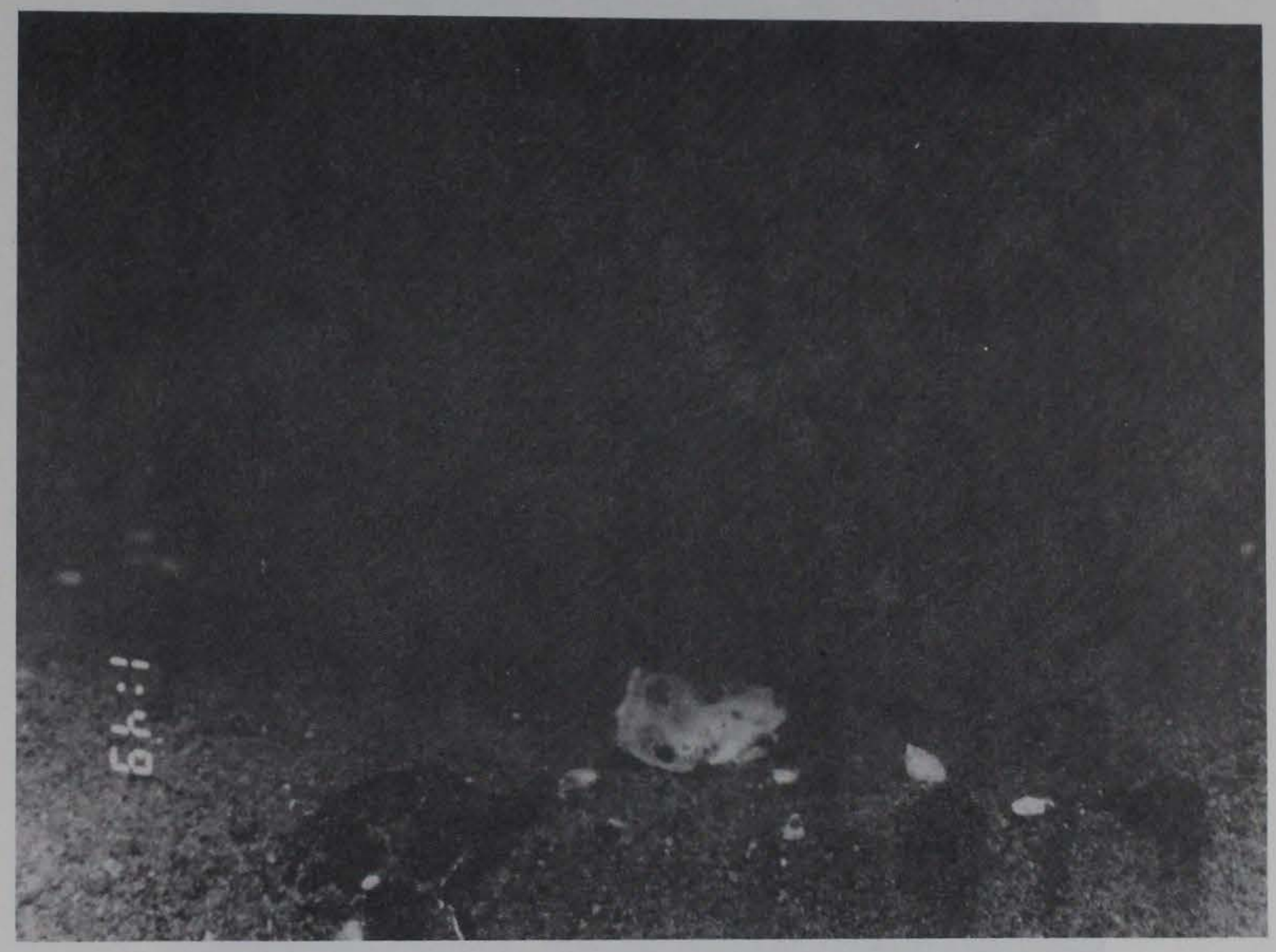

Figure 26. REMOTS $^{\circledR}$ image from station $22-\mathrm{E}$ showing reduced mud clasts (foreground) at the sediment surface. Scale $=1 X$. 


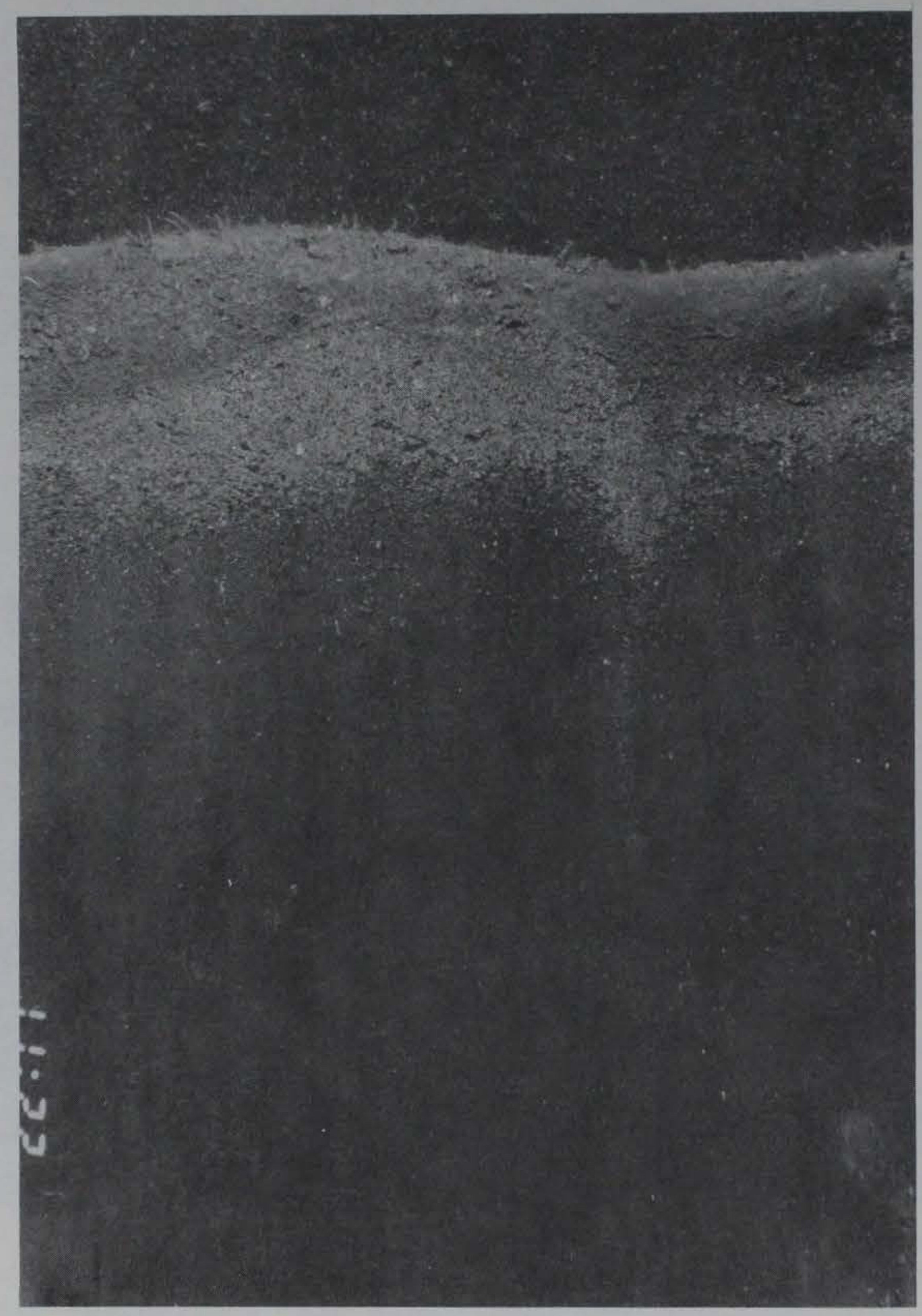

Figure 27. REMOTS ${ }^{\circledR}$ image from station $500-\mathrm{S}$ showing a thin layer of finegrained sand overlying low-reflectance apparent dredged material at depth. Scale $=1 \mathrm{X}$. 


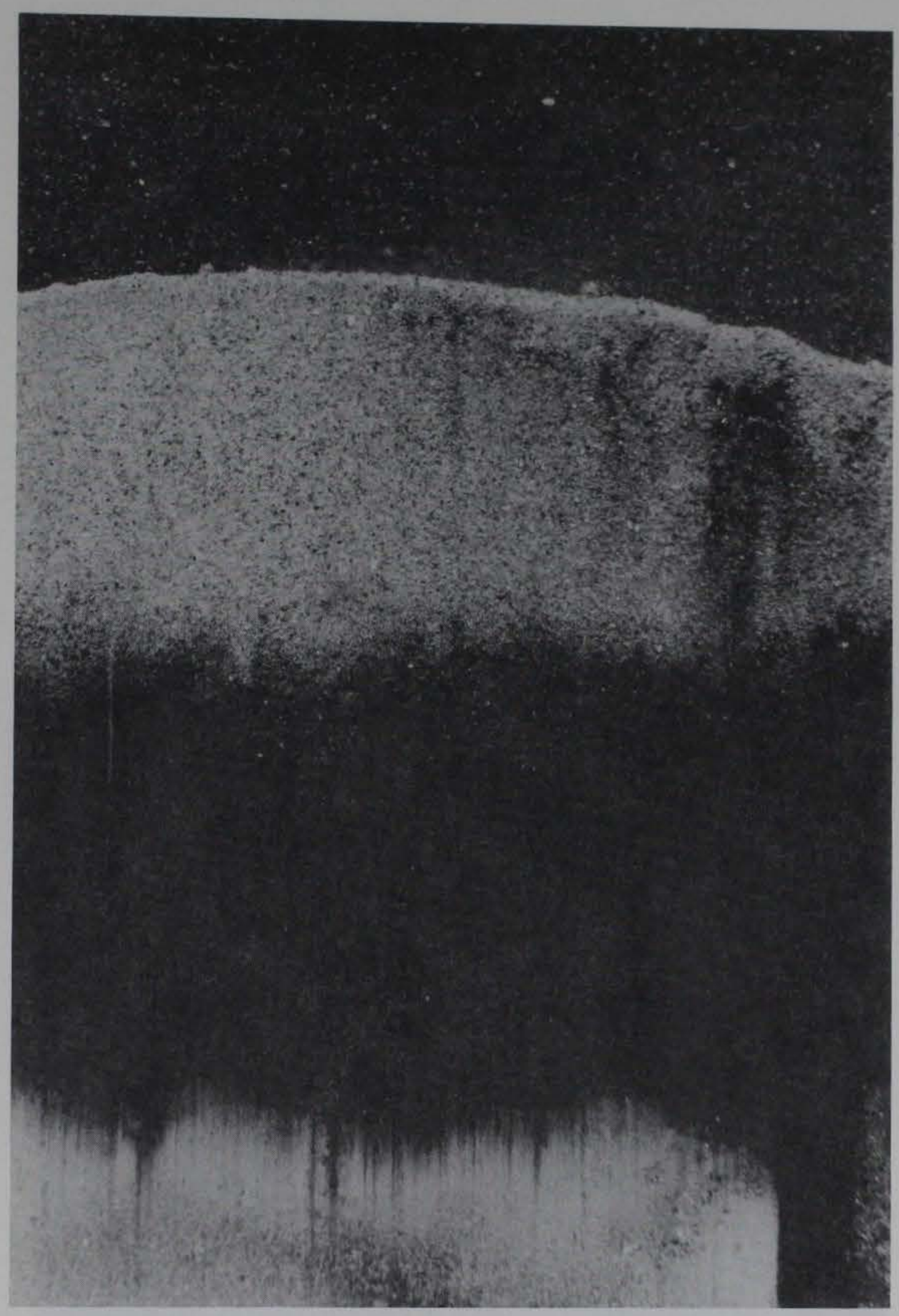

Figure 28. REMOTS $^{\circledR}$ image from station CTR showing a thin layer of highreflectance sand overlying a low-reflectance layer of apparent dredged material, which in turn overlies a second high-reflectance sand layer. This stratigraphy may have been caused by transport of dredged material onto the sand cap and its subsequent burial by surrounding high-reflectance sand. Scale $=1 \mathrm{X}$. 


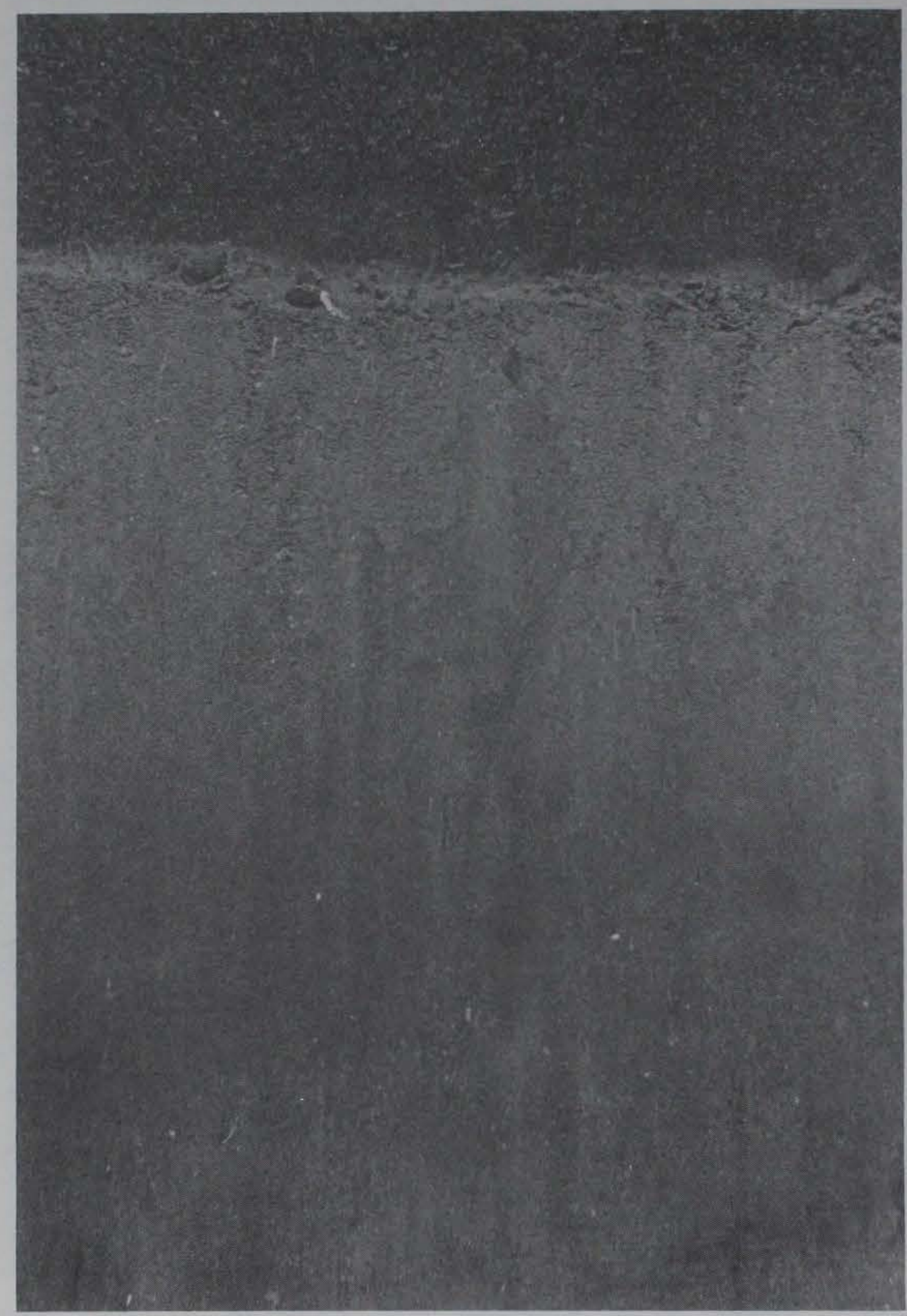

Figure 29. Low-reflectance mud, possibly dredged material, characterizes the sediment surface at station $200-\mathrm{NE}$. Scale $=1 \mathrm{X}$. 


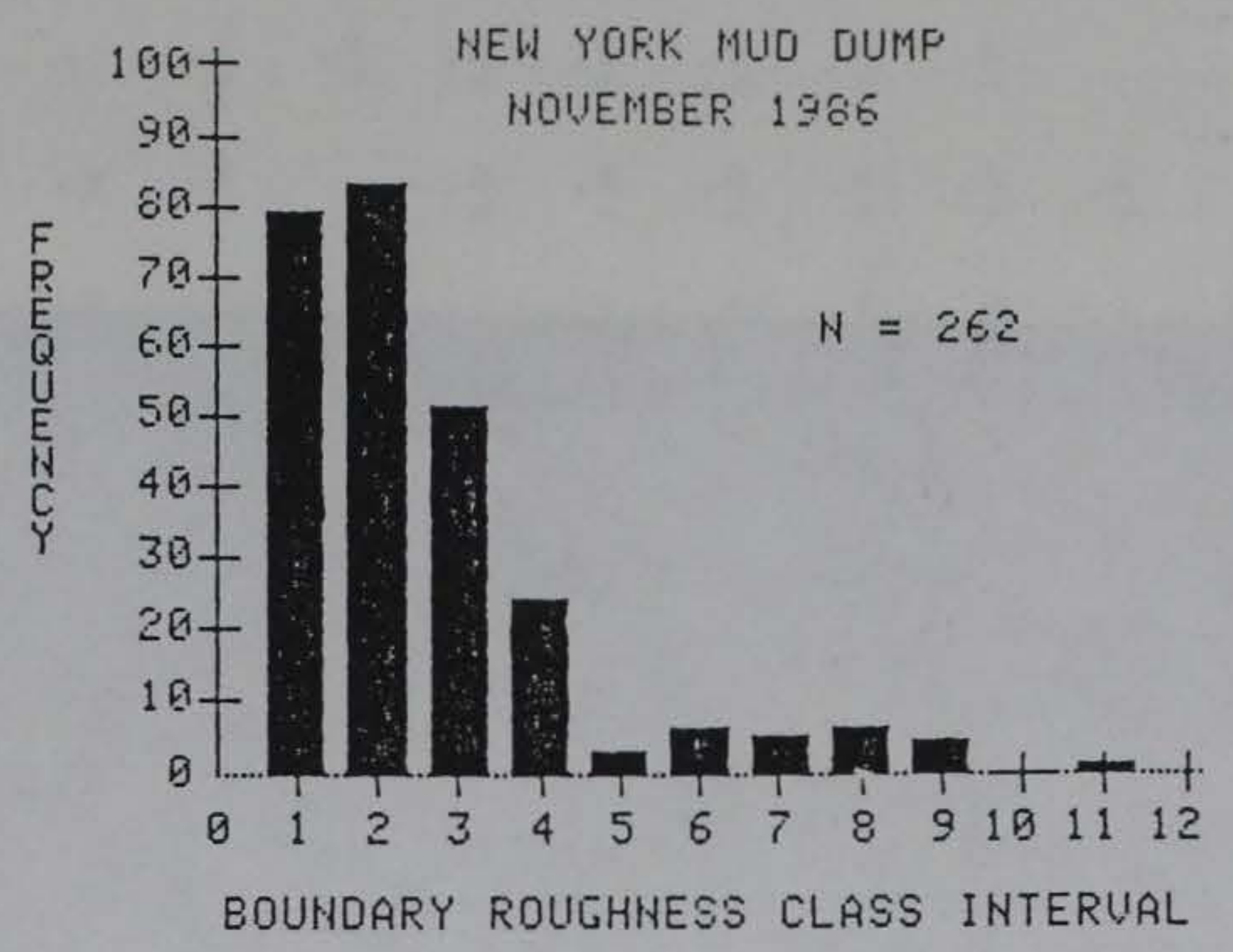

$\underline{\mathrm{KEY}}$

\begin{tabular}{cc}
$\begin{array}{ll}\text { Class } \\
\text { Interval }\end{array}$ & $\begin{array}{l}\text { Range of Boundary } \\
\text { Roughness }(\mathrm{cm})\end{array}$ \\
\cline { 2 - 3 } 1 & $0.0-0.6$ \\
2 & $0.6-1.0$ \\
3 & $1.0-1.4$ \\
4 & $1.4-1.8$ \\
5 & $1.8-2.2$ \\
6 & $2.2-2.6$ \\
7 & $2.6-3.0$ \\
8 & $3.0-3.4$ \\
9 & $3.4-3.8$ \\
10 & $3.8-4.2$ \\
11 & $4.2-4.6$ \\
12 & $4.6-5.0$
\end{tabular}

Figure 30. Frequency distribution of small-scale boundary roughness (in $\mathrm{cm}$ ) for stations sampled in the REMOTS ${ }^{\circledR}$ survey. 


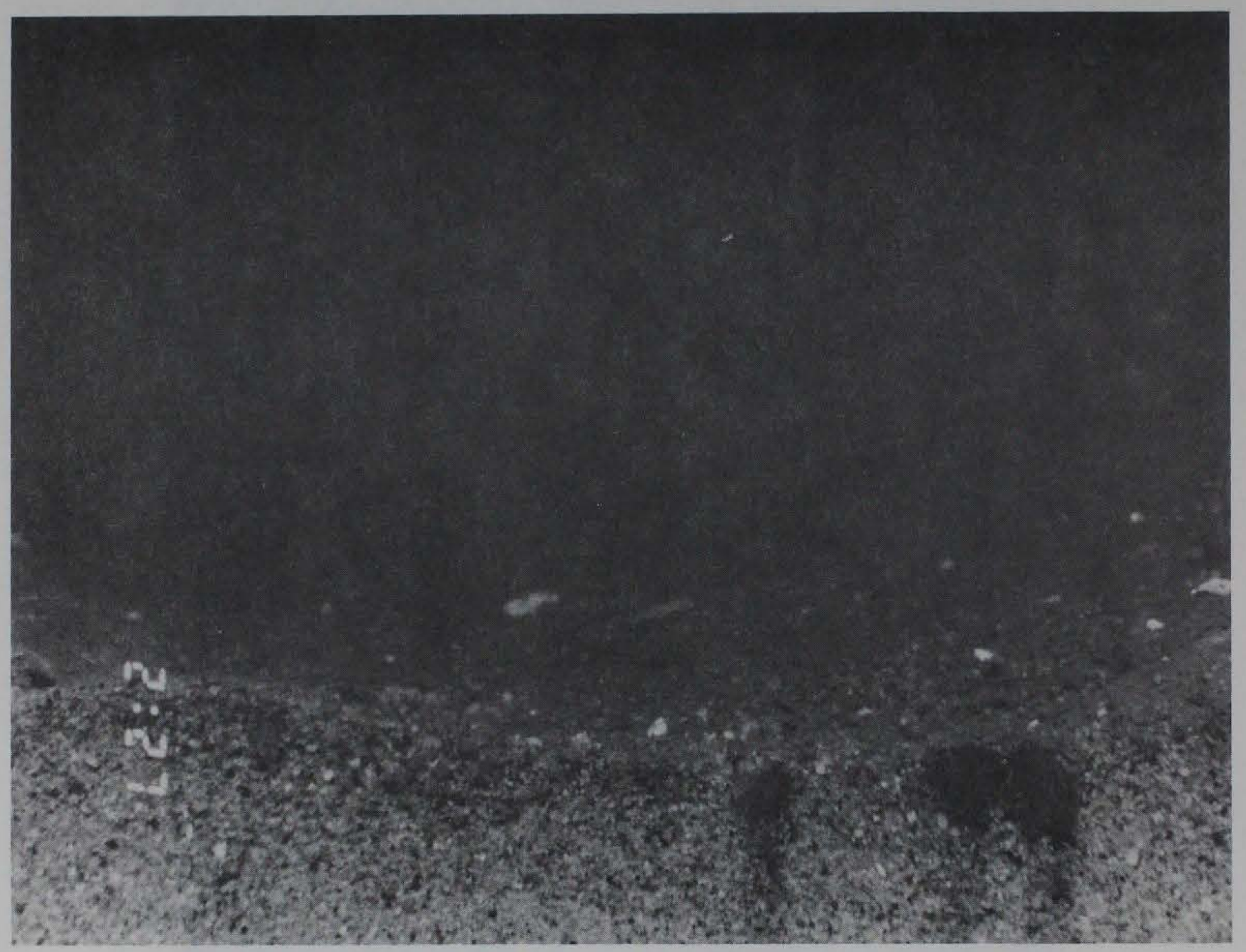

Figure 31. REMOTS ${ }^{\circledR}$ image from station 1000-SE shows a sand bedform which is characteristic of this part of the survey area (see Figure 2la). The fine-grained material visible at the surface typically accumulates in the troughs between bedforms. Scale $=1 \mathrm{X}$. 


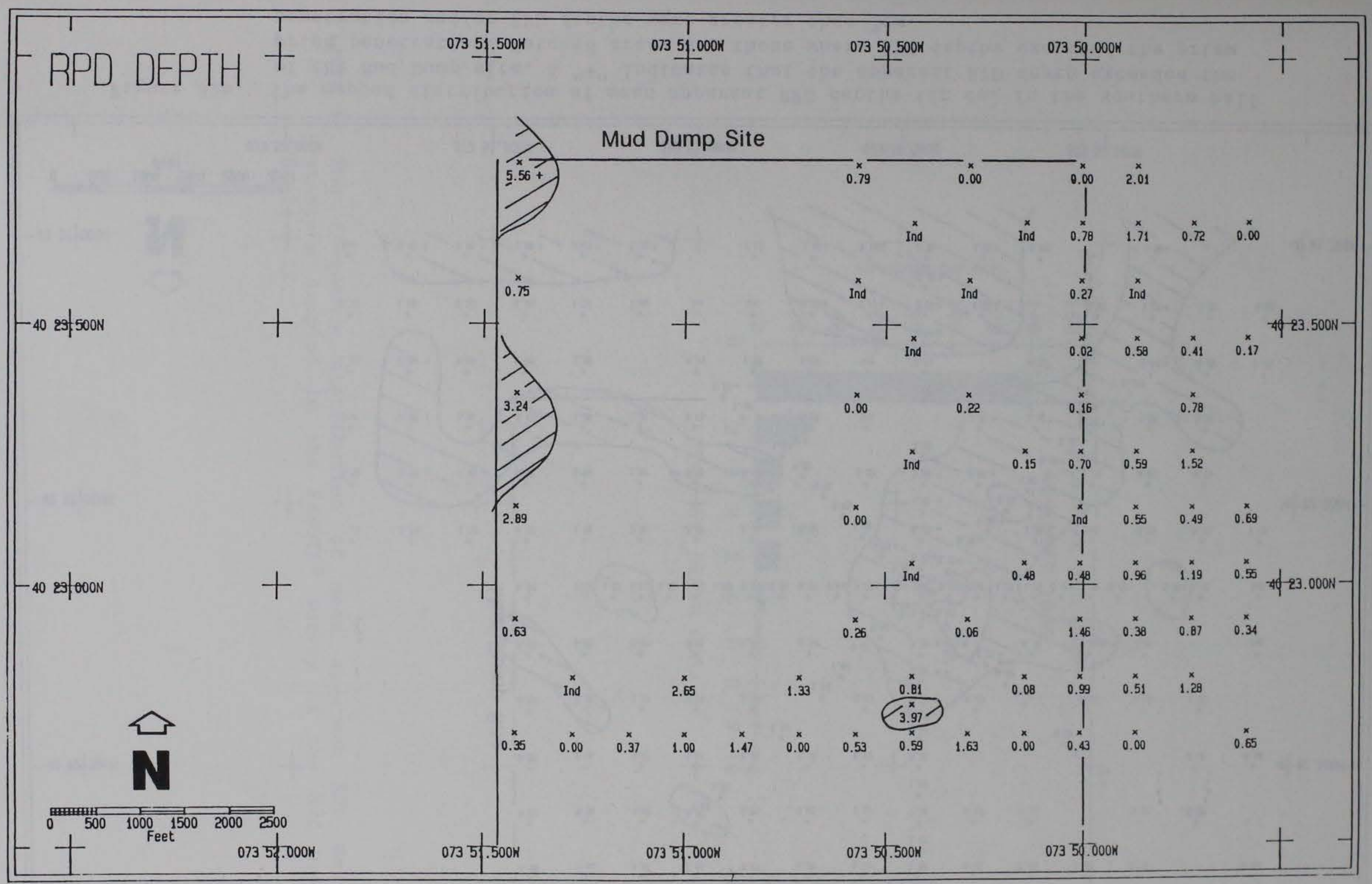

Figure 32a. The mapped distribution of mean apparent RPD depths (in $\mathrm{cm}$ ) in the northern half of the Mud Dump site. A "+" indicates that the apparent RPD depth exceeded the prism penetration. Hatched areas are those where RPD depths exceeded the prism penetration and/or RPD depths were greater than $3 \mathrm{~cm}$. 


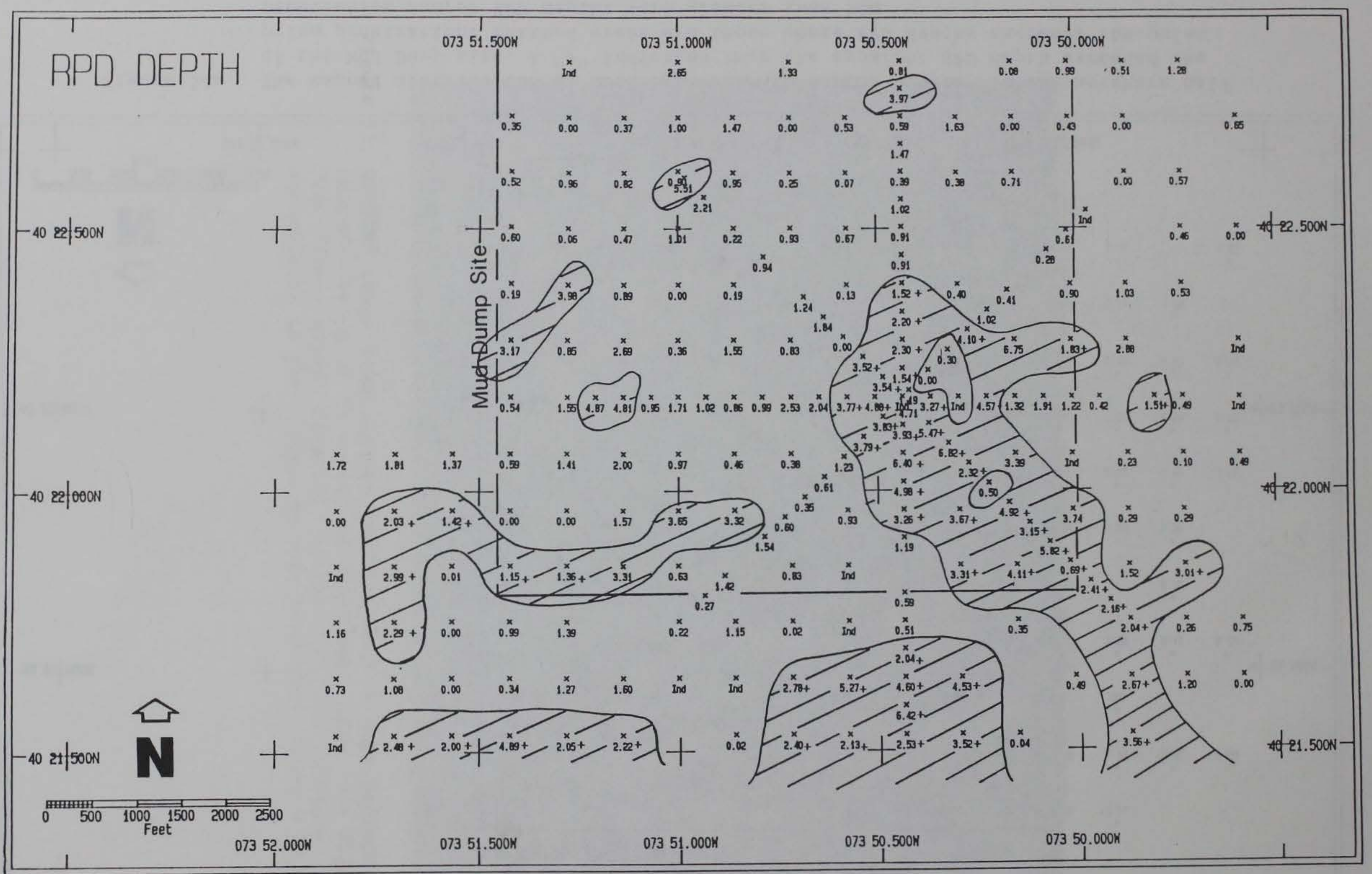

Figure 32b. The mapped distribution of mean apparent RPD depths (in $\mathrm{cm}$ ) in the southern half of the Mud Dump site. A "+" indicates that the apparent RPD depth exceeded the prism penetration. Hatched areas are those where RPD depths exceeded the prism penetration and/or RPD depths were greater than $3 \mathrm{~cm}$. 


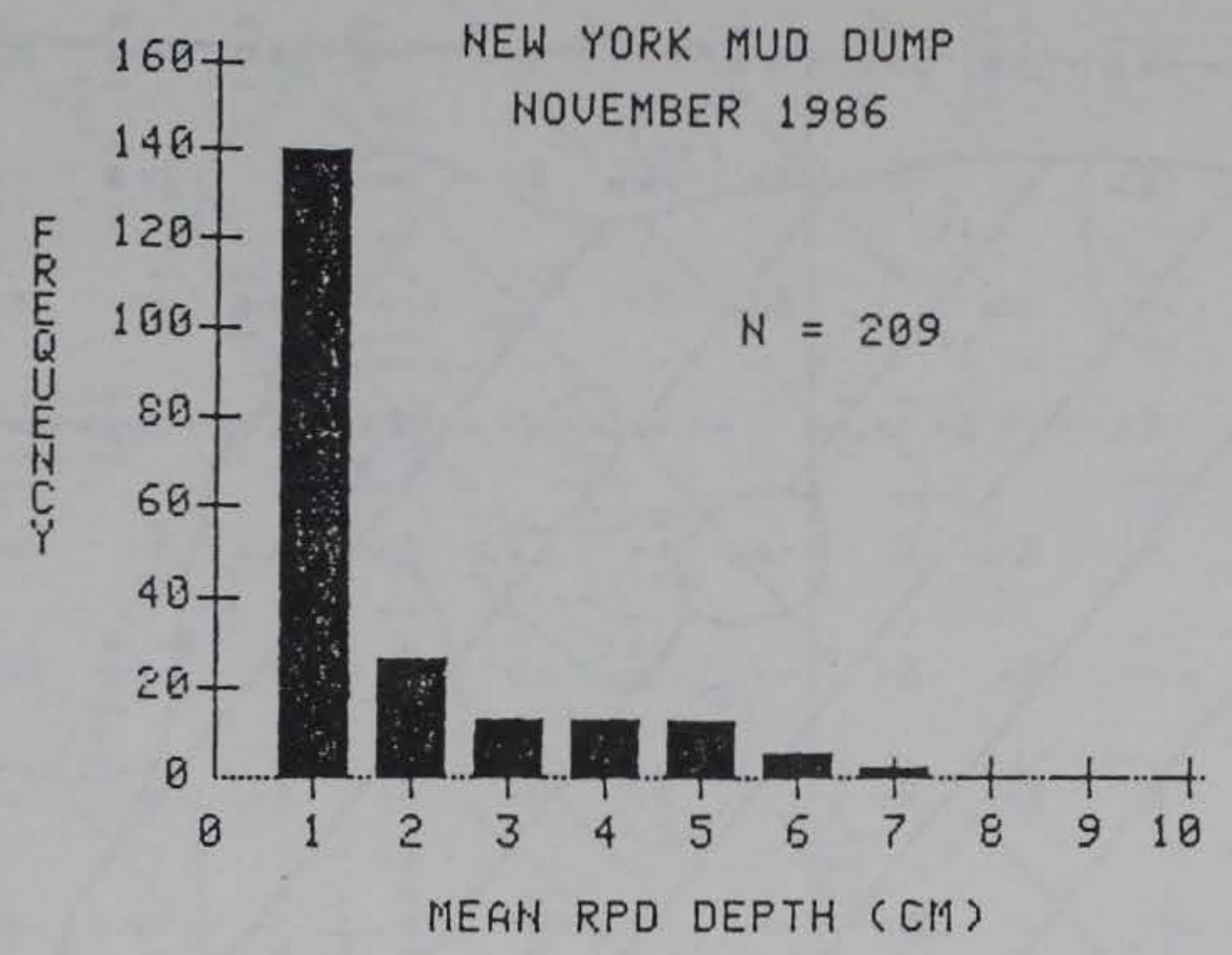

Figure 33. The frequency distribution of mean apparent RPD depths for stations sampled in the REMOTS $^{\circledR}$ survey of the Mud Dump site. Scale $=1 \mathrm{X}$. 


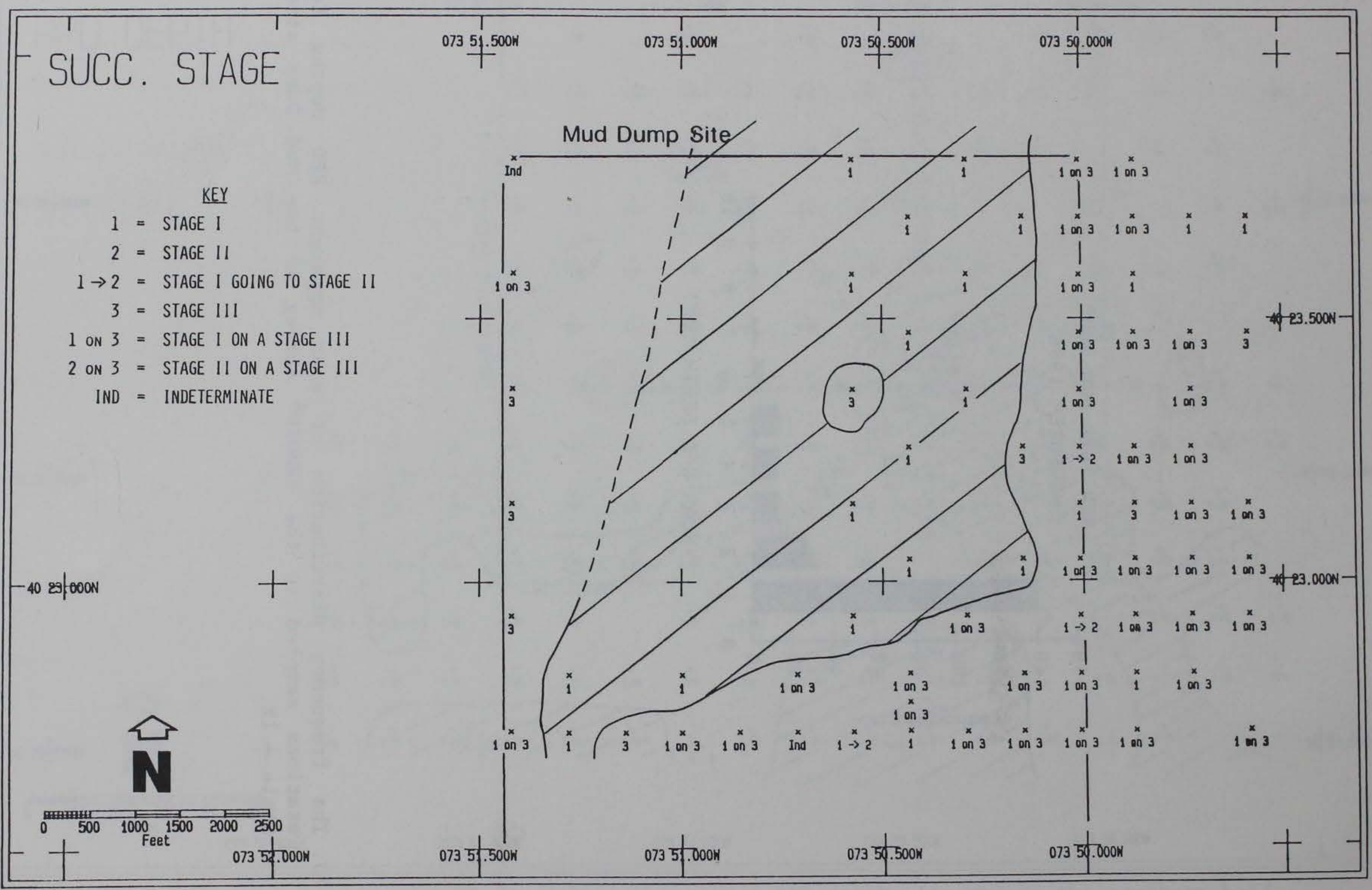

Figure 34a. The mapped distribution of infaunal successional stages in the northern half of the Mud Dump site. Hatched area denotes a Stage I successional stage. 


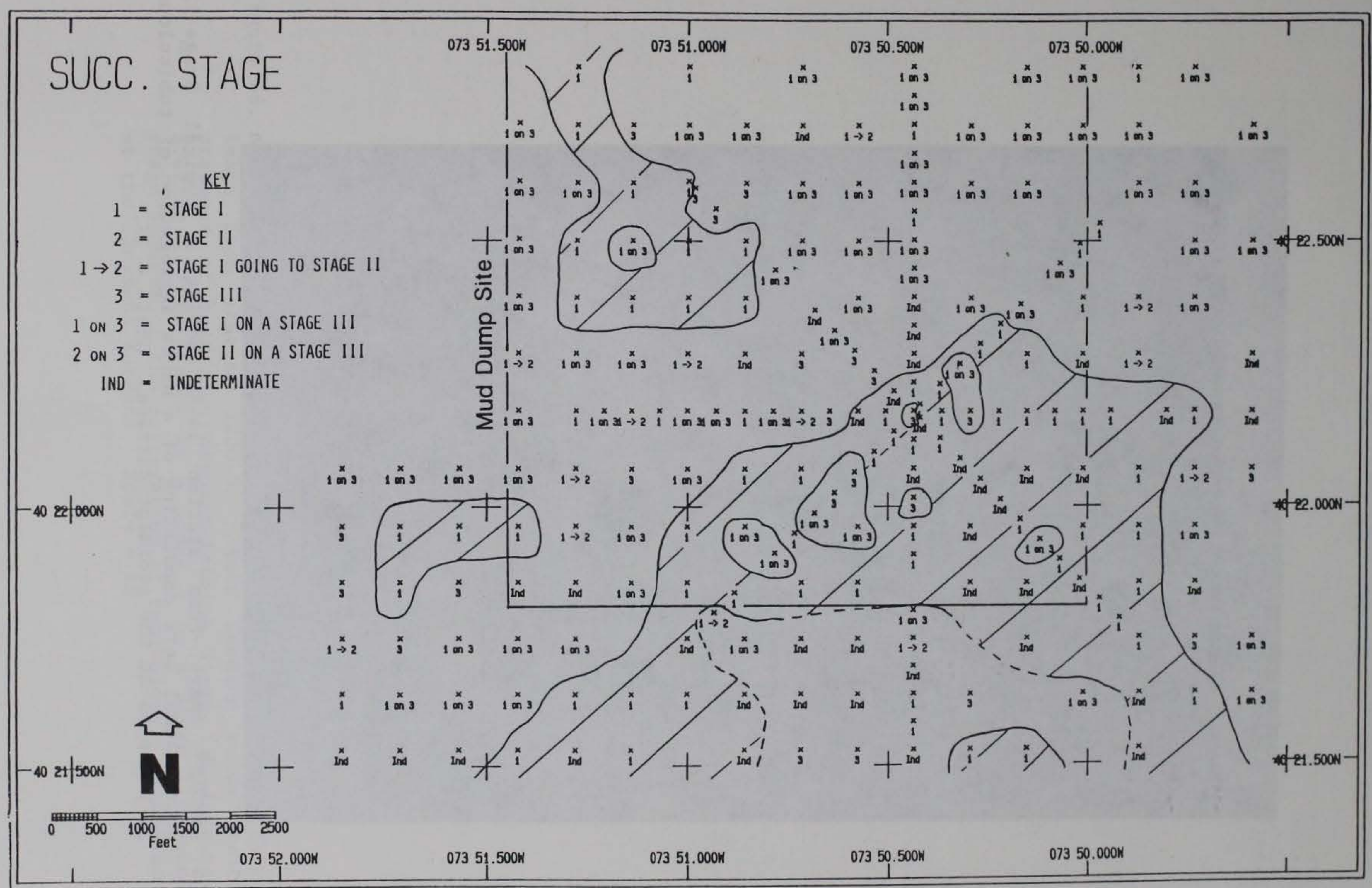

Figure 34b. The mapped distribution of infaunal successional stages in the southern half of the Mud Dump site. Hatched areas are those having a Stage I successional stage. 
Figure 35. REMOTS ${ }^{\circledR}$ image from station $14-\mathrm{E}$ showing a typical Stage I successional sere consisting of a dense aggregation of tubicolous polychaetes at the sediment surface. Scale $=1 \mathrm{X}$. 


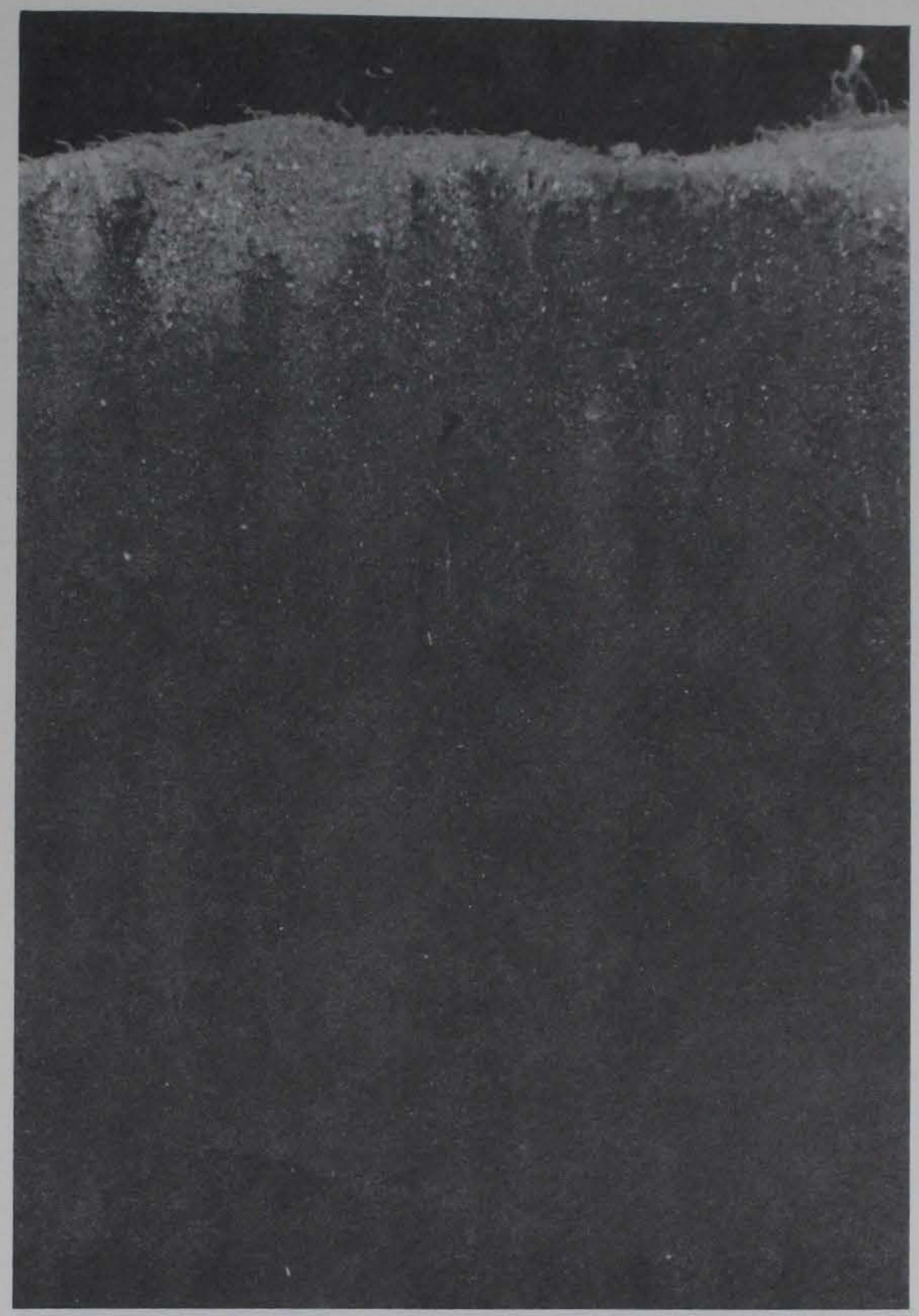

Figure 36. A typical feeding void (arrow) is visible at depth in this REMOTS ${ }^{\circledR}$ image from station $1200-\mathrm{N}$. Such feeding voids indicate the presence of head-down deposit-feeding Stage III infauna. This station is designated as a Stage I on a Stage III successional stage because of the aggregation of tubicolous polychaetes visible at the sediment surface. Scale $=1 \mathrm{X}$. 


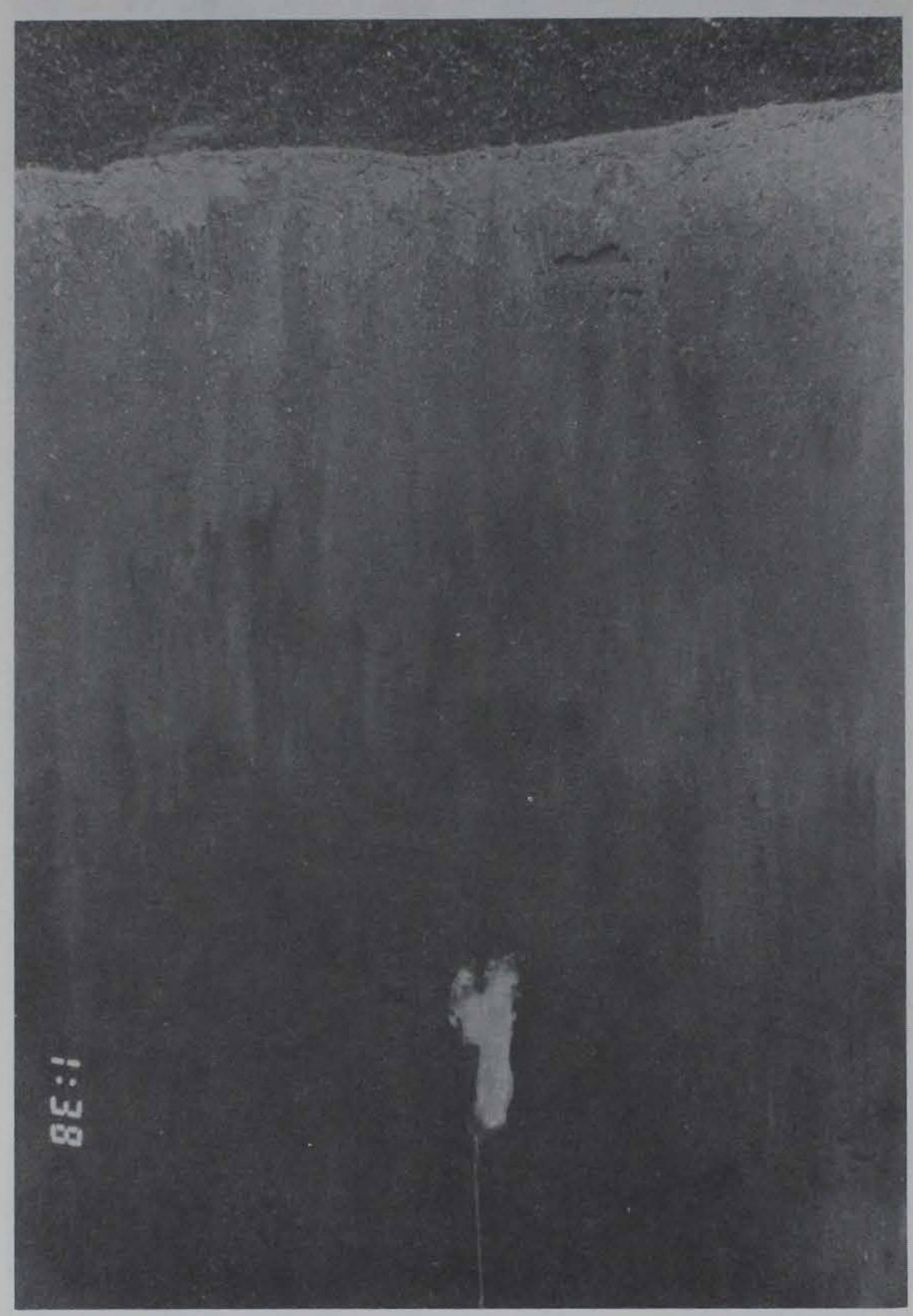

Figure 37. The organism indicated by the arrow is presumed to be the burrowing anemone Ceriantheopsis americanus in this REMOTS $^{\circledR}$ image from station 5-P. The low-reflectance sediment at this station appears to have high sediment oxygen demand. Approximate scale $=0.78 \mathrm{X}$. 


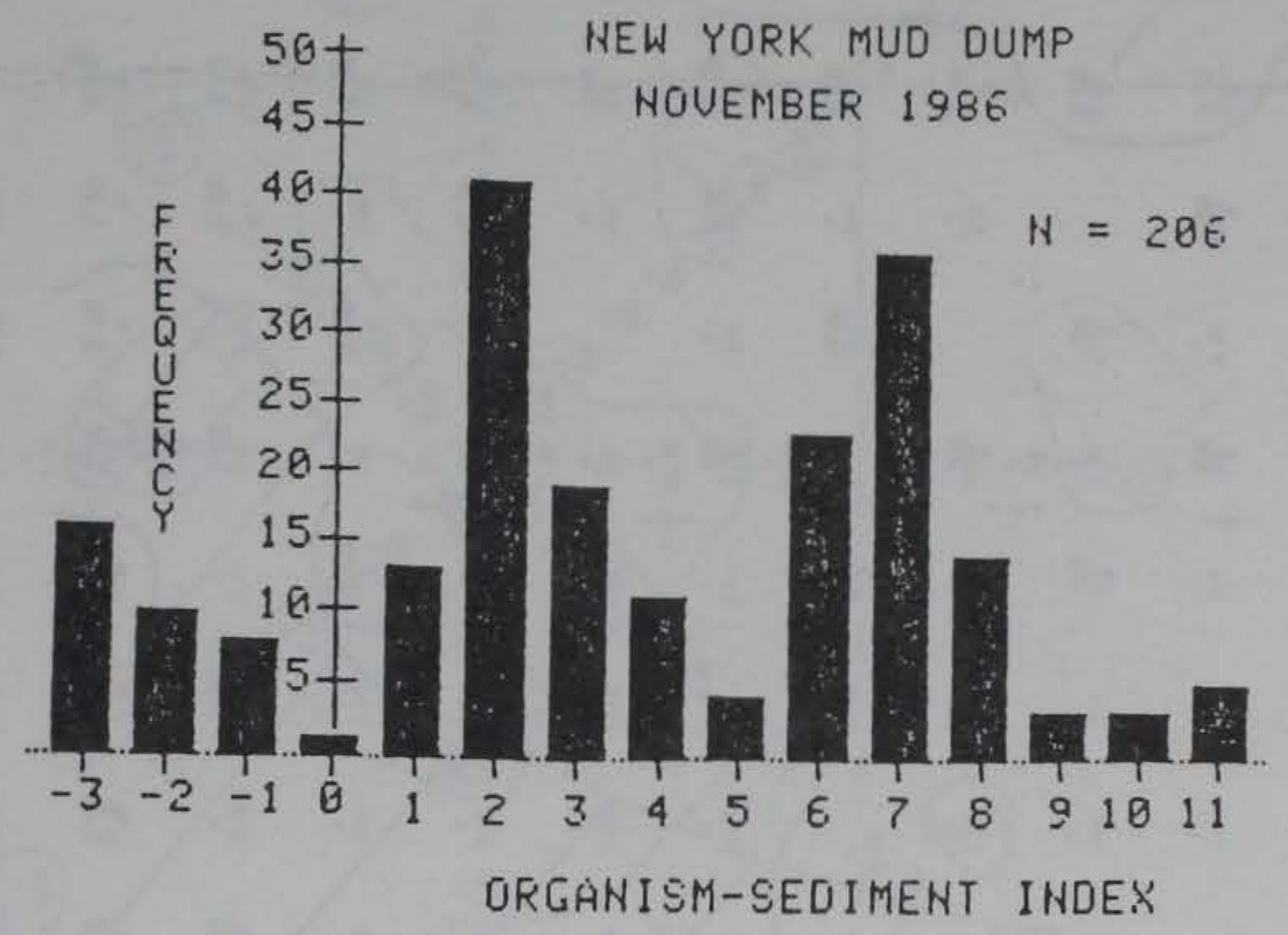

Figure 38. The frequency distribution of Organism-Sediment Index (OSI) values for stations sampled in the REMOTS ${ }^{\circledR}$ survey at the Mud Dump site. 


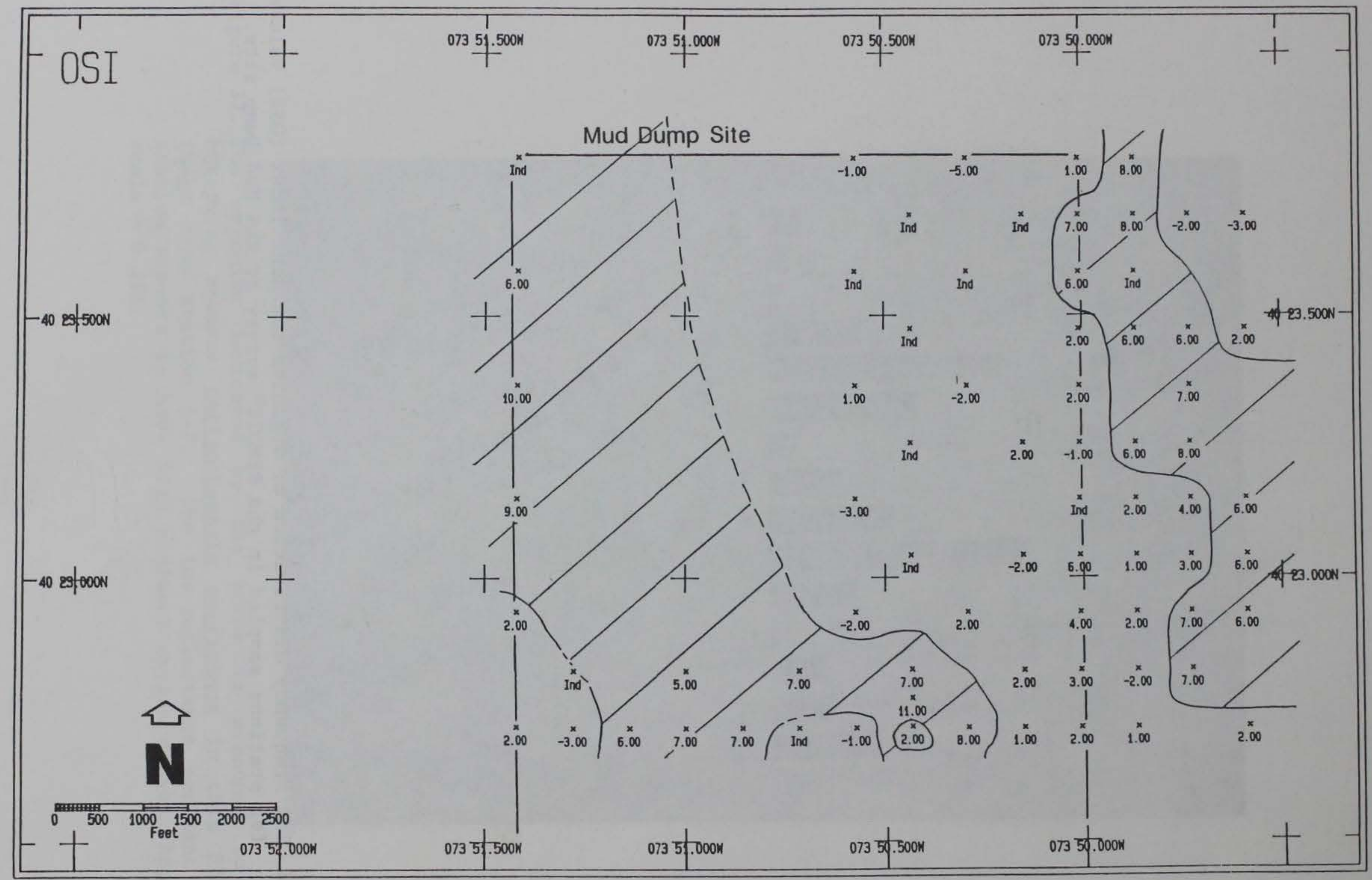

Figure 39a. The mapped distribution of OSI values in the northern half of the Mud Dump site. The hatched areas are those having OSI values greater than or equal to +5 . "Ind" means the OSI was indeterminate at that station. 


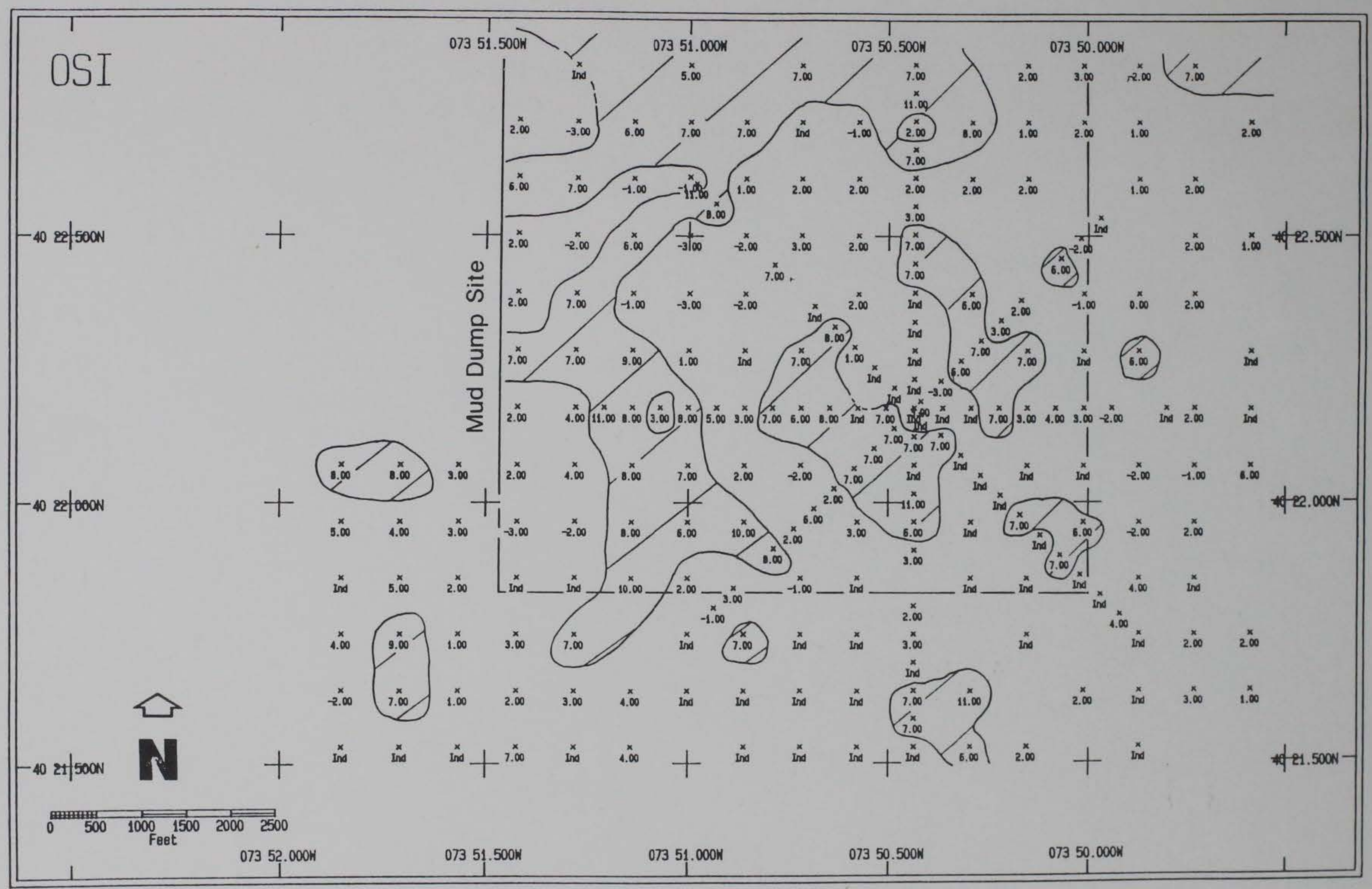

Figure 39b. The mapped distribution of OSI values in the southern half of the Mud Dump site. The hatched areas are those having OSI values greater than or equal to +5. "Ind" means the OSI was indeterminate at that station. 